Portland State University

PDXScholar

$1-1-2011$

\title{
Antioxidant Anthocyanidins and Calcium Transport Modulation of the Ryanodine Receptor of Skeletal Muscle (RyR1)
}

Thomas J. Dornan

Portland State University

Follow this and additional works at: https://pdxscholar.library.pdx.edu/open_access_etds Let us know how access to this document benefits you.

Recommended Citation

Dornan, Thomas J., "Antioxidant Anthocyanidins and Calcium Transport Modulation of the Ryanodine Receptor of Skeletal Muscle (RyR1)" (2011). Dissertations and Theses. Paper 319.

https://doi.org/10.15760/etd.319

This Thesis is brought to you for free and open access. It has been accepted for inclusion in Dissertations and Theses by an authorized administrator of PDXScholar. Please contact us if we can make this document more accessible: pdxscholar@pdx.edu. 
Antioxidant Anthocyanidins and Calcium Transport Modulation of the Ryanodine Receptor of Skeletal Muscle (RyR1)

\author{
by \\ Thomas J. Dornan
}

A thesis submitted in partial fulfillment of the requirements for the degree of

Master of Science

in

Physics

Thesis Committee:

Jonathan Abramson, Chair

Pavel Smejtek

Robert Strongin

Portland State University

(C)2011 


\begin{abstract}
Cardiovascular disease (CVD) claims more lives than any other disease in the world. Although numerous biological pathways share the blame, ventricular tachyarrhythmia (VT) is estimated to account for $\sim 25 \%$ of all CVD deaths. A complete understanding of the molecular mechanisms underlying VT is unknown but recent studies have linked VT to improper calcium handling in the heart (canine). The principle calcium regulator in the muscle cell is the calcium ion release channel (aka RyR). Numerous endogenous and exogenous compounds can affect the way the RyR regulates calcium. In particular, abnormal levels of oxidants (reactive oxygen species) can oxidize critical thiol groups on the RyR and modulate its activity. Interestingly, high levels of oxidants are also associated with numerous bodily disease states including cancers, muscle fatigue/failure, and CVD.
\end{abstract}

In this thesis, two important dietary antioxidant compounds, the anthocyanidins pelargonidin and delphinidin, are evaluated for their effects on regulating the transport of calcium through the calcium release channel (RyR1) of the sarcoplasmic reticulum of skeletal muscle. Pelargonidin and delphinidin are structurally similar with delphinidin only differing from pelargonidin by the addition of two hydroxyl groups. Both compounds undergo time dependent structural changes in aqueous solutions at physiological $\mathrm{pH}$ and a mixture of more than 
four structures of each compound can be present in solution simultaneously. Pelargonidin and delphinidin show distinct differences in their calcium flux regulating effect on the RyR1. Delphinidin stimulates calcium flux and RyR1 activity whereas pelargonidin can cause both inhibition and stimulation of the RyR1. The strength of stimulation and inhibition of calcium transport through the RyR by delphinidin and pelargonidin may be attributed to the structural and chemical changes in those compounds that occur in solutions near physiological $\mathrm{pH}$ and the subsequent chemical characteristics of the diverse set of structures that are simultaneously present in solution. 


\section{Dedication}

This thesis is dedicated to my mother and father. Their unconditional love and support throughout the years has shaped my soul and provided me with all of the opportunity that l've ever needed. They both passed away during the course of this thesis work but I can easily see the smiles on their faces in response to this achievement. 


\section{Acknowledgements}

A sincere appreciation is extended to my advisor Jon Abramson for all of his time and support with regards to the completion of this project. Additionally, financial support was partially provided by the award of a teaching assistantship for two years by the Department of Physics and by the award of a two term research assistantship provided by Erik Sanchez in conjunction with Jon Abramson. 


\section{Table of Contents}

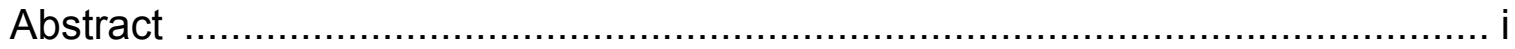

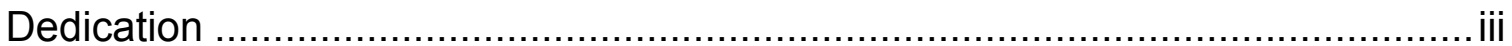

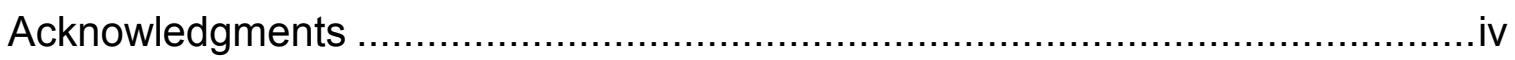

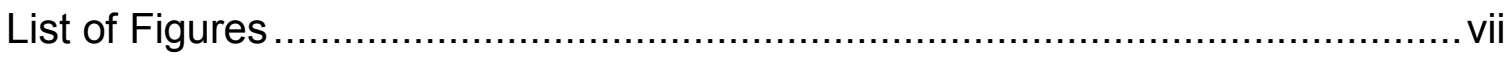

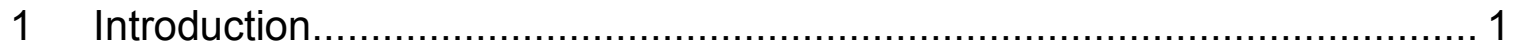

1.1 Oxidative Stress and Calcium Homeostasis in Muscle......................... 4

1.2 Oxidative Stress and Disease ........................................................ 8

1.3 The Flavonoid Antioxidant - Calcium Homeostasis Connection ........... 9

1.4 The Anthocyanidins................................................................... 12

1.4.1 Pelargondin and Delphinidn - The Antioxidants ......................... 13

1.4.2 Pelargondin and Delphinidn - The Prooxidants ......................... 17

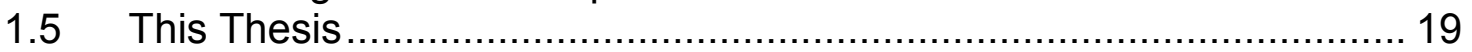

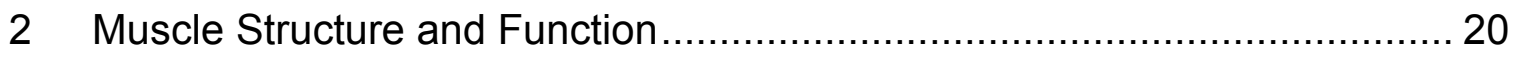

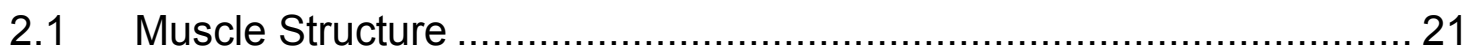

2.1.1 Skeletal Muscle Macro Structure........................................... 21

2.1.2 The Muscle Cell Structure .................................................. 22

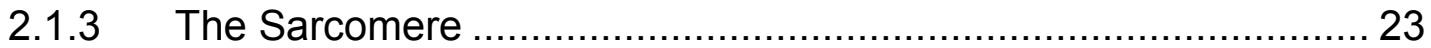

2.1.4 The Sarcoplamic Reticulum (SR) ...................................... 25

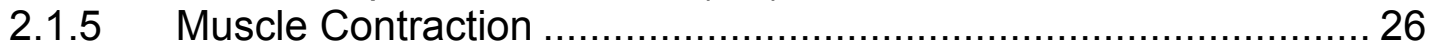

2.1.6 Excitation-Contraction Coupling ……….............................. 28

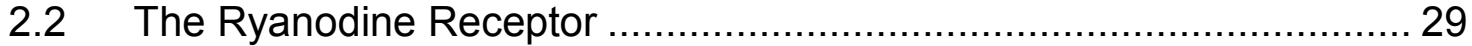

2.2.1 The Ryanodine Receptor - Structure ..................................... 30

2.2.2 Sub-nanometer cryo-EM Structures ......................................... 31

2.2.3 The Ryanodine Receptor Function........................................... 34

3 The Anthocyanidins: Pelargonidin and Delphinidin ............................... 40

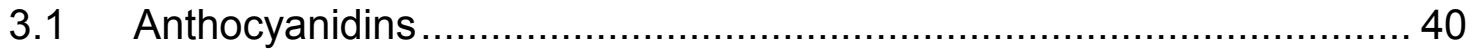

3.2 Anthocyanidin Structural Equilibrium ............................................. 42

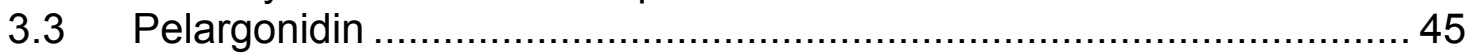

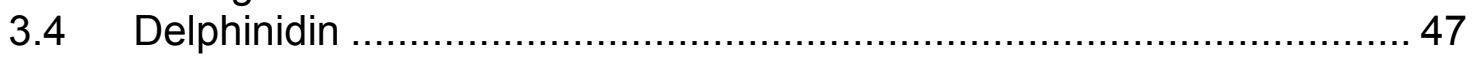

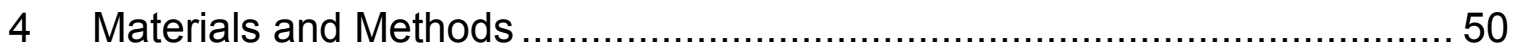

4.1 Sarcoplasmic Reticulum Vesicles..................................................... 50

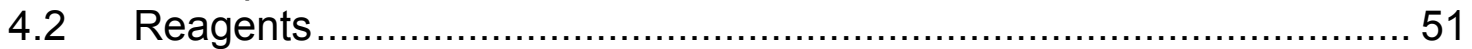

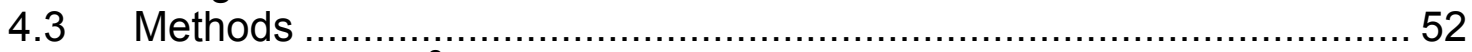

4.3.1 Passive $\mathrm{Ca}^{2+}$ Loading of SR Vesicles ...................................... 52

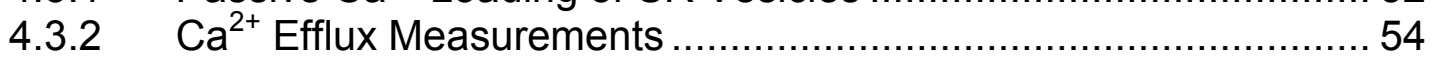

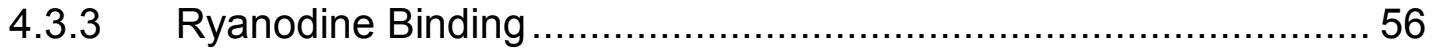




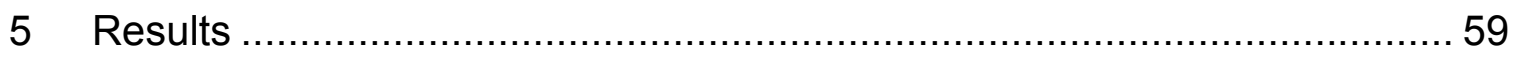

5.1 Spectrometric Analysis of $\mathrm{Ca}^{2+}$ Efflux from SR Vesicles ....................59 5.1.1 Pelargondin Inhibits / Delphinidin Stimulates $-\mathrm{Ca}^{2+}$ Efflux from SR

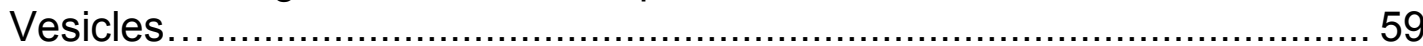

5.1.2 Pg Modulates the Initial Rate of Release in a Biphasic Manner .... 63

5.1.3 Dp stimulates $\mathrm{Ca}^{2+}$ release from the RyR of the SR ..................65

5.1.4 Pelargonidin and Delphinidin; Different Forms, Different Effects .. 68

$5.2 \quad$ Ryanodine Equilibrium Binding ................................................. 70

5.2.1 Pelargonidin and Delphinidin Modulate $\left[{ }^{3} \mathrm{H}\right]$-Ryanodine Binding ... 70

5.3 Initial Rate of Ryanodine Binding .............................................. 72

5.4 Spectrophotometric Characteristics of Pelargonidin and Delphinidin ... 75

5.4.1 Absorbance Spectrum of $\mathrm{Pg}$ and $\mathrm{Dp}$.................................... 75

5.4.2 $\mathrm{pH}$ Dependent Transformation Kinetics of Pg and Dp.................. 78

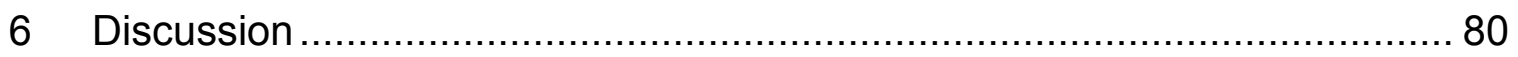

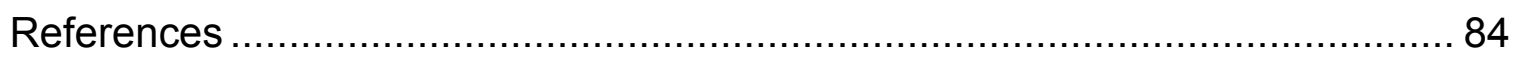




\section{List of Figures}

Figure 1.1 Heart Disease, Anti/Pro Oxidants, and $\mathrm{Ca}^{2+}$ handling ...................... 1

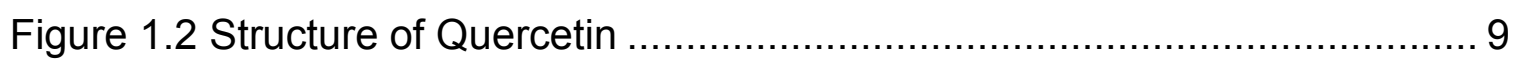

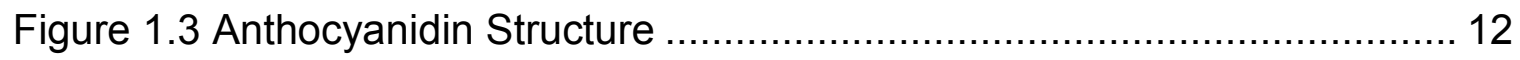

Figure 1.4 Structures of pelargonidin and delphinidin................................... 13

Figure 2.1 Cryo-EM reconstruction of RyR1 in open and closed states ............ 33

Figure 3.1 Basic Structure of Anthocyanidins .............................................. 40

Figure 3.2 The forms of pelargonidin in neutral $\mathrm{pH}$ solutions ......................... 43

Figure 3.3 Molecular Structure of Pelargondin ............................................ 45

Figure 3.4 Molecular Structure of Delphinidin.............................................. 47

Figure 3.5 The forms of delphinidin in neutral pH solutions ............................. 48

Figure 4.1 Molecular Structure of Ryanodine ............................................. 56

Figure 5.1 Dp stimulates $\mathrm{Ca}^{2+}$ release and $\mathrm{Pg}$ inhibits $\mathrm{Ca}^{2+}$ release from the

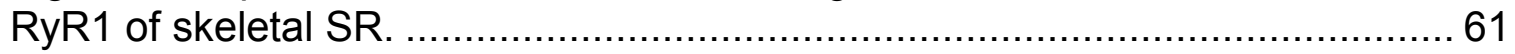

Figure 5.2 Initial Rate of $\mathrm{Ca}^{2+}$ Efflux from SR is Modulated by Pg and Dp. ........ 62

Figure 5.3 Pg modulates the initial rate of $\mathrm{Ca}^{2+}$ efflux from skeletal $\mathrm{SR}$ in a

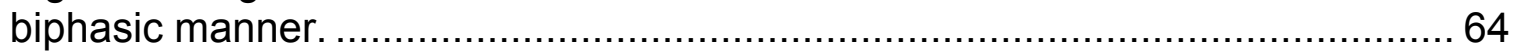

Figure 5.4 Dp stimulates initial rate of $\mathrm{Ca}^{2+}$ release from skeletal SR. .............66

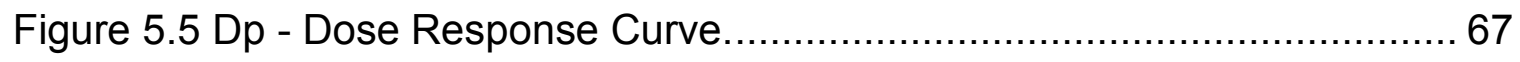

Figure 5.6 Time of exposure to $\mathrm{pH} 7.4$ alters the modulation effects that $\mathrm{Dp}$ and $\mathrm{Pg}$ have on the initial rate of $\mathrm{Ca}^{2+}$ release on skeletal SR............................... 69

Figure 5.7 Pg and Dp stimulate ryanodine equilibrium binding ....................... 71

Figure 5.8 Pelargonidin inhibits caffeine stimulated ryanodine binding ............. 73

Figure 5.9 Comparison of ${ }^{3}[\mathrm{H}]$-ryanodine binding effects of $\mathrm{Pg}$ at short and long exposures to $\mathrm{a} \mathrm{pH} 7.1$ aqueous buffer............................................................ 74

Figure $5.10 \mathrm{pH}$ dependant absorbance spectrum of pelargonidn ..................... 76

Figure $5.11 \mathrm{pH}$ dependant absorbance spectrum of delphinidin ...................... 77 
Figure $5.12 \mathrm{pH}$ dependent transformation kinetics of $\mathrm{Pg}$ and $\mathrm{Dp}$ 


\section{Introduction}

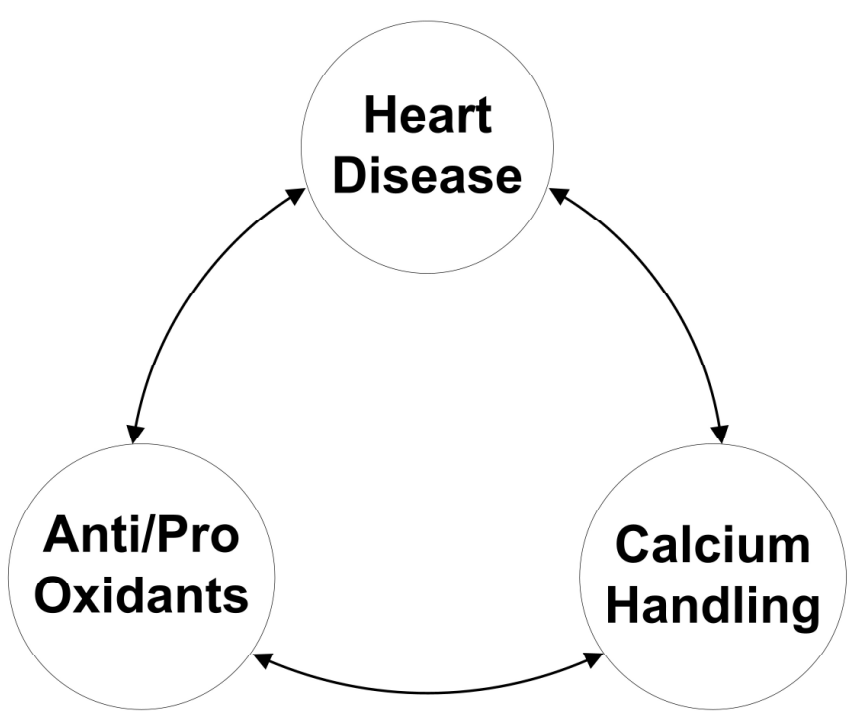

Figure 1.1 Heart Disease, Anti/Pro Oxidants, and $\mathrm{Ca}^{2+}$ handling

Cardio vascular disease (CVD) causes more deaths than any other disease on the globe (World Health Organization). Although CVD encompasses numerous distinct pathological mechanisms, sudden cardiac death (SCD), the abrupt loss of heart function, is estimated to account for approximately $50 \%$ of CVD related deaths. A majority of the SCD fatalities is attributed to ventricular tachyarrythmias (VT) (Huikuri, Castellanos, and Myerburg 2001). In an effort to improve the quality of life for non-fatal CVD victims, reduce CVD deaths, and minimize the enormous economic costs associated with CVD, extensive epidemiological studies and laboratory research continue to be funded and performed in hopes to better explain the pathological molecular mechanisms of CVD. 
Non-behavioral risk factors of CVD include increasing age, male gender, and heredity related factors (children of people with heart disease and race related increased risks). Behavioral risk factors (ones that we can change) account for over $90 \%$ of the risk of heart failures (HF). These factors include cigarette smoking, abnormal blood lipid levels (high cholesterol), hypertension (high blood pressure related), diabetes, abdominal obesity, a lack of physical activity, low daily fruit and vegetable consumption, alcohol over consumption, and psychosocial index. (AHA-Heart and Stroke Update 4/2009 referenced Lancet. 2004;364:937-952).

Interestingly, a subsequent epidemiological study found an exception to that rule, the people of southern France consume more fat and smoke more cigarettes than other countries with a similar incidence of CVD deaths. Additional studies revealed that the same population also had a slightly different diet which included higher intakes of vegetables, fruits, and wine. The lower incidence of CVD was quickly attributed to the constituents of those foods which were abundant in flavonoid antioxidant compounds. Since then, research has been conducted on almost every conceivable natural antioxidant to be found in those foods. Extensive quantitative-structure activity relationship (QSAR) studies have characterized those compounds for their antioxidant properties. Naturally, those compounds that exhibited the highest level of antioxidant activity in vitro were perceived as the best of the best'. These compounds have been studied extensively in the literature. If antioxidants are the 'cure', then it follows that 
oxidants may be the cause. Researchers targeted native reactive oxidant species (ROS) and studied their effects on the proliferation of CVD biomarkers in vitro. The results all seem to imply that ROS cause severe damage to biological processes and can be attributed to increased incidence of several CVD pathologies. In addition to the ROS connection, recent studies (Lehnart et al. 2004; Belevych et al. 2007; Belevych et al. 2008; Belevych et al. 2009; Belevych and Terentyev 2010) related to ventricular tachyarrythmias, a significant contributor to sudden heart failure, have shown a connection between VT and increased levels (overload) of calcium $\left(\mathrm{Ca}^{2+}\right)$ in the heart muscle cell via 'leaky' calcium release ion channels (ryanodine receptor). The ryanodine receptor (RyR) is known to have reactive thiol residues that are extremely sensitive to the oxidation by ROS and numerous other compounds. Oxidation of these thiols can causes increased channel activity and $\mathrm{Ca}^{2+}$ conductance (J.J. Abramson and G. Salama 1988; Jonathan J. Abramson and Guy Salama 1989; J. J. Abramson et al. 1988; J. J Abramson, Cronin, and G. Salama 1988).

There may indeed be a connection between increased oxidative stress in the cell (oxidative stress) and abnormal calcium handling by the RyR (calcium overload) in cardiac myocytes, and deaths by ventricular tachyarrythmias. Dietary antioxidants that play a part in reducing ROS in the cell may indeed have part in the decreased incidence of CVD deaths of those populations engaged in higher (disease) risk activities. However, numerous studies have shown that antioxidant compounds, especially the good ones, can also act as prooxidants. These 
antioxidant compounds have also been shown to bind to proteins and protective enzymes impacting their function (Graziani et al. 1982; Kaldas et al. 2005). The intention of the investigation of various dietary antioxidants is to characterize that compound for its potential beneficial properties and its potential deleterious properties so that fully informed and educated decisions can be made as to whether or not their benefits outweigh their risks. Due to the possible prooxidant activity of flavonoid antioxidants, it is clear that before recommendations can be made regarding their dietary inclusion, any impact that they may have on other biological systems must be understood. Given the importance of $\mathrm{Ca}^{2+}$ homeostasis in both skeletal and cardiac muscle, the interaction of these compounds need to be evaluated with regards to their possible modulation effects on the RyR.

\subsection{Oxidative Stress and Calcium Homeostasis in Muscle}

Calcium can signal and activate biological processes via dynamic variations in its concentration within cells. The concentration of free $\mathrm{Ca}^{2+}$ is generally controlled by its transport in and out of the cytoplasm of cells by ion channel proteins located in the membrane of the endoplasmic/sarcoplasmic reticulum organelles within the cell. This $\mathrm{Ca}^{2+}$ movement alters the cytoplasmic (intra-cellular) $\mathrm{Ca}^{2+}$ concentration which in turn impacts $\mathrm{Ca}^{2+}$ binding to various biological substrates. An important example of $\mathrm{Ca}^{2+}$ signaling is the binding of $\mathrm{Ca}^{2+}$ to specific muscle 
cell proteins. This interaction is mandatory for our muscles to contract and it also controls how much force is generated during the contraction. Indeed, without $\mathrm{Ca}^{2+}$ signaling, our muscles would cease to function and we would die. Improper functioning of the $\mathrm{Ca}^{2+}$ regulatory proteins can lead to pathological $\mathrm{Ca}^{2+}$ homeostasis conditions that can severely decrease the quality of human life and also lead to eventual death. The importance of knowing how $\mathrm{Ca}^{2+}$ levels in muscle cells is regulated and knowing what cause changes in that regulation cannot be overstated. Studies to determine why muscles malfunction, fatigue, and fail have consumed researchers for many decades. Although the normal functioning of the muscle is the result of synergistic cooperation from numerous proteins that reside in the muscle cell, the main regulatory protein, the one that controls the fast $\mathrm{Ca}^{2+}$ transient signals within the cell, is called the ryanodine receptor (RyR). The RyR is, simply put, the valve that opens and closes controlling the concentration of $\mathrm{Ca}^{2+}$ within the cell. Increased $\mathrm{Ca}^{2+}$ levels allow for the $\mathrm{Ca}^{2+}$ - protein interactions that allow the contractile process of the muscle to occur. The RyR is very sensitive to the environment within the cell. It is sensitive to $\mathrm{Ca}^{2+}$ concentrations, the redox environment, binding of other closely associated proteins, and numerous other endogenous and exogenous compounds. All of these can have an effect on the way the RyR manages the $\mathrm{Ca}^{2+}$ level in the cell. This is of utmost importance because too much, or too little, $\mathrm{Ca}^{2+}$ can cause the concert of cooperation between the cellular proteins to breakdown which may lead to various pathological conditions and even death. It 
has been shown that one of the most important cellular conditions, with regards to proper $\mathrm{Ca}^{2+}$ homeostasis regulation by the $\mathrm{RyR}$, is the redox environment within the cell (Jonathan J. Abramson and Guy Salama 1989; Jonathan J. Abramson and Guy Salama 1988; J. L. Trimm, G. Salama, and J. J. Abramson 1986). The redox potential in the cell is related to the relative ease in which the constituents in the cell environment can reduce (donate electrons or hydrogens to) the RyR or oxidize (accept electrons or hydrogens from) the RyR. The RyR is a large homotetrameric membrane protein containing approximately 5000 amino acids and weighing more than 2.2 megadaltons. The protein contains approximately 320-400 cytoplasmic, oxidation sensitive, cysteine residues (Xu et al. 1998). These cysteines have thiol side chains that are very sensitive to oxidization. When the thiols are oxidized, intra-molecular cystines or cysteineoxidizer adducts can be formed. It has been shown that some of the thiols on the RyR activate the channel when they are exposed to oxidizing conditions and that some of the thiols inhibit the channel when oxidized. (Jonathan J. Abramson and Guy Salama 1988; Jonathan J. Abramson and Guy Salama 1989; A. Dulhunty et al. 2000). To maintain proper cell function, the redox potential of the muscle cell environment is kept in a tightly controlled and reduced state by the relative ratios (redox couple) of a few important endogenous compounds capable of cyclic redox states. The redox state of the cellular environment can be impacted by all of the cellular redox couples present with each couple contributing via an additive effect. However, due to its high concentration and respective reducing capacity, 
the glutathione disulfide/glutathione (GSSG/2GSH) couple is considered to be the main redox buffer of the cell and the state (value) of this couple alone is typically used as an indication of the state of the redox environment of the cell (Schafer and Buettner 2001). The relative concentration of GSH present in the cell, and consequently, the redox environment is impacted by the invasion of oxidative species. The main endogenous oxidative species are derivatives of either oxygen or nitrogen. In particular, oxidative free radical compounds, hydrogen peroxide, and derivatives of nitric oxide. These are commonly referred to as reactive oxygen species (ROS) or reactive nitrogen species (RNS). ROS are natively generated and released from the oxidative phosphorylation processes of the mitochondria in the cell and by other mechanisms such as xanthine oxidase $(\mathrm{XO})$ and $\mathrm{NAD}(\mathrm{P}) \mathrm{H}$ oxidases. ROS can impart their damage by further increasing ROS levels via autoxidation reactions that further increase the levels of oxidants by directly attacking and altering (taking or donating electrons) cellular membranes and proteins causing altered function (Sen and Packer 2000). Increased levels of ROS can be generated during increased levels of exercise, exposure to environmental pollutants, and consumption of pro-oxidant compounds in food and beverages. In order to keep the redox environment tightly controlled (and in a reduced state), the body has a host of endogenous antioxidant defenses against these oxidants. Antioxidants are tasked with neutralizing the ROS by donating or accepting electrons or hydrogens to or from the ROS minimizing or nullifying its reactivity before the ROS reaches critical 
cellular substrates. In doing so, the antioxidant generally becomes a radical species itself but one that is more stable and relatively unreactive as compared to the original ROS. The main endogenous antioxidant compounds of the cell are glutathione $(\mathrm{GSH})$, the glutathione peroxidase system, CoEnzyme $Q$, superoxide dismustase (SOD), and catalase. This defense network is effective at protecting against various ROS under normal cell conditions but high levels of oxidants, generated during times of high oxygen consumption (strenuous exercise) or as a result of prooxidant intake (air pollutants or high fat diets), can overwhelm the endogenous defenses. These increased levels of oxidant compounds can easily overwhelm the endogenous antioxidants inducing a state of oxidative stress in the cell (M. J. Davies and Dean 1997; Fridovich 1978; K.J. Davies et al. 1982).

\subsection{Oxidative Stress and Disease}

It is now well accepted that elevated ROS levels are associated with numerous bodily disease states including numerous cardio vascular diseases including but not limited to atherosclerosis pathology (Khatri et al. 2004), cardiac hypertrophy (Higuchi et al. 2002), and myocardial lipotoxicity (S. Sharma et al. 2004). It is also connected with a variety of cancers, Alzheimer's Disease, inflammatory diseases (Hidalgo and Donoso 2008; Zima and Blatter 2006; Belevych et al. 2009) as well as skeletal muscle fatigue and failure (Moopanar and David G Allen 2005). Lipid peroxidation and sulfhydryl group oxidation during ischemia- 
reperfusion can lead to abnormally high cell $\mathrm{Ca}^{2+}$ levels and contractile dysfunction (Dhalla et al. 1999). Improper $\mathrm{Ca}^{2+}$ handling in the heart muscle has been connected to atrial arrhythmogenesis and contractile dysfunction in dogs with congestive heart failure (CHF) (Yeh et al. 2008). Evidence has shown that reactive oxygen species (ROS) alter calcium pump function (Kourie 1998; Kaplan et al. 2003), alter calcium current reduction in L-type calcium channels (Guerra et al. 1996), and decrease contractility via altered calcium handling (He et al. 2003) in cardiac myocytes. Recently, there have been numerous studies pointing to $\mathrm{Ca}^{2+}$ overload via improper $\mathrm{Ca}^{2+}$ handling by the RyR as an underling cause of arrhythmias and sudden cardiac death (Belevych et al. 2007; Belevych et al. 2009).

\subsection{The Flavonoid Antioxidant - Calcium Homeostasis Connection}<smiles>O=c1c(O)c(-c2ccc(O)c(O)c2)oc2cc(O)cc(O)c12</smiles>

Figure 1.2 Structure of Quercetin 
The effects of flavonoid compounds on the activity of the RyR need to be evaluated before they can be considered viable nutraceuticals. These compounds may be good antioxidants and even promote anticancer effects but if they or their radical species react directly with the RyR or other $\mathrm{Ca}^{2+}$ homeostasis associated proteins, they may cause harmful calcium overloading effects.

Studies on the interaction of flavonoids with the RyR are sparse. However, one popular flavonoid antioxidant, quercetin, has been shown to activate $\mathrm{Ca}^{2+}$ release from the SR skeletal muscle (D. H. Kim, Ohnishi, and Ikemoto 1983). Quercetin is a popular dietary antioxidant found in numerous vegetables, fruits, nuts, and teas. It has been extensively studied due to its excellent antioxidant properties and inclusion in numerous foods. Lee et. al. (Eun Hui Lee, Gerhard Meissner, and Do Han Kim 2002) showed that quercetin activates single RyR channel open probability $\left(\mathrm{EC}_{50}\right.$ of $91.0+/-15 \mu \mathrm{M}$ at $\left.10 \mu \mathrm{M} \mathrm{Ca}^{2+}\right)$ more effectively than the well known RyR activator caffeine $\left(\mathrm{EC}_{50}\right.$ of $\sim 2.93 \mathrm{mM}$ at $\left.10 \mu \mathrm{M} \mathrm{Ca}^{2+}\right)$. Quercetin also exhibited a higher maximal open probability $\left(P_{0}=0.89\right.$ at $\left.250 \mu \mathrm{M}\right)$ as compared to caffeine $\left(P_{0}=0.66\right.$ at $\left.9 \mathrm{mM}\right)$. Quercetin is effective at stimulating the RyR but it didn't exhibit any inhibitory actions. With regards to the redox sensitivity of the RyR, further tests were conducted to assay the effects of quercetin in the presence of the reduced and oxidized forms of glutathione (a cellular redox couple and as well as an endogenous antioxidant). The results showed that the effects of 5 mM GSSG (a RyR1 stimulant) plus quercetin on the RyR1 were not reversed by mM GSH (a known RyR1 inhibitor (Anthony C Zable, Terence G 
Favero, and Jonathan J Abramson 1997)). This may indicate that quercetin does not work via a redox dependent pathway. They also showed that the known stimulatory effects of $\mathrm{K}^{+}$-ATP on the RyR partially inhibited the stimulation by quercetin indicating that they may share the same binding site or that the effects of ATP on the channel may allosterically affect quercetin binding. These results are interesting from the stand point that quercetin appears to have a direct effect on the RyR yet not via a redox pathway. This is surprising since quercetin has a catechol group (ortho hydroxyls) on its B-ring which is notorious for being oxidized to semiquinone radicals and quinones which have prooxidant properties and directly react with protein thiols (Metodiewa et al. 1999; Boots et al. 2003). 


\subsection{The Anthocyanidins}

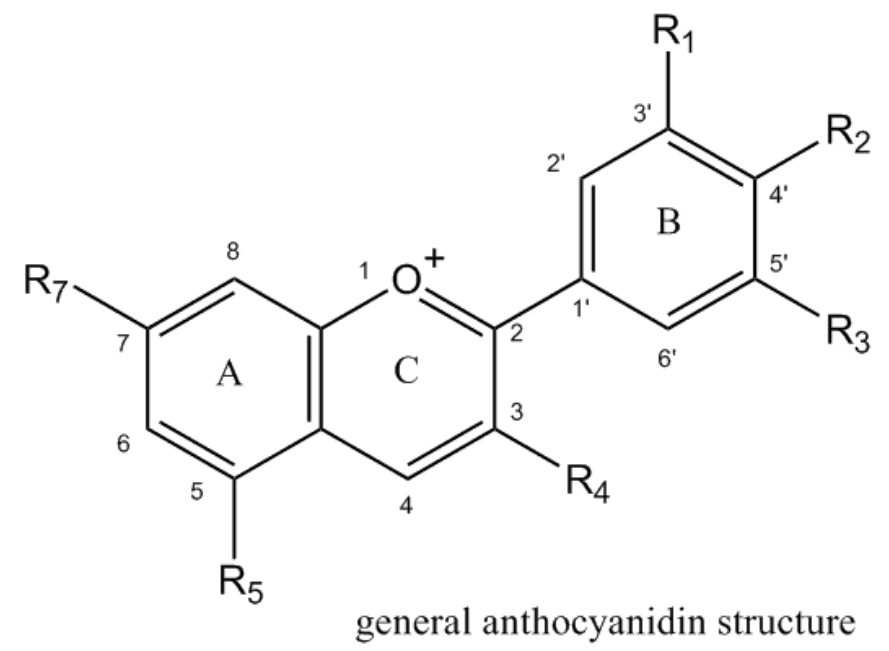

\section{Figure 1.3 Anthocyanidin Structure}

Anthocyanidins are a subclass of flavonoids and are best known for the beautiful colors they impart to nature. Based on their simplicity and wide ranging abundance, the anthocyanidins delphinidin (Dp), cyanidin (Cy), and pelargonidin $(\mathrm{Pg})$ are considered the three main anthocyanidins of more than 500 that are known to exist. They are responsible for most of the intense oranges, reds, blues, and purple colors exhibited in leaves, flowers, and fruits (J. B. Harborne, T. J. Mabry, and H. Mabry 1975). The chemical and biological properties of these compounds are very complex. Unlike other flavonoids, anthocyanidins are structurally unstable in weakly acidic to alkaline solutions. Upon exposure to these conditions, they will immediately start to transform into several different structural forms each with distinct chemical properties. The relative proportions of these forms is dependent on the $\mathrm{pH}$ of the solution and the specific 
functionalization of the compound (Brouillard and Delaporte 1977; Brouillard and Dubois 1977; Brouillard, lacobucci, and Sweeny 1982; Jurd 1963; Jurd and Geissman 1963; Jurd 1964; Jurd and Waiss 1965) (for more information see chapter 3 ). Along with the possible health benefits previously mentioned, these anthocyanidins are interesting and commercially valuable due to their ability to act as food colorants and food preservatives (antioxidants).

\subsubsection{Pelargonidin and Delphinidin - The Antioxidants}<smiles>Oc1ccc(-c2[o+]c3cc(O)cc(O)c3cc2O)cc1</smiles><smiles>Oc1cc(O)c2cc(O)c(-c3cc(O)c(O)c(O)c3)[o+]c2c1</smiles>

Figure 1.4 Structures of pelargonidin and delphinidin 
Although both pelargonidin $(\mathrm{Pg})$ and delphinidin $(\mathrm{Dp})$ exhibit good antioxidant properties as compared to the well accepted antioxidant vitamin E, delphinidin is dominantly superior to pelargonidin as an antioxidant. Delphinidin's antioxidant quality is attributed to its tri-hydroxyl structure in its B-ring. Those groups are very easily oxidized and its mechanism of antioxidant action is probably by electron donation and formation of a semiquinone moiety. The donation of a second electron then will form a quinone. (S. A. Van Acker et al. 1996; A. Sekher Pannala et al. 2001). Pelargonidin only has a mono-hydroxyl B-ring and is a less effective antioxidant. Its mechanism of action is probably by donation of an electron and subsequent formation of a phenoxyl radical (Galati et al. 1999; Ananth Sekher Pannala et al. 2001).

Both Pg and Dp exhibit superoxide and hydroxyl scavenging activity and can inhibit hydrogen peroxide induced lipid peroxidation. In a study of pomegranate extract, a hypoxanthine-xanthine oxidase superoxide generating system where DMPO-OOH spin adducts (indicator of superoxide concentration) were measured by ESR, Dp and Pg both exhibited scavenging properties with Dp being over two orders of magnitude better than $\mathrm{Pg}\left(\mathrm{IC}_{50}=0.8 \mu \mathrm{M}\right.$ and $130 \mu \mathrm{M}$ respectively). They also scavenged hydroxyl radicals with $\mathrm{Dp}$ being more effective than $\mathrm{Pg}$ although their scavenging properties may involve indirect rather than direct scavenging and possibly by more than one scavenging mechanism (Noda et al. 2002) 
Dp and $\mathrm{Pg}$ also were shown to inhibit $\mathrm{H}_{2} \mathrm{O}_{2}$ induced lipid peroxidation in rat brain homogenate when $\mathrm{H}_{2} \mathrm{O}_{2}$ and $\mathrm{Dp}$ and $\mathrm{Pg}$ were incubated together with the brain substrate for 60 minutes $\left(\mathrm{IC}_{50}=0.7 \mu \mathrm{M}\right.$ and $85 \mu \mathrm{M}$ respectively) (Noda et al. 2002). In a similar extract study (grape seed, etc), Dp and Pg also exhibited (with one exception) scavenging properties for superoxide, hypochlorite ion, hydroxyl radical, and linolenic acid with $\mathrm{Dp}$, again, being a better scavenger in all cases. Pg did not exhibit superoxide scavenging properties in this study (Wada et al. 2007).

Another study assessed the ability of Pg and Dp to scavenge the DPPH (1,1Diphenyl-2-Picrylhydrazyl) radical (4 min incubation in $\mathrm{MeOH}$ ), prevent MeLo (Methyl Linoleate) emulsion (10\% oil in water) hydroperoxide formation after 72 hours ( $\mathrm{pH}$ 5.5), inhibit Cu initiated hexanal formation from oxidation of LDL (2 hr incubation @ pH7.4), and prevent bulk MeLo (100\%) hydroperoxide formation after 72 hours. Generally, Pg and Dp both exhibited antioxidant activity with Dp being a better antioxidant. However, at a low concentration $(2.5 \mu \mathrm{M})$, Dp exhibited prooxidant activity but $\mathrm{Pg}$ was still an antioxidant in the LDL assay. They attributed the better antioxidant property of $\mathrm{Pg}$ to the fact that it has low polarity and thus may have better access to the lipid peroxidation site of the LDL (they sited similar results from another study). The researchers also admitted that the method of antioxidant action at higher concentrations may be due to hydrogen donation to the tocopheryl radical back to tocopherol (vitamin E) or by scavenging radicals and protecting tocopherol from consumption. Additionally, 
the anthocyanidins may bind with apolipoprotein B and prevent its subsequent binding to LDL thus blocking Cu catalyzed oxidation. Interestingly, they also noted that polar antioxidants (hydrophilic) are generally are more efficient in bulk oils than non-polar antioxidants (hydrophobic). This is due to a higher concentration or accumulation of a hydrophilic compound that accumulates at the oil water interface (Kahkonen and Heinonen 2003).

The radical scavenging ability of $\mathrm{Pg}$ and $\mathrm{Dp}$ is $\mathrm{pH}$ dependent. In a study by Borkowski et al., the TEAC antioxidant values (antioxidant action relative to Trolox) are measured for $\mathrm{Pg}$ and $\mathrm{Dp}$ (and several other anthocyanidins). The TEAC assay is based on the ABTS ${ }^{*}$ radical and the ability of the antioxidant to scavenge it and thus reduce its characteristic absorption spectrum. This particular compound was used due to its stability in a wide range of pHs. (2-9.5). Results basically indicated that $\mathrm{Dp}$ is a powerful antioxidant (several times better than Trolox) and its increase in scavenging activity is related to the deprotonations of its C4' hydroxyl ( $\mathrm{pK}_{\mathrm{a} 1} \sim 5.3$ (experimentally determined)) and its C5 hydroxyl ( $\mathrm{pK}_{\mathrm{a} 2} \sim 6.73$ (computationally predicted)). $\mathrm{Pg}$ on the other hand had an activity similar to Trolox but did not show a strong increase in activity with the deprotonation of C5.( $\mathrm{pK}_{\mathrm{a} 1} \sim 5.79$ (experimentally determined)) and the deprotonation at $\mathrm{C}^{\prime}$ ( $\mathrm{pK}_{\mathrm{a} 2} \sim 7.05$ (computationally predicted)) (Borkowski et al. 2005). 


\subsubsection{Pelargonidin and Delphinidin - The Prooxidants}

As hinted at in the previous section, both $\mathrm{Pg}$ and $\mathrm{Dp}$ can exhibit prooxidant properties. Delphinidin's pyrogallo group in its B-ring is highly oxidizable and autoxidation of this group is possible at physiological $\mathrm{pH}$. Autoxidation is accompanied by generation of superoxide and hydrogen peroxide (Hodnick et al. 1986; Hodnick et al. 1988). This property may also be enhanced by delphinidin's metal chelating ability which is also known to catalyze the autoxidation of (similarly oxidizable) catechol groups (dihydroxy group) (Vanacker et al. 1995; Canada et al. 1990; Dangles, Fargeix, and Dufour 2000).

Pelargonidin, with only a monohydroxyl group in the B-ring, does not exhibit autoxidation and doesn't chelate metals. Its reduction in hydrogen peroxide induced lipid peroxidation activity may be due to a different oxidation mechanism (Saskia A. B. E Van Acker et al. 1996). In one study, it was found that the phenoxyl radicals of similarly structured compounds with a mono-hydroxyl substituted $\mathrm{B}$ ring redox cycled and caused extensive $\mathrm{GSH}$ oxidation at $\mathrm{pH} 7$ to form thiyl- radicals which reduced oxygen. Surprisingly, flavonoids containing a catechol B-ring did not show the same oxidative properties (Galati et al. 1999).

In a LDL oxidation assay (Satue-Gracia, Heinonen, and Frankel 1997), both Dp and $\mathrm{Pg}$ act as prooxidants when 3uM copper is used as an oxidation initiator. Interestingly, when $10 \mu \mathrm{M}$ copper is used, $\mathrm{Pg}$ acts as an antioxidant and $\mathrm{Dp}$ continues to be prooxidant. It was noted that more work was needed to be able 
to propose a mechanism for why Pg changes its antioxidant/prooxidant activity with various copper concentrations. 


\subsection{This Thesis}

Due to the importance of understanding the effects that potential nutraceuticals have on the $\mathrm{Ca}^{2+}$ homeostasis in muscle tissue, this thesis will attempt to evaluate the modulation effects that pelargonidin and delphinidin have on the ryanodine receptor calcium release channel of skeletal muscle. 


\section{Muscle Structure and Function}

At a macro level, muscles are well defined organs capable of generating great force when stimulated to do so. Some of these stimuli are consciously controlled (voluntary muscle) and some are not consciously controlled (involuntary muscle). The heart (cardiac muscle), the iris of the eye, the arrector pili of the skin, the bladder, blood vessels, the gastrointestinal tract, are all examples of organs that contain involuntary muscle. Skeletal muscle is the only muscle tissue that is consciously controlled. It is responsible for locomotion, posture, voluntary eye lid movement, and sphincter control to name a few. Both cardiac muscle and skeletal muscle are classified as striated muscle due to the striated appearance of muscle fibers when viewed under the light microscope. These striations are due to a repeating, end-to-end, pattern of contractile proteins at the molecular level of the tissue. There are three types of muscle tissue: cardiac, skeletal, and smooth. They all have unique characteristics depending on the function for which they are designed. For instance, non-striated smooth muscle lacks the end-toend pattern of contractile proteins as mentioned. The random orientation and alignment of the contractile proteins of smooth muscle allows it to accommodate larger variations in stretch while still maintaining contractility. These characteristics are favorable in organs such as the bladder and the GI tract. On the other hand, the end-to-end and aligned orientation characteristics of skeletal and cardiac muscle allow them to generate large forces with longer contractile 
distances. These characteristics are required for generating large movements like bending a leg and also for generating high fluid pressures within the heart ventricles.

\subsection{Muscle Structure}

The original work presented in this thesis is most closely related to the function of the calcium release channel of skeletal muscle and thus it will be the primary muscle tissue discussed. However, probably the most benefit to society can be obtained if these types of studies are applied to cardiac muscle. For that reason, the finer details of the function of cardiac muscle may also be discussed. Smooth muscle is also very important with regards to human anatomy and physiology, but due to the limited scope of this thesis, it will generally not be discussed.

\subsubsection{Skeletal Muscle Macro Structure}

Skeletal muscle is composed of both muscle tissue and connective tissue and is highly compartmentalized. Each compartment is contained and protected by fibrous connective tissue (epimysium, perimysium, and endomysium). The largest of these compartments contains the whole macro muscle (muscle belly) and is surrounded by the epimysium. The muscle belly is composed of fascicles which are many smaller bundles of parallel strands encased in the perimysium. The fascicles contain groups of the long muscle cell which also known as the myofiber. 


\subsubsection{The Muscle Cell Structure}

Skeletal myofibers span the complete length of the bulk muscle that contains it. They range from $10 \mu \mathrm{m}$ to $100 \mu \mathrm{m}$ in diameter and up to $30 \mathrm{~cm}$ long (depending on the macro muscle length). Due to their long shape, myocytes are also referred to as myofibers. Myofibers are surrounded by the endomysium which provides the fiber access to capillaries and nerves. Layered underneath and proximal to the endomysium is the cell membrane of the myofiber, the sarcolemma. The sarcolemma is the plasma membrane that contains the intracellular fluid of the myofiber called the sarcoplasm. The sarcolemma is designed to receive nervous system stimuli and conduct that signal throughout the cell via membrane invaginations (transverse tubules or T-tubules) that project directly into the cylindrically shaped cell at locations associated to the Z-disks of the sarcomere (contractile sub-unit of the myofiber). Internal to the sarcolemma are highly aligned and orientated filamentous motor proteins (myofibrils). Surrounding the myofibrils throughout the myofiber resides an organized and highly functional organelle network called the sarcoplasmic reticulum (SR). The SR is designed to act as a storage compartment for $\mathrm{Ca}^{2+}$. The SR extends from T-tubule to $\mathrm{T}$ tubule and the group of organelles where two SR membranes from adjacent sarcomeres meet a t-tubule is called a triad (SR membrane: T-tubule: SR membrane). Proximal to the T-tubule, the SR exhibits an enlargement or sac which is referred to as the terminal cisternae (TC). The matrix of SR between the T-tubules and proximal to the longitudinal center of the myofibrils is the 
longitudinal SR. The myofiber is composed of an end-to-end chain of many contractile sub-units called the sarcomere. The sarcomere is a highly organized and complex arrangement of numerous proteins. Filamentous actin (f-actin or thin filament) and filamentous myosin (f-myosin or thick filament) are the contractile proteins of muscle. Tropomyosin and troponin are the primary regulatory proteins. Additionally there are structural proteins that help maintain the form of the muscle cells. Titin is an elastic protein filament that runs through the center of the myosin filaments and emerges from the end of the filament to connect to the Z-disks proximal to each end of the filament. The Z-disks are composed of an elastic protein filament called connectin. The Z-disks are the highly light refracting portion of the fiber that gives rise to the striated appearance of the muscle. Z-disks provide direct anchorage for both the titin and the actin filaments. The area between two Z-disks that contains both f-actin and f-myosin is the sarcomere.

\subsubsection{The Sarcomere}

F-myosin filaments (thick filaments) are about $15 \mathrm{~nm}$ in diameter and are made of hundreds of motor proteins molecules, myosin II (hence forth referred to as just myosin). One molecule of myosin is comprised of two polypeptide chains intertwined to form a golf club shaped structure where one end is the tail and the other end the head. A myosin filament is several hundred of these golf club shaped molecules linked together end to end with the tail sections intertwined and the heads extending outward from the filament. Thin filaments are about 7 
$\mathrm{nm}$ in diameter and are made up of two twisted strands of f-actin (filamentous actin). F-actin is a string like assembly of globular actin (G-actin) protein molecules. Each G-actin molecule has an active site that can bind to the head domain of the myosin molecules of F-myosin. Wrapped around the thin filament is another long polypeptide chain of proteins called tropomyosin. Tropomyosin has the function of blocking the binding of the myosin heads to the G-actin. Bound to the tropomyosin is a smaller and intermittently spaced calcium binding protein called troponin. Troponin has the function of binding calcium, undergoing a conformational change, and moving the tropomyosin filament which allows myosin to bind to the G-actin sites. Troponin has three sub-units and is bound to both the thin and thick filaments. The three sub-units are: Tnl (bound to actin), TnT (bound to myosin), and TnC (calcium binding sub-unit).

When the sarcomere is viewed under a light microscope, the varying densities and refracting properties of the protein structures can be observed, and thus distinguished. The area spanning adjacent sarcomeres that includes the Z-disk but does not include the F-actin is called the "I Band". The area that spans the length of one F-myosin filament is called the "A Band", the area near the center of the F-myosin that does not overlap F-actin is called the "H zone", and the area where the F-actin meets at adjacent sarcomeres is connected is called the Z-disk (as explained previously). The length of a sarcomere is approximately $1.7 \mu \mathrm{m}$ in the contracted state and $2.2 \mu \mathrm{m}$ in the extended state. The F-mysoin's structure is such that the myosin heads orient themselves in a corkscrew shape along the 
filament. This gives rise to a repeating pattern with six crossbridge head groups positioned in a radial pattern at multiples of 60 degrees. These repeating patterns are oriented such that the crossbridge heads align with each other along the length of the F-mysoin. F-actin and F-mysoin are orientated in hexagonal pattern when viewed as a cross section. There are six F-actin filaments surrounding each F-myosin filament, one F-actin per crossbridge head row and one F-actin filament may bind to more than one F-actin filament. This orientation is maintained throughout the myofiber which contains hundreds of myofilaments per fiber.

\subsubsection{The Sarcoplasmic Reticulum (SR)}

The SR is an organelle in the myocyte that has the primary function of storing $\mathrm{Ca}^{2+}$. The $\mathrm{SR}$ is a webbed network of an enclosed membranous system extending along the length of each sarcomere. As previously noted, the SR has two main structural and functional regions: 1) the terminal cisternae are the enlarged sac like structures nearest to the T-tubules and 2) the longitudinal SR is located along the length of the sarcomere. The area where the TC meets the ttubule is highly functional and complex and it's commonly referred to as the triadic junction, the dyadic junction, or (when referring to the SR specifically in this region) the junctional SR. The TC region of the SR contains a large amount of the $\mathrm{Ca}^{2+}$ binding protein calsequestrin. Calsequestrin is able to bind up to 50 $\mathrm{Ca}^{2+}$ ions per monomer and this binding of free $\mathrm{Ca}^{2+}$ increases the total $\mathrm{Ca}^{2+}$ storage potential of the SR. The junctional SR is the home of the main regulatory 
$\mathrm{Ca}^{2+}$ ion channel, the ryanodine receptor (RyR) (see next section more for additional detail) as well as other associated transmembrane proteins such as junctin and triadin. On the T-tubule, there resides a voltage gated $\mathrm{Ca}^{2+}$ ion channel called the dihydropyridine receptor (DHPR) which is also an important player in the functionally of muscle. Located primarily in the longitudinal SR is the $\mathrm{Ca}^{2+}$ ATPase pump (aka SERCA). There are almost 100 fold more SERCA pumps than RyRs in the SR. The $\mathrm{Ca}^{2+}$ ATPase is responsible for accumulating $\mathrm{Ca}^{2+}$ into the SR which allows the muscle to relax.

\subsubsection{Muscle Contraction}

The signal for a muscle to contract is sent from the brain via a neuron/axon to the neuromuscular junction. There, the signaling action potential opens voltage gated $\mathrm{Ca}^{2+}$ ion channels in the axon's plasma membrane which causes the internal levels of $\mathrm{Ca}^{2+}$ to increase. The elevated $\mathrm{Ca}^{2+}$ causes intracellular vesicles containing acetylcholine (ACh) to fuse with the cell membrane and, through exocytosis, dump the Ach into the synaptic cleft. ACh then binds to ligand gated $\mathrm{Na}^{+}$ion channels causing them to open and allow the subsequent influx of $\mathrm{Na}^{+}$in to the cell. This process causes the immediate opening of $\mathrm{K}^{+}$ion channels and the subsequent efflux of $\mathrm{K}^{+}$out of the muscle cell. Because of concentration differences, more $\mathrm{Na}^{+}$flows into the cell than $\mathrm{K}+$ flows out of the cell and this causes an electrochemical depolarization across sarcolemma. This 
depolarization self-propagates over the whole muscle cell and down the Ttubules. The depolarization of the T-tubules signals for the opening of the resident voltage gated L-type $\mathrm{Ca}^{2+}$ ion channel, the dihydropyridine receptor (DHPR). In the skeletal muscle cell, the DHPR is believed to be mechanically coupled to the ryanodine receptor and the opening of the DHPR has shown to be the determinate cause of the opening of the ryanodine receptor. In cardiac muscle, the DHPR is not structurally associated with the ryanodine receptor. The opening of the DHPR allows $\mathrm{Ca}^{2+}$ to enter the cell from the cytoplasm. The process of $\mathrm{Ca}^{2+}$ influx through the DHPR and subsequent elevation in $\mathrm{Ca}^{2+}$ concentration is responsible for cardiac ryanodine receptor activation. This process is called "calcium induced calcium release". The elevated levels of cytoplasmic $\mathrm{Ca}^{2+}$ causes $\mathrm{Ca}^{2+}$ binding to troponin which moves tropomyosin and allows myosin access to the actin binding sites. Myosin binding to the G-actin initiates the conformation change of myosin from a high energy conformation to a low energy conformation. This is commonly referred to as the power stroke. This change pulls the thin filament along the thick filament. The thin filament is attached to the Z-disks on each end of the sarcomere and the power stroke causes the sarcomere to shorten or contract. Thousands of these cellular contractions occurring in unison causes the muscle contraction we're familiar with at the macro level. After the power stoke occurs, the low energy conformation of myosin remains attached to f-actin until an ATP molecule binds to it. If there isn't any ATP available, the muscle remains in this contracted state 
(rigor). If ATP is available, it binds to the myosin head and the head de-binds from actin. Once it is free, myosin can hydrolyze the ATP into ADP and $P_{i}$. The hydrolysis of ATP provides the energy for myosin to change back into the high energy conformation and then rebind to actin. This cyclic process is referred to as cross-bridge cycling. When the signal from the central nervous system stops initiating depolarizations of the cell membrane, the DHPR closes and the RyR

closes as a result. $\mathrm{Ca}^{2+}$ concentrations are decreased and troponin changes its conformation to allow tropomyosin to block actin-myosin binding. This is the resting state of the muscle.

\subsubsection{Excitation-Contraction Coupling}

Excitation-Contraction Coupling (EC coupling) is the term used when describing the process of converting the cell depolarization into the actual muscle contraction. Although the overall process of the sliding filaments (sliding filament theory) is well established and accepted, the mechanism in which the DHPR communicates the depolarization signal to the RyR in skeletal dyads still remains uncertain. Cardiac dyadic junctions are organized differently than skeletal dyadic junctions. RyRs have the ability to self-organize into repeating patterns and do so in the junctional SR of both cardiac and skeletal muscle. Cryo-EM images of dyads have shown that the DHPRs of cardiac dyads are not arranged in any pattern with respect to the RyRs. They oppose the RyRs but in a random way. However, the DHPRs of skeletal dyads are arranged so that every other RyR1 is directly opposed to a cluster of four DHPRs and each cluster is associated with 
one monomer of the RyR (Block 1988). It has been shown that cardiac RyRs don't require the interaction with the DHPR to release large stores of $\mathrm{Ca}^{2+}$ from the SR. Instead, fast increases of $\mathrm{Ca}^{2+}$ near the junctional SR causes $\mathrm{Ca}^{2+}$ release from the RyR. For this reason, the release of $\mathrm{Ca}^{2+}$ from the SR of cardiac $\mathrm{SR}$ has been characterized as calcium induced calcium release (CICR). For skeletal dyads, the mechanism is more complex. The highly organized arrangement between the DHPR and the RyR implies a high level of association between them and indeed it has been shown that in functional triads, the molecular modification of what is called the II-III loop or the DHPR can cause the RyR to cease to release $\mathrm{Ca}^{2+}$ from the SR. Studies of simpler protein complexes like the voltage dependent $\mathrm{K}^{+}$ion channels have shown that cell membrane depolarizations trigger movements in voltage sensing domains and those movements can be trans-located across the membrane (Jiang, A. Lee, et al. 2003; Jiang, Ruta, et al. 2003). Together with the organized DHPR-RyR1 structures, it is hypothesized that charge dependent movements in the DHPR directly interact with the RyR and trigger the opening of the channel causing $\mathrm{Ca}^{2+}$ release. However, there are still a lot of unanswered questions stemming from a wealth of research and discussion and the understanding of the exact mechanisms required for EC coupling is still undetermined.

\subsection{The Ryanodine Receptor}

Ryanodine receptors are the largest membrane ion channels known. Three mammalian RyR isoforms are known to exist. These include the skeletal muscle 
RyR (RyR1), the cardiac muscle RyR (RyR2), and the smooth muscle RyR (RyR3). All of the isoforms have a sequence homology of approximately $70 \%$. The skeletal RyR1 (rabbit) sequence consists of 5,037 amino acids and has a molecular weight of 565,223 Da. The complex is a homotetramer of four identical subunits with a total weight of $\sim 2.3 \mathrm{MDa}$.

\subsubsection{The Ryanodine Receptor - Structure}

Knowing the 'exact' structure of a dynamically functional protein can give vast insight as to the biophysical mechanics and chemistry of the molecule.

Unfortunately the RyR is too small to be viewed under a light microscope and too large and complex to solve with traditional structural techniques such as x-ray crystallography. Original freeze-fractured electron microscopy images of skeletal triads by Ferguson et al. (Ferguson, Schwartz, and C Franzini-Armstrong 1984) were among the first to show the square foot structure of the skeletal RyR. They also were able to show the significant association of the RyR and DHPRs in skeletal muscle (Clara Franzini-Armstrong and Kish 1995). Since then, cryo-EM of single particles has emerged as a very useful technique to study the structure of these particles. Utilizing fluorescent probes with EM can also give us an idea of where important modulators bind on the macro structure. Sample preparation includes solubilizing the protein with detergent to separate it from the SR and then freezing it in liquid ethane $\left(\sim-88^{\circ} \mathrm{C}\right)$. Many images $(1,000$ to 100,000$)$ are computationally aligned and averaged and screened for artifacts to obtain the final result. Since the proteins have many different orientations, images from 
different perspectives are obtained and images can be reconstructed to produce 3-D images (Serysheva, Chiu, and Ludtke 2007). Capturing images of different conformational states is also possible by putting the RyR in an environment that favors a particular conformation prior to freezing it. Sub-nanometer resolutions have now been achieved by several groups (Ludtke et al. 2005; Serysheva et al. 2008; Serysheva et al. 2007) and it has been shown by some of these same groups that resolutions of $6-10 \AA$ is adequate for determining secondary molecular structures ( $\alpha$-helices and $\beta$-sheets).

\subsubsection{Sub-nanometer cryo-EM Structures}

The RyR has a mushroom shape with a large cytoplasmic (CY) head and a smaller transmembrane (TM) stem. From above it has four-fold symmetry (quatrefoil shaped). The $C Y$ region is $280 \AA \times 280 \AA \times 120 \AA$ with the $120 \AA$ being the dimension from the SR membrane to the top of the channel. The CY region is of low amino acid density and shows numerous possible locations for ligand binding. The TM region is much more dense and has dimensions of $120 \AA \times 120$ $\AA$ x $60 \AA$. The orientation of the TM region is rotated approximately 40 degrees with respect to the CY region (Ludtke et al. 2005). At the corners of the CY structure, there are clamp shaped regions. These 'clamps' are connected to central rods by dense bridging structures. Images have been captured with the channel in both open and closed states. When going from the closed to the open channel state, conformational changes are apparent with: the removal of amino acid density in the center of the channel (pore opening), CY clamps change from 
a closed shape to an open clamp shape, the TM domain rotates relative to the CY domain by $\sim 4$ degrees, and mass movements are seen in the central cavity and TM region (Orlova et al. 1996; Serysheva et al. 1999). The binding sites of several channel modulators have been mapped to the RyR structure by fluorescent tagging techniques. Calmodulin (Samsó and Wagenknecht 2002), FKBP12 (Samsó, Shen, and P. D Allen 2006), and other ligand binding sites have been located in the distal CY structure between clamp regions ('handle' region). Additionally, RyR mutations associated with malignant hypothermia and central core disease are known to be within the clamp region. This information supports beliefs that the channel is gated by allosteric means. 


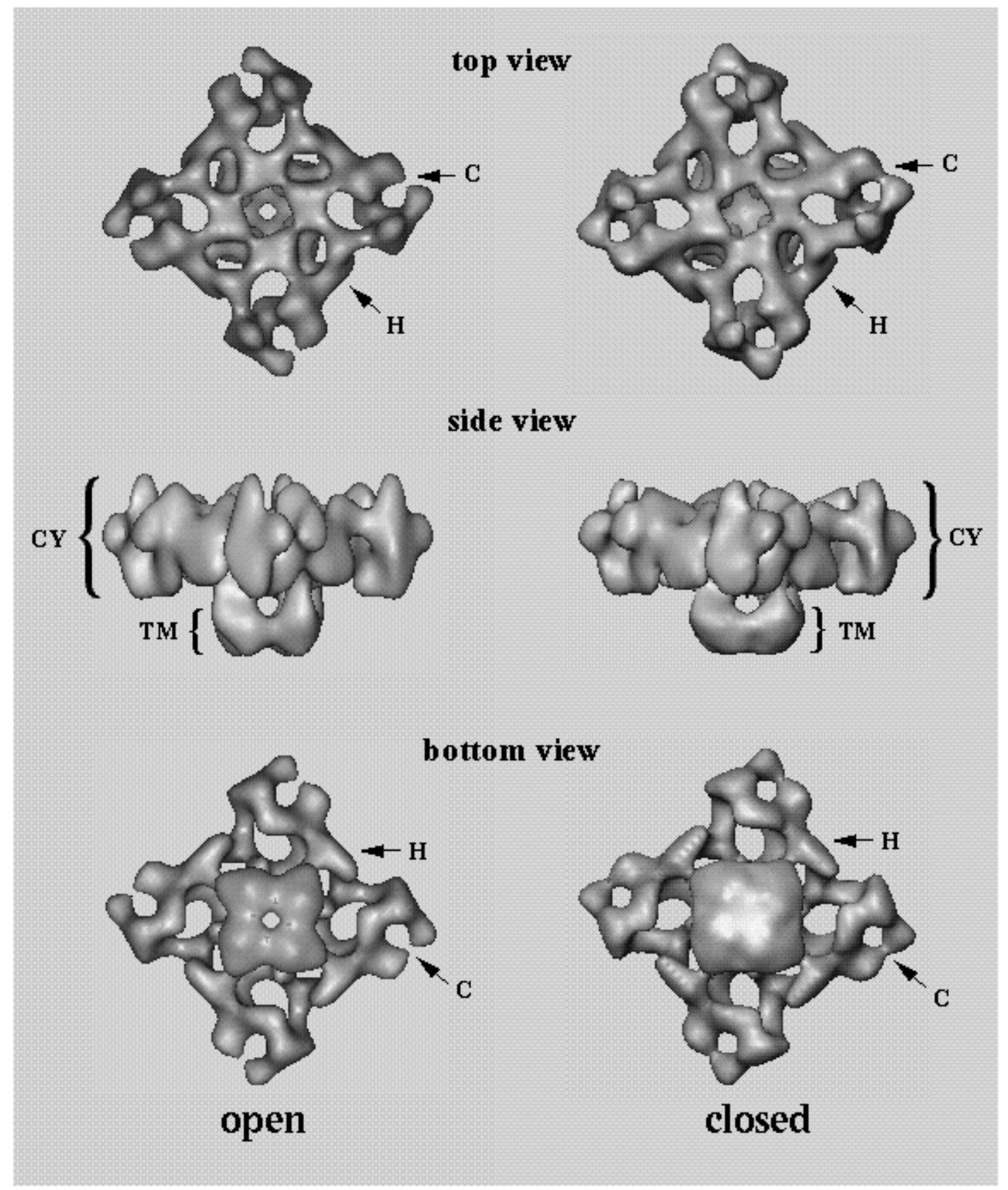

Figure 2.1 Cryo-EM reconstruction of RyR1 in open and closed states (Orlova, E. et al. Nature Structural Biology v3(6) 547-52. 1996) . 


\subsubsection{The Ryanodine Receptor Function}

\subsubsection{Associated Proteins and Endogenous Modulators of the RyR}

Dihydropyridine Receptor (DHPR): The DHPR is an L-type voltage gated $\mathrm{Ca}^{2+}$ ion channel located in the T-tubule membrane of the dyadic junction. It is highly associated with RyR1 both from a structural organization relationship and in function. It is the primary $\mathrm{Ca}^{2+}$ release initiator and is required for proper RyR1 function. The DHPR is less associated with RyR2. The structural organization is lacking and a direct interaction with the DHPR is not required for RyR2.

FKBP12/12.6: FKBP12 is a 12kDa protein associated with the RyR1 (FKBP12.6 is associated to RyR2) and binds in the 'handle' region at a ratio of four FKBP molecules per RyR (one FKBP per monomer). FKBP12 stabilizes the RyR and disassociation of FKBP from the RyR causes an increase in $\mathrm{Ca}^{2+}$ conductance.

Calcium: The RyR is a $\mathrm{Ca}^{2+}$ activated $\mathrm{Ca}^{2+}$ channel. The response of the RyR to free $\mathrm{Ca}^{2+}$ concentration is bell shaped. $\mathrm{Ca}^{2+}$ conduction through the RyR is minimal at low $(<1 \mu \mathrm{M})$ concentrations, maximal $\sim 100 \mu \mathrm{M}$ (depending on conditions), and again minimal above $1000 \mu \mathrm{M}$ free $\mathrm{Ca}^{2+}$ (J.S. Smith, Coronado, and G. Meissner 1986). This type of behavior is typically attributed to more than one binding site with each binding site having either differing ligand affinities or conformational accessibility limitations. Due to the small size of $\mathrm{Ca}^{2+}$, the accessibility option is probably not a concern. Therefore, the belief is that there is 
a high affinity activating binding site that gets populated at low $\mathrm{Ca}^{2+}$ concentrations and a low affinity inhibition binding site is populated at high $\mathrm{Ca}^{2+}$ concentrations.

Calmodulin (CaM): $\mathrm{CaM}$ is a $\mathrm{Ca}^{2+}$ binding protein with a molecular weight of 16.8 kDa. CaM's structure is made up of four $\mathrm{Ca}^{2+}$ binding domains (EF-hands) and it can bind four $\mathrm{Ca}^{2+}$ ions per protein. It is known to bind with RyR1 and cause stimulation at low $\mathrm{Ca}^{2+}$ concentrations and inhibition at high $\mathrm{Ca}^{2+}$ concentrations. Binding with RyR2 causes only channel inhibition (J. S Smith, Rousseau, and G. Meissner 1989; Tripathy et al. 1995).

Magnesium $\left(\mathrm{Mg}^{2+}\right): \mathrm{Mg}^{2+}$ is a known inhibitor of the RyR. Due to its similar nature and size as compared to $\mathrm{Ca}^{2+}$, it is believed that $\mathrm{Mg}^{2+}$ may compete with $\mathrm{Ca}^{2+}$ for the high affinity inhibition sites which is believed to cause inhibition of the channel with high concentrations of $\mathrm{Ca}^{2+}$ (J.S. Smith, Coronado, and G. Meissner 1986).

Adenosine-5'-triphosphate (ATP): ATP as well as other adenine nucleotides (cAMP, ADP, AMP, etc) are stimulators of the RyR (G. Meissner, Darling, and Eveleth 1986).

Glutathione (GSH): GSH is a tri-peptide of glutamate, cysteine, and glycine. GSH is a good reducing agent and is one of the principle endogenous compounds tasked with keeping the cellular redox status in check. Its concentration in the cell varies between $1 \mathrm{mM}$ and $10 \mathrm{mM}$. When in an oxidizing 
environment, it can be oxidized and form glutathione disulfide (GSSG). GSH (reduced form) inhibits the RyR and GSSG (oxidized form) stimulates the RyR. The two forms show to be competitive and therefore it is believed that they both act on the same regulatory sulfhydryls on the RyR. (A C Zable, T G Favero, and J J Abramson 1997)

Superoxide $\left(\mathrm{O}^{\circ-}\right)$ : Superoxide is commonly generated by leaks in the ETC (electron transport chain) pathway of the mitochondria in cells and is a major contributor to oxidative stress. Superoxide has shown to decrease calmodulin content and increase $\mathrm{Ca}^{2+}$ efflux from heavy SR. It was also shown that single channel activation was dependent on the presence of calmodulin. (Kawakami and Okabe 1998)

Hydrogenperoxide $\left(\mathrm{H}_{2} \mathrm{O}_{2}\right): \mathrm{H}_{2} \mathrm{O}_{2}$ was shown to induce release from actively loaded SR vesicles at $>1 \mathrm{mM}$ concentrations and induce a bi-phasic response in $\left[{ }^{3} \mathrm{H}\right]$-ryanodine binding assays (activation range: $100 \mu \mathrm{M}-10 \mathrm{mM}$ ). (T G Favero, A C Zable, and J J Abramson 1995)

Junctin and Triadin: Junctin is a $\sim 27 \mathrm{kDa}$ MW membrane protein and Triadin is a 95kDa MW membrane protein (Fan, Brandt, and Caswell 1995). Junctin and Triadin both bind to the RyR and are believed to help associate calsequestrin to the RyR (J. M Lee et al. 2004; Goonasekera et al. 2007; Jones et al. 1995; Angela Dulhunty, Lan Wei, and Nicole Beard 2009). They both have been shown 
to activate the RyR when added to the luminal side of the channel and seem to activate at independent sites (L. Wei, Gallant, et al. 2009).

Calsequestrin (CSQ): CSQ is a $44 \mathrm{kDa} \mathrm{Ca}^{2+}$ binding protein located in the lumen of the SR that effectively binds up to $50 \mathrm{Ca}^{2+}$ ions per molecule (MacLennan and Wong 1971). CSQ has been found to increase channel activity when removed from the of RyR complex and inhibit activity when added back in to the luminal space (N. A Beard et al. 2002). There are two CSQ genes, CSQ1 (fast and slow twitch skeletal muscle) and CSQ2 (slow twitch skeletal and cardiac). Single channel studies have shown that CSQ1 may inhibit RyR1 but stimulate RyR2 (L. Wei, Hanna, et al. 2009) It should be noted that numerous studies of the interaction between RyR, CSQ, junctin, and triadin are being reported in current literature and important and relevant information regarding the interaction of these protein complexes are being discovered.

\subsubsection{Non-Endogenous Modulators}

Ryanodine (Ry): Ryanodine is an alkaloid found in the plant Ryania speciosa of South America. It has a high affinity to the RyR (and thus the reason for its name) and locks it in a varying degree open state depending on concentration. (I. N. Pessah et al. 1986; Lai et al. 1988).

Ruthenium Red: Ruthenium is a potent channel inhibitor and can block channel activity at sub micromolar concentrations. It is commonly used to verify the presence of the RyR in assays (Ma 1993). 
4-chloro- $m$-cresol (4-CmC): 4-CmC a drug preservative stimulates ( 75-100 $\mu \mathrm{M})\left[{ }^{3} \mathrm{H}\right]-$ ryanodine binding and planar bilayer activity. (Herrmann-Frank et al. 1996)

Anthraquinones: Doxorubicin, mitoxantrone, daunorubicin, and rubidaxone all stimulate RyR1 activity by a direct interaction with the caffeine and the $\mathrm{Ca}^{2+}$ binding sites. (J. J. Abramson et al. 1988)

\subsubsection{Redox Activity Characteristics}

The RyR has approximately 100 cysteines per monomer (Takeshima et al. 1989) with approximately 80 of those accessible to be oxidized. Cysteines are highly reactive and well known to be redox active compounds in other biological molecules. The RyR has also been shown to be very sensitive to its redox environment. When the RyR is subject to an oxidizing environment, the RyR is stimulated, when the oxidizer is pre-treated with a reducing compound (DTT), the oxidizer loses its stimulating capability. (Jonathan J. Abramson and Guy Salama 1989; Jonathan J. Abramson and Guy Salama 1988; Carnes et al. 2009; Marinov BS and J.J. Abramson 2005; Xia, Stangler, and J. J Abramson 2000; Anthony C Zable, Terence G Favero, and Jonathan J Abramson 1997; J.J. Abramson et al. 1983; A. Dulhunty et al. 2000).

Redox active compounds that have shown to modulate the RyR include: 
Heavy Metals $\left(\mathrm{Hg}^{2+}, \mathrm{Ag}^{+}, \mathrm{Cu}^{2+}, \mathrm{Cd}^{2+}, \mathrm{Zn}^{2+}\right)$ : Heavy metals bind with high affinity to protein sulfhydryl groups and activate the ryanodine receptor at low micromolar concentrations (J. J. Abramson et al. 1983).

Phtalocyanine Dyes: Oxidation by the phthalocyanine dyes (alcian blue (AB), $\mathrm{Cu}^{2+}$ phthalocyanine tetrasulfonic acid, and Luxol fast blue MBSN) were found to induce rapid $\mathrm{Ca}^{2+}$ release from actively $\left(\mathrm{Ca}^{2+}\right)$ loaded $\mathrm{SR}$. Pre-reduction of $\mathrm{AB}$ with reducing agents causes loss of stimulating effect indicating that the compounds are acting via redox sensitive interactions with the RyR. (J. J Abramson, Cronin, and G. Salama 1988)

Quinones : Naphthoquinone and benzoquinone have been shown to activate channel activity by oxidation of hyperactive cysteine thiols on the RyR 1 and RyR2 (Feng et al. 1999).

\section{Coumarin maleimide 7-diethylamino-3-(4'-maleimidylphenyl)-4-} methylcoumarin (CPM) : CPM (1-50 nM) binds to RyR-triadin hyper-reactive thiols when RyR is in a closed state. Covalent interactions of those thiols with nanomolar CPM inhibits gating activity. (G. Liu et al. 1994)

1,4-Napthoquione: 1,4-Napthoquione (0.4-40pmol/ $\mu \mathrm{M})$ oxidizes hyperactive thiols on RyR-triadin and stimulates $\mathrm{Ca}^{2+}$ release from SR vesicles. (G. Liu et al. 1994) 


\section{The Anthocyanidins: Pelargonidin and Delphinidin}

\subsection{Anthocyanidins}

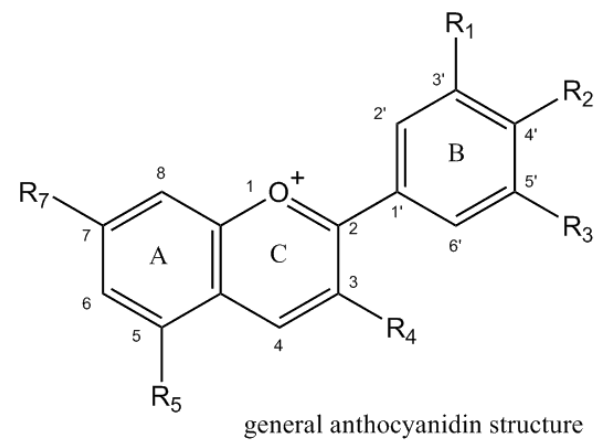

Figure 3.1 Basic Structure of Anthocyanidins

Anthocyanidins are one of the six sub-classes of Flavonoids (itself being a subclass of polyphenols). They are compounds of the plant kingdom that have the general structure of a flavylium cation (2-phenylchromenylium) with a $\mathrm{C}_{6} \mathrm{C}_{3} \mathrm{C}_{6}$ skeleton and with functionalization occurring at specific locations on the structure (see Figure 3.1). Functional groups are typically referred to by the number of the carbon to which it is attached (eg. The C4' hydroxyl or the 4'-OH). Additionally, the compound is sometimes characterized by its individual aromatic rings A, B, and $\mathrm{C}$. Anthocyanidins are salts and usually are identified along with a chloride counter ion. The counter ion dissociates with the main molecule in solution which leave a positive charge on the compound. This charge allows anthocyanidins to absorb light and exhibit intense colors from the orange-reds to the purples. They provide most of the red to purple colors observed in flowers, leaves, fruits, and 
vegetables. They share a common function in the phyto-kingdom as pigments used to attract insects for pollination, cellular signaling molecules, anti-fungal protection, and UV light protection. Specific anthocyanidins are identified by how the base structure is functionalized with hydrogens, hydroxyl, methoxy, and sugar groups and the amount and type of substitution contributes greatly to the color properties of the molecule. There are 23 known anthocyanidins (Øyvind M. Andersen and Markham 2006). Anthocyanidins have poor solubility in aqueous solutions but when sugar groups are attached (anthocyanins), they become more soluble and as such, that is the form that is found most in nature with more than 500 known anthocyanins documented. Although anthocyanins are the more prevalent, the functional properties of those compounds are due to the aglycon form (anthocyanidin) and thus most studies focus on that group of compounds (Estevez and Mosquera 2008; J. B. Harborne, T. J. Mabry, and H. Mabry 1975).

The six anthocyanidins that are considered to be the most important mainly due to their widespread distribution in nature are pelargonidin, cyanidin, delphinidin, petunidin, peonidin, and malvidin. Three of these six are considered to be the principle anthocyanidins due to their minimal substituent groups: delphinidin (Dp), cyanidin, (Cy), and pelargonidin $(\mathrm{Pg})$. These three all have the same hydroxyl functionality on the 3,5 , and 7 carbons of the $A$ and $C$ rings. They differ in the amount of hydroxyl groups on the B-ring. The addition of hydroxyl groups to the B-ring $\left(\mathrm{R}_{2}=\mathrm{OH}\right.$ for pelargonidin, $\mathrm{R}_{2}=\mathrm{R}_{3}=\mathrm{OH}$ for cyanidin, and $\mathrm{R}_{1}=\mathrm{R}_{2}=\mathrm{R}_{3}=\mathrm{OH}$ for delphinidin) causes a bathochromic (red) shift in their absorption spectrum. They 
have absorbance maxima at 530nm, 545nm, and 556nm (respectively) when prepared in acidified ethanol (Cabrita, Fossen, and Øyvind M. Andersen 2000).

\subsection{Anthocyanidin Structural Equilibrium}

Anthocyanidins are native to the acidic conditions of the plant cell. Under these conditions, the anthocyanidins predominately occur in the 'flavylium cation' form as shown in Figure 3.1. Upon placing them in a more alkaline aqueous environment, they become very unstable and their structure is altered in various ways depending mainly on the $\mathrm{pH}$ but temperature and light can also be effectors. At very acidic $\mathrm{pH}$, anthocyanidins exist almost exclusively in the flavylium cationic form $\left(\mathrm{AH}^{+}\right)$(see Figure 3.2). When subjected to higher pHs ( 5), anthocyanidins exhibit three distinct chemical reactions involving proton transfers, hydration, and tautormerizations. Upon a $\mathrm{pH}$ jump to $\sim 5$, deprotonation immediately occurs on the hydrogen (or hydrogens) of the flavylium cation with the lowest bond disassociation enthalpy $(B D E)$ resulting in the quinoidal base form $(A)$ or the quinoidal base anion form $\left(\mathrm{A}^{-}\right)$. The flavylium cation $\left(\mathrm{AH}^{+}\right)$and the quinoidal base (A) quickly ( $<1 \mathrm{sec}$ ) come to an equilibrium. On a slower time scale (minutes to hours), $\mathrm{AH}+$ undergoes hydration to obtain the carbinol pseudobase (B) and/or the carbinol pseudobase anion $\left(B^{-}\right)$. The rate of these reactions are dependent upon the $\mathrm{pH}$ of the environment and on the degree and type of substitutions. Higher $\mathrm{pH}$ generally leads to a slower transformation to the carbinol form (Brouillard and Delaporte 1977; Brouillard and Dubois 1977). This will depend on the $\mathrm{pK}_{\mathrm{a}}$ 's of the substituents of the different anthocyanidins. In addition, the 
quinoidal base transforms to the colorless carbonyl pseudobase (C) form. For cyanidin (the only kinetic study of a related

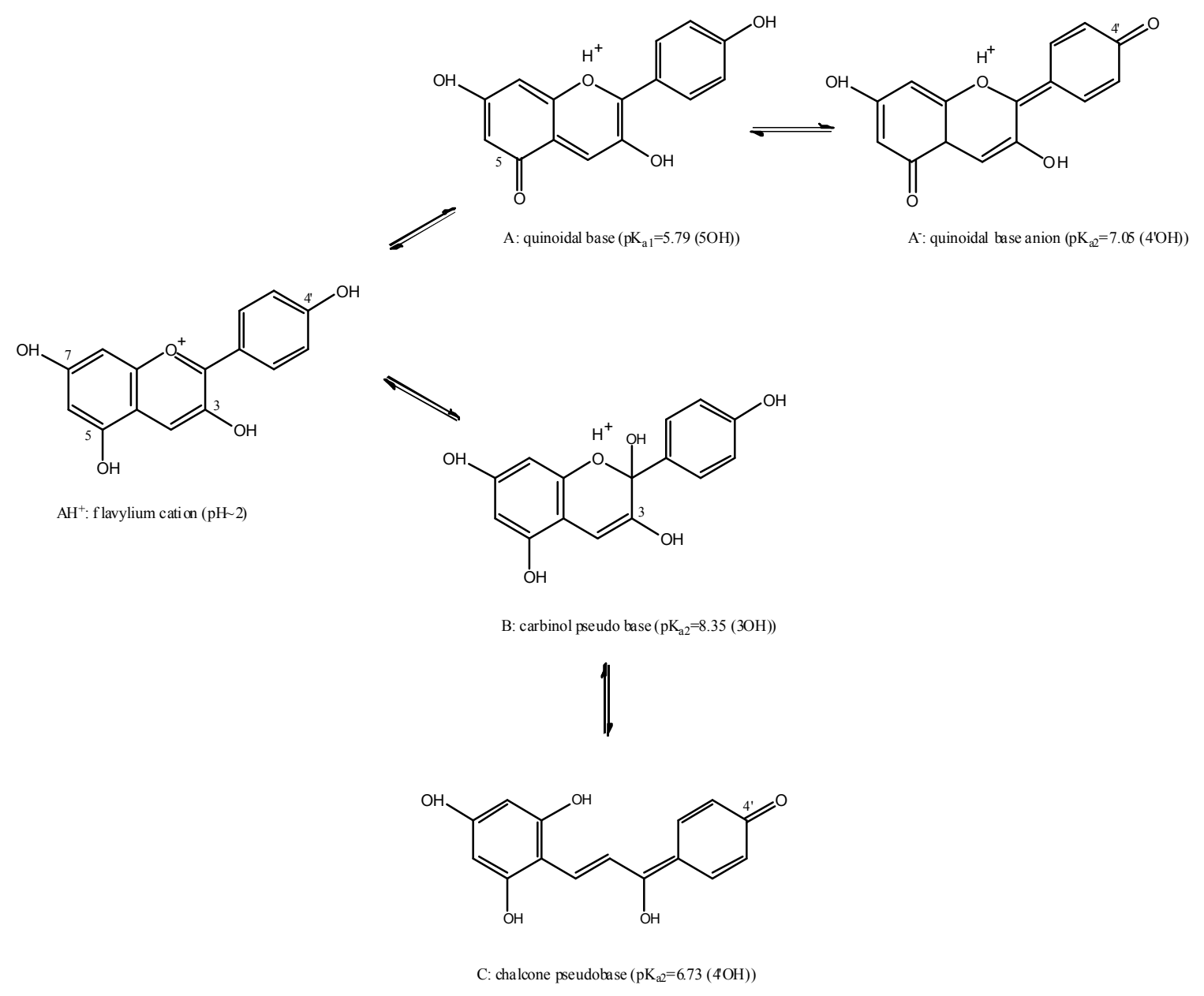

Figure 3.2 The forms of pelargonidin in neutral $\mathrm{pH}$ solutions 
anthocyanidin that I found in literature), the half life of this structural

transformation is reported to be 0.5 days (at $\mathrm{pH} 2.8$ ) (lacobucci and Sweeny 1983). 


\subsection{Pelargonidin}

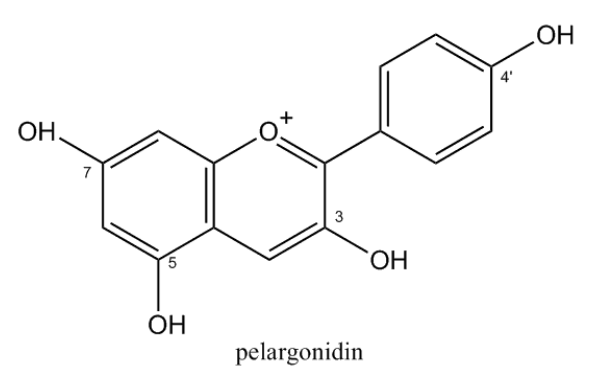

Figure 3.3 Molecular Structure of Pelargonidin

Pelargonidin (Figure 3.4) was first obtained by Willstater and Bolton in 1914 by the hydrolysis of pelargonin of Pelargonium zonale. It has absorbance maxima in the 530nm (in EtOH-HCl). Pelargonidin is found in the skin of the red radish, strawberries, petals of geraniums, and the rose (among others). 22 glycosides of pelargonidin are known (J.B. Harborne 1967). Pelargonidin has hydroxyl (-OH) groups at the $3,5,7$, and (para) 4' positions. The structural configurations of pelargonidin are shown in Figure 3.3. When exposed to increasing $\mathrm{pH}$ conditions, compounds with a monohydroxylated B ring (pelargonidin) exhibit a gradual bathochromic (red) shift up to $\mathrm{pH} \sim 6$, an extensive red shift from $\mathrm{pH} \sim 6$ to $\mathrm{pH} 7.3$, and a stable $\lambda_{\max }$ from $\mathrm{pH} 7.3$ to $\mathrm{pH} 10-11$ (Cabrita, Fossen, and Oyvind $\mathrm{M}$ Andersen 2000). These color changes are caused by structural changes as mentioned in the previous sections. Although the first $\mathrm{pK}_{\mathrm{a}}\left(\mathrm{pK}_{\mathrm{a} 1}\right)$ can be determined experimentally, subsequent deprotonation $\mathrm{pK}_{\mathrm{a}}$ 's ( $\mathrm{pK}_{\mathrm{a} 2}$ etc.) are difficult to determine experimentally due to the simultaneous existence of multiple 
forms of the compound in solution. Thus, to predict the $\mathrm{pK}_{\mathrm{a}}$ of subsequent deprotonations of each structural form, quantum mechanical calculations determining the disassociation energies of each hydrogen must be performed. The lowest computed BDEs based on the lowest energy structures are considered the first to deprotonated. In reality, there may be several similarly valued low energy structures and several hydrogens with similar valued BDEs which imply a mixture of compounds in solution at all times. When subjected to a neutral $\mathrm{pH}$ environment, pelargonidin rapidly deprotonates and changes from the flavylium cation from to its quinoidal base form. The first deprotonation is experimentally been shown to be at $\mathrm{pH} 5.79$. The favored deprotonation site as calculated numerically is the $5-\mathrm{OH}$ group. The predicted $\mathrm{pK}_{\mathrm{a} 2}$ for the quinoidal base form is at $\mathrm{pH} 7.05$ and located at the 4'-OH. At physiological $\mathrm{pH}(\sim 7.4)$, pelargonidin is probably in an anionic quinoidal base form (see Figure 3.2). The transformation to the anionic quinoidal base is very fast coming with equilibrium in less than 1 second. A second transformation to the carbinol pseudobase has slower kinetics with a half life in the 10 minute range (see result section). The $\mathrm{pK}_{\mathrm{a} 2}$ for the carbinol form is predicted to be 8.35 and therefore is probably not anionic at the experimental $\mathrm{pH}$ of $\sim 7.1-7.4$. The structural change to the chalcone form is on order of 12-24 hours (data for cyanidin, not pelargonidin). The predicted $\mathrm{pK}_{\mathrm{a} 2}$ for the chalcone is 6.73 also at the 4' position and therefore it is predicted to be in an anionic form (Borkowski et al. 2005) 


\subsection{Delphinidin}<smiles>Oc1cc(O)c2cc(O)c(-c3cc(O)c(O)c(O)c3)[o+]c2c1</smiles>

Figure 3.4 Molecular Structure of Delphinidin

Delphinidin (Figure 3.4) was first obtained by hydrolysis of delphin (of the larkspur (Delphinium consolida). It has an absorbance maxima of 556nm (EtOH$\mathrm{HCl}$ ) and is responsible for rich purple and dark violet colors of berries. It is found in the skin of eggplant, grapes, and pedals of the hyacinth just to name a few. (J.B. Harborne 1967)

Compounds with a trihydroxylated B-ring (delphinidin) show a gradual bathochromic (red) shift up to $\mathrm{pH} \sim 6$, an extensive red shift from $\mathrm{pH} 6$ to $\mathrm{pH} 7.3$, an extensive blue shift from $\mathrm{pH} 7.3$ to $\mathrm{pH} \sim 8.5$, and then another red shift at even higher pH's. Due to the same (mixture of forms) difficulties as addressed in the pelargonidin section, the $\mathrm{pK}_{\mathrm{a} 2}$ 's for 


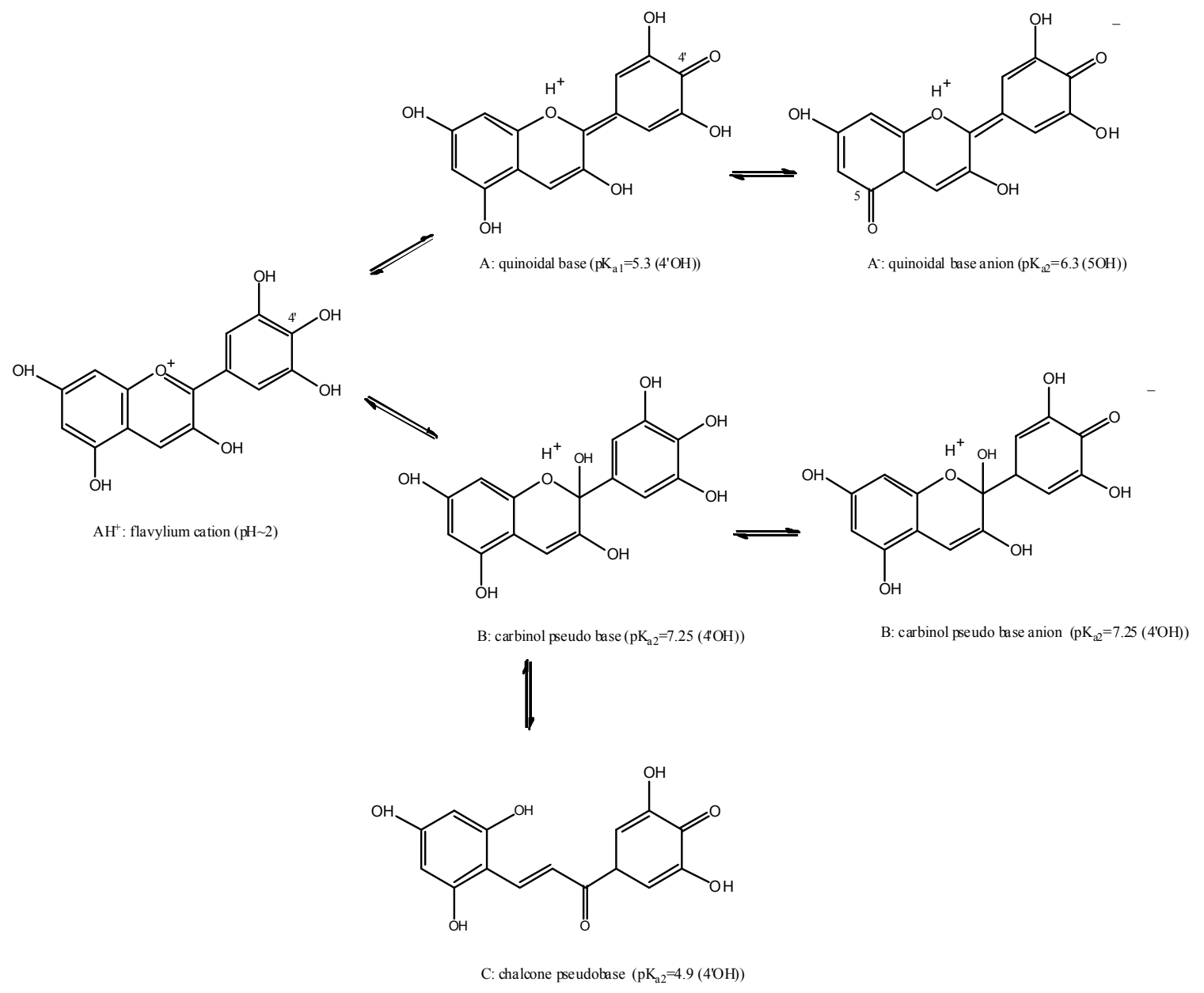

Figure 3.5 The forms of delphinidin in neutral pH solutions 
delphinidin are also predicted numerically rather than experimentally. Delphinidin's first deprotonation is at $\mathrm{pH} 5.30$ (experimental) and numerical based deprotonation energies predict it to be the 4' hydrogen. The predicted $\mathrm{pK}_{\mathrm{a} 2}$ is at 6.73 at $\mathrm{C} 5$. At physiological $\mathrm{pH}$, delphinidin is predicted to rapidly deprotonate to the quinoidal base anion form with lost hydrogens on 4' and 5 . The carbinol pseudo base has a predicted $\mathrm{pK}_{\mathrm{a} 2}$ on $\mathrm{C}^{\prime}$ ' at 7.25 and thus may be in a mix of its neutral and anionic forms at physiological $\mathrm{pH}$. The predicted $\mathrm{pK}_{\mathrm{a} 2}$ for the chalcone form is 4.9 also at the 4' position and therefore it is predicted to be in a neutral form as well (Borkowski et al. 2005). 


\section{Materials and Methods}

\subsection{Sarcoplasmic Reticulum Vesicles}

Sarcoplasmic reticulum was isolated from fast twitch back and hind leg skeletal muscle extracted from 2-3 $\mathrm{kg}$ New Zealand white male rabbits according to the methods of MacLennan et al (1970) with modifications. Live rabbits were euthanized, bled, and put on ice. Removed muscle was also put on ice. Fat and red muscle was trimmed from the fast twitch muscle and discarded. Fast twitch muscle was cut to approximately 1 inch peices and placed into a cold proteolysis inhibiting buffer of $120 \mathrm{mM} \mathrm{NaCl}, 10 \mathrm{mM}$ imidazole, $100 \mu \mathrm{M}$ DTT, $10 \mu \mathrm{M}$ EGTA, and $100 \mu \mathrm{M}$ leupeptin at $\mathrm{pH}$ 7.4. Muscle was then homoginized with a common household blender (Waring) by a $4 \mathrm{X}$ repeating cycle of $15 \mathrm{sec}$ at low speed, 60 sec high speed, and $30 \mathrm{sec}$ of no blending. Homogenate is then centrifuged at $1,600 \times \mathrm{g}$ for 10 minutes. Supernate is then filtered through four layers of cheesecloth to remove excess debris and fat. Remaining homogenate is adjusted to $\mathrm{pH} 7.4$ with imidazole and centrifuged at $10,000 \times \mathrm{g}$ for 15 minutes to remove mitochondria. Supernate is retained and centrifuged at $44,000 \times \mathrm{g}$ for an additional 70 minutes to collect SR. Supernate is discarded and remaining pellet is homogenized to approximately $10 \mathrm{mg} / \mathrm{ml}$ with a buffer of $120 \mathrm{mM} \mathrm{NaCl}, 10 \mathrm{mM}$ imidazole, $100 \mu \mathrm{M}$ DTT, and $50 \mu \mathrm{M}$ EGTA at $\mathrm{pH}$ 7.4. The resulting homogenate is then centrifuged at $7,500 \times \mathrm{g}$ for 10 min to remove any remaining myosin. Supernate is retained and centrifuged at $78,000 \times \mathrm{g}$ to obtain the SR pellet. The 
pellet is then homogenized to approximately $20 \mathrm{mg} / \mathrm{ml}$ in a buffer of $100 \mathrm{mM} \mathrm{KCl}$ and $20 \mathrm{mM}$ HEPES at pH 7.0. Aliquots of SR are put in cryo-storage tubes and stored in liquid $\mathrm{N}_{2}$ until needed.

The protein concentration of the SR is then quantified by the method of Kalckar (1947). The $280 \mathrm{~nm}$ absorbace of aromatic amino acids tyrosine and tryptophan combined with the $230 \mathrm{~nm}$ absorbace of the peptide backbone can be utilized to determine the total protein concentration (see Equation 4.1). Equation 4.2 is a correction factor for the possible contamination of nuclecic acids which absorb at $230 \mathrm{~nm}$.

Equation 4.1

$$
[S R]_{m g / m l}=1.45 \times\left(A b s_{280}\right)-0.74 \times\left(A b s_{260}\right)
$$

Equation 4.2

$$
[S R]_{m g / m l}=0.185 \times\left(A b s_{230}\right)-0.075 \times\left(A b s_{260}\right)
$$

\subsection{Reagents}

Ryanodine was purchased from CalBiochem (San Diego, CA), ${ }^{3}[\mathrm{H}]$-Ryanodine was purchased from Du Pont - New England Nuclear Co. (Boston, MA), Pelargonidin chloride (CAS\#134-04-3) was purchased from Sigma Aldrich, Delphinidin chloride (CAS\#528-53-0) was purchased from Sigma Aldrich and 
Extrasynthese (France), Antipyrylazo III and A23187 was purchased from Sigma Aldrich, EtOH was analytical grade 200 proof, anhydrous $>99.5 \%$, all water used has a resistivity of 18 Mohm and was obtained from a Mili-Q System (Millipore Co), all other reagents (buffers, salts, etc) were of typical laboratory grade unless noted.

Pelargonidin and delphinidin were prepared at $10 \mathrm{mM}$ concentrations in $\mathrm{EtOH}$ and stored at $\sim 4^{\circ} \mathrm{C}$ between experiments.

Stock solution was diluted to lower concentration in $\mathrm{EtOH}$ in necessitated by the experiment.

\subsection{Methods}

\subsubsection{Passive $\mathrm{Ca}^{2+}$ Loading of SR Vesicles}

$\mathrm{Ca}^{2+}$ was passivily loaded into $\mathrm{SR}$ vesicles by incubating undiluted stock $\mathrm{SR}$ ( $20 \mathrm{mg} / \mathrm{ml}$ protein) in $0.5 \mathrm{mM}$ to $1 \mathrm{mM} \mathrm{CaCl} 2$ by the procedure as follows. SR was removed from $\mathrm{LN}_{2}$ storage and thawed by rubbing between the hands until no solid SR particles were observed. Multiple storage tubes are thawed and combined as needed to obtain an amount nessesary for the experiment. An appropriate amount of $100 \mathrm{mM} \mathrm{CaCl}_{2}$ is added to the $\mathrm{SR}$ and then vortexed for 35 seconds. The tube is then plunged into $\mathrm{LN}_{2}$ and allowed to freeze solid for $\sim 5-$ 
10 seconds. The tube is then thawed again as previously decribed and placed under crushed ice overnight. 


\subsection{2 $\mathrm{Ca}^{2+}$ Efflux Measurements}

$\mathrm{Ca}^{2+}$ release from SR vesicles can be monitored and quantified by spectrophotometric methods utilizing polycationic indicator dyes that change absorbance with corresponding changes in sample free $\mathrm{Ca}^{2+}$ concentration (Scarpa, Brinley Jr, and Dubyak 1978). The polycationic indicator dye Antipyrylazo III (APIII) and a time sharing dual wavelength spectrophotometer (Chance et al. 1975) (purchased from the University of Pennsylvania) was utilized for all efflux experiments. The spectrophotometer is a rotating wheel type with bandpass filters that pass $720 \mathrm{~nm}$ and $780 \mathrm{~nm}$ wavelengths from a halogen source. The passed wavelengths are incident on a photomultiplier tube which is connected to a multiplexing amplification control module. The control module conditions the signals by taking the difference between the $\left(\mathrm{Ca}^{2+}\right.$ responsive $)$ $780 \mathrm{~nm}$ signal from the $\left(\mathrm{Ca}^{2+}\right.$ non-responsive $) 720 \mathrm{~nm}$ signal. The difference is then output as an analog voltage signal, digitized, and recorded on a PC (AxoScope software, Axon Instruments (now Molecular Devices)). An APIII buffer containing $100 \mathrm{mM} \mathrm{KCl}, 20 \mathrm{mM}$ HEPES, and $200 \mu \mathrm{M}$ APIII at $\mathrm{pH} 7.4$ was used. SR vesicles were loaded with $\mathrm{Ca}^{2+}$ as previously described. A typical experiment involves $2 \mathrm{ml}$ of the APIII buffer added to a $4.5 \mathrm{ml}$ polystyrene cuvette with $1 \mathrm{~cm}$ path length and a magnetic stir bar. Approximately $40 \mu \mathrm{l}-50 \mu \mathrm{l}(0.4-0.5$ $\mathrm{mg} / \mathrm{ml}$ final protein concentration) of prepared SR is pipetted into the APIII buffer. The intravascular $\mathrm{Ca}^{2+}$ concentration is now approximately 50-40 fold greater 
than the extravesscular $\mathrm{Ca}^{2+}$. The concentration gradient forces release of $\mathrm{Ca}^{2+}$ through the channel. APIII's spectrum changes in response to the rising $\mathrm{Ca}^{2+}$ concentration and the resulting signal change is recorded for further analysis. At the completion of $\mathrm{a} \mathrm{Ca}^{2+}$ efflux experiment, the $\mathrm{Ca}^{2+}$ ionophore $\mathrm{A} 23187$ is added $\left(2 \mu \mathrm{l} @ \sim 1.0 \mathrm{ug} / \mathrm{ml}\right.$ ) to initiate release of all unreleased intravesscular $\mathrm{Ca}^{2+}$ (to determine total vesicle loading capability and to assist in data analysis). A known amount $(\sim 5 \mu \mathrm{M})$ of $\mathrm{CaCl}_{2}$ can also be added for $\mathrm{Ca}^{2+}$ signal calibration. To assay for the effect of possible modulators, the modulator is added immediately $(<1 \mathrm{sec})$ prior to the addition of the SR. The resultant signal is compared to the signal of the contro. To ensure that the increasing $\mathrm{Ca}^{2+}$ signal is from $\mathrm{Ca}^{2+}$ leaving the RyR1, the potent inhibitor Ruthenium Red is added immediately prior to the SR. Ruthenium Red control should block the release of $\mathrm{Ca}^{2+}$ from the SR vessicles.

To quantifiy the results, the data representing the $\mathrm{Ca}^{2+}$ release phase is fit to a first order exponential rise to max equation (Sigma Plot). Typically, the initial rate of $\mathrm{Ca}^{2+}$ release is calculated by taking the product of the value of maximum amount of $\mathrm{Ca}^{2+}$ released $(\mu \mathrm{M})$ and the rate constant $\left(\mathrm{s}^{-1}\right)$ which gives the initial rate of $\mathrm{Ca}^{2+}$ in units of $\mu \mathrm{M} / \mathrm{s}$. The initial rate of $\mathrm{Ca}^{2+}$ release is then compared.

It was verified that $\mathrm{Pg}$ and $\mathrm{Dp}$ do not significantly alter the $\mathrm{Ca}^{2+}$ response of APIII. 


\subsubsection{Ryanodine Binding}

\subsubsection{Ryanodine}

Ryanodine (Figure 4.1) is an alkaloid found in the plant Ryania speciosa of South America. It has a high affinity to the RyR and locks it in a varying degree open state depending on concentration. Due to it's specific affinity to the RyR and it's use as a label for the first purification of the RyR, the RyR is commonly known as the ryanodine receptor.

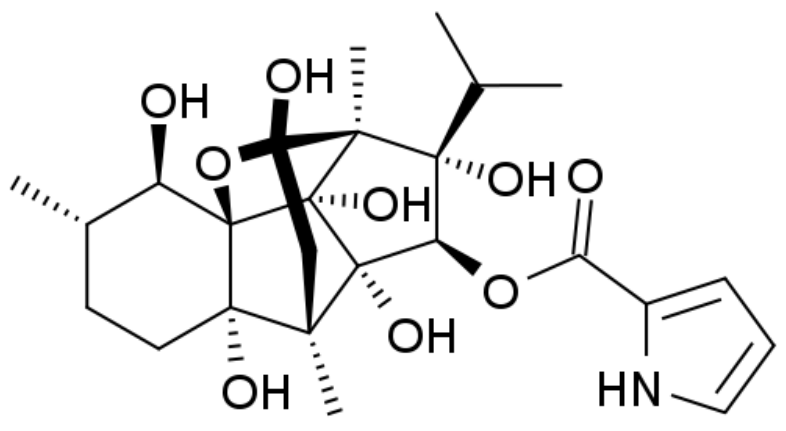

Figure 4.1 Molecular Structure of Ryanodine

The rate of ryanodine binding to the RyR depends on the open probablility of the RyR. The higher the open probability of the RyR, the greater the rate of Ry 
binding. By using tritiated ryanodine, the amount of rayanodine that binds to the RyR in a specidfied amount of time can be quantified by a scintillation counter and be indirectly used to the open state of the RyR. The Beckman LS6500 scintillation counter is utilized for this purpose.

\subsubsection{Binding Assays}

$\mathrm{SR}(0.5 \mathrm{mg} / \mathrm{ml})$ is combined with a standard ryanodine buffer of $250 \mathrm{mM} \mathrm{KCl}, 15$ $\mathrm{mM} \mathrm{NaCl}$, and $20 \mathrm{mM}$ HEPES at $\mathrm{pH}$ 7.1. $\left[{ }^{3} \mathrm{H}\right]$-ryanodine is added to obtain a final $\left[{ }^{3} \mathrm{H}\right]$-ryanodine concentration of $2 \mathrm{nM}$. Mixtures are kept on ice. Solutions of pelargonidin and delphinidin were taken from stock and diluted to obtain a useable stock concentration if required. $\left[{ }^{3} \mathrm{H}\right]$-ryanodine, $\mathrm{SR}$, and pelargonidin or delphinidin are mixed to obtain desired final concentrations. Mixtures are placed in a $37^{\circ} \mathrm{C}$ water bath for the period of time needed for the experiment. At the end of the time period, the ryanodine binding reaction is then quenched by rapid filtration through Whatman GF/B glass fiber filter sheets on a Brandel cell harvester. Sample tubes are rinsed $2 x$ using a standard rinse buffer similar to standard ryanodine buffer. Filtered samples are placed in scintillation vials with $5 \mathrm{ml}$ scintillation fluid, placed on a shaker overnight, and then counted on a Beckman L-6500 scintillation counter. RyR non-specific binding is measured by addition of a 200X excess of non-labeled ryanodine to a control sample. Total 
activity is measured by counting an unfiltered sample ( $2 \mathrm{nM}\left[{ }^{3} \mathrm{H}\right]$-ryanodine $)$.

Binding quantification is determined by the following equations:

Equation 4.3

$$
B_{\text {pmol } / m g}=\frac{1}{\left[S R_{\text {sample }}\right] \times v o l_{\text {sample }}} \times \frac{d p m_{\text {sample }}-d p m_{N S}}{S A}
$$

Where

$$
S A=\frac{d p m_{T A}}{\left[R y_{\text {total }}\right] \times \text { vol }_{\text {ryanodine }}}
$$




\section{Results}

\subsection{Spectrometric Analysis of $\mathrm{Ca}^{2+}$ Efflux from SR Vesicles}

\subsubsection{Pelargonidin Inhibits / Delphinidin Stimulates $-\mathrm{Ca}^{2+}$ Efflux from SR Vesicles}

This experiment was performed as noted in the methods section. Pg and Dp were added to the APIII buffer immediately (within $1 \mathrm{sec}$ ) prior to the addition of the $\mathrm{Ca}^{2+}$ loaded SR vesicles. At the concentrations tested $(25 \mu \mathrm{M}$ and $50 \mu \mathrm{M})$, the $\mathrm{Pg}$ and $\mathrm{Dp}$ stock solutions added $0.25 \%$ and $0.5 \% \mathrm{EtOH}$ (vol) respectively to the APIII buffer. To minimize any effect that the EtOH may have on the RyR and $\mathrm{Ca}^{2+}$ efflux, $0.5 \% \mathrm{EtOH}$ was also added to the control trials. Ruthenium Red $(5 \mu \mathrm{m})$ was utilized to ensure $\mathrm{Ca}^{2+}$ efflux was occurring through the RyR and not through other means such as membrane diffusion. Results show (Figure 5.1) that $25 \mu \mathrm{M}$ and $50 \mu \mathrm{M} \mathrm{Pg}$ both inhibit the release rate of $\mathrm{Ca}^{2+}$ from the RyR in a dose dependent manner and that $25 \mu \mathrm{M}$ and $50 \mu \mathrm{M}$ Dp both stimulate the release rate of $\mathrm{Ca}^{2+}$ from the RyR in a dose dependent manner with respect to the control. It is worth noting that $50 \mu \mathrm{M} \mathrm{Pg}$ exhibits a $\left[\mathrm{Ca}^{2+}\right]_{\max }$ that is less than half of the $\left[\mathrm{Ca}^{2+}\right]_{\max }$ for all other traces. This may be due the existence of a high affinity $\mathrm{Pg}$ binding site that is exposed at higher levels of inhibition (higher Pg concentrations). Once the site is revealed, the abundant levels of $\mathrm{Pg}$ can bind strongly and effectively close the channel to $\mathrm{Ca}^{2+}$ flux. This is highly speculative 
however and similar results were not duplicated in other concentration dependent experiments (see Figure 5.3). 


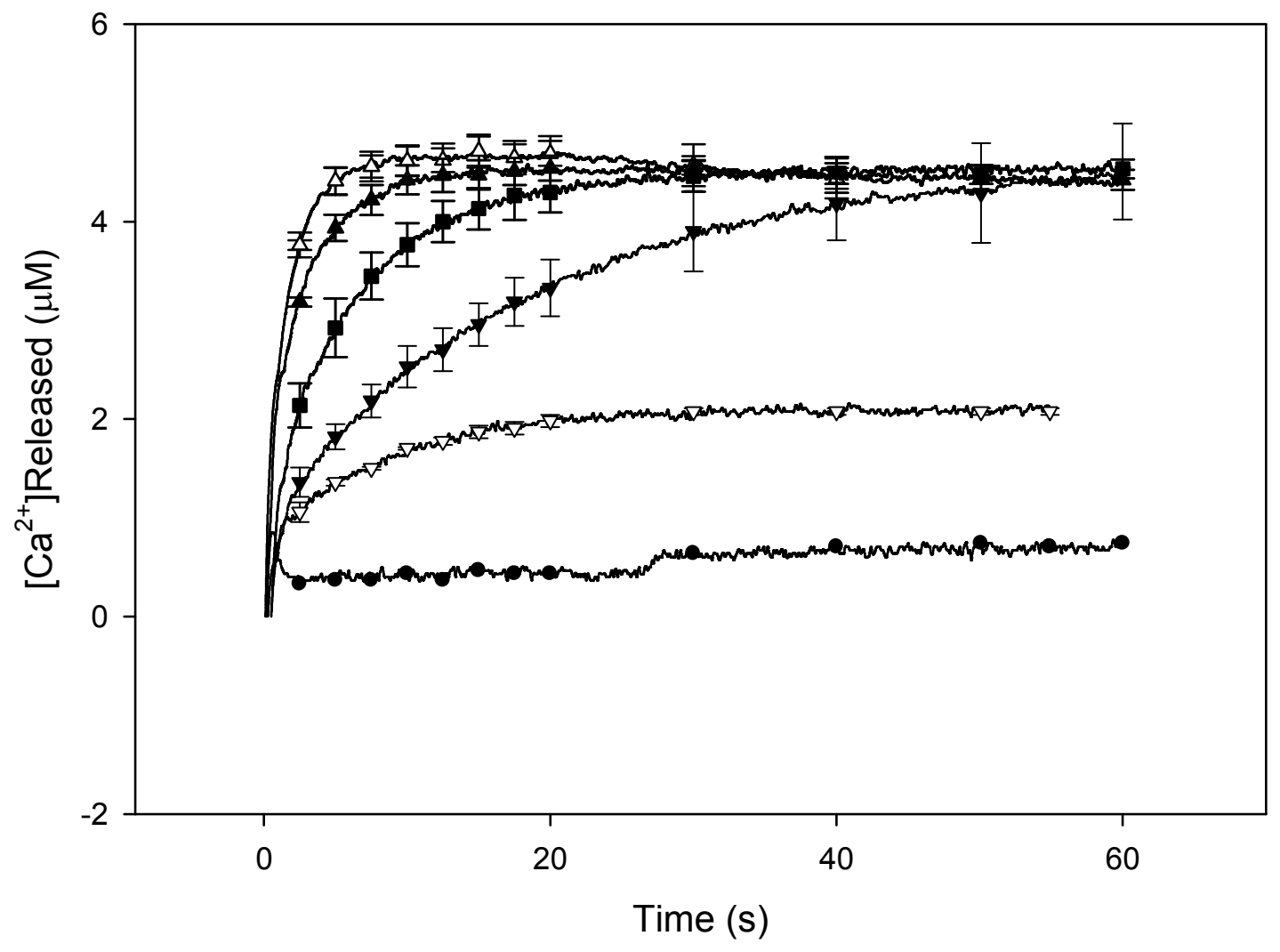

Figure 5.1 Dp stimulates $\mathrm{Ca}^{2+}$ release and $\mathrm{Pg}$ inhibits $\mathrm{Ca}^{2+}$ release from the RyR1 of skeletal SR.

Traces of $\mathrm{Ca}^{2+}$ efflux from $\mathrm{Ca}^{2+}$ loaded skeletal SR vesicles. Stock SR vesicles $(\sim 20 \mathrm{mg} / \mathrm{ml}$ protein) incubated with $1 \mathrm{mM} \mathrm{CaCl}$ overnight ( 12-16 hours) on ice. Experiments performed in $200 \mu \mathrm{M}$ APIII, $100 \mathrm{mM} \mathrm{KCI}, 20 \mathrm{mM}$ HEPES, pH 7.4. $\mathrm{Ca}^{2+}$ release is stimulated by dilution of SR into APIII buffer ( 40:1). Final protein concentration $=0.3-0.5 \mathrm{mg} / \mathrm{ml}$. Ca ${ }^{2+}$ release is stimulated by both $25 \mu \mathrm{M}(\Delta)$ and $50 \mu \mathrm{M}(\Delta)$ Dp and inhibited by both $25 \mu \mathrm{M}(v)$ and $50 \mu \mathrm{M}(\nabla) \mathrm{Pg}$ with respect to the control ( $\bullet)(0.5 \%$ EtOH). $5 \mu \mathrm{M}(\bullet)$ Ruthenium Red added to verify release is through RyR1. Both Pg and Dp were added to APIII buffer immediately prior to addition of SR. Error bars represent standard deviation for $n=4$ for control and $n=3$ for all other data. 


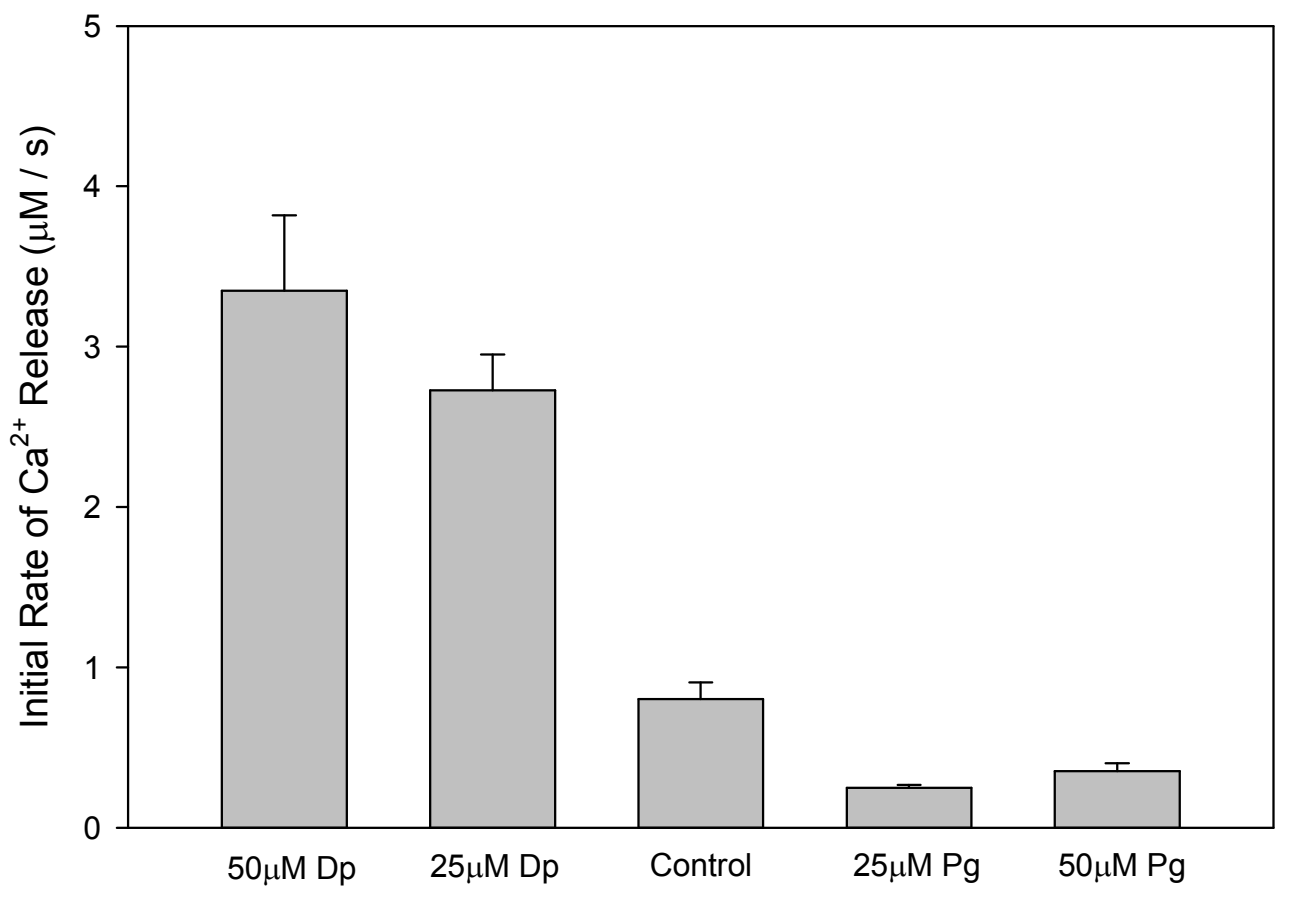

Figure 5.2 Initial Rate of $\mathrm{Ca}^{2+}$ Efflux from SR is Modulated by $\mathrm{Pg}$ and $\mathrm{Dp}$.

Initial rate of $\mathrm{Ca}^{2+}$ release is stimulated by both $25 \mu \mathrm{M}$ and $50 \mu \mathrm{M}$ Dp and inhibited by both $25 \mu \mathrm{M}$ and $50 \mu \mathrm{M} \mathrm{Pg}$ with respect to the control $(0.5 \% \mathrm{EtOH})$. Data from figure 5.1 were fit to first order rise to max exponential functions and results used to calculate the initial rate. Experiments performed in $200 \mu \mathrm{M}$ APIII, $100 \mathrm{mM} \mathrm{KCI}, 20 \mathrm{mM}$ HEPES, $\mathrm{pH}$ 7.4. $\mathrm{Ca}^{2+}$ release is stimulated by dilution of SR into APIII buffer ( 40:1). Final protein concentration $=0.3-0.5$ $\mathrm{mg} / \mathrm{ml}$. Both Pg and Dp were added to APIII buffer immediately prior to addition of SR. Error bars represent standard deviation for $n=4$ for control and $n=3$ for all other data. 


\subsubsection{Pelargonidin Modulates the Initial Rate of Release in a Biphasic Manner}

The initial rate of $\mathrm{Ca}^{2+}$ efflux from the $\mathrm{SR}$ is stimulated by $1 \mu \mathrm{M}$ and $5 \mu \mathrm{M}$ concentrations of Pg. Concentrations from $40 \mu \mathrm{M}$ to $160 \mu \mathrm{M}$ showed increased

inhibition of $\mathrm{Ca}^{2+}$ efflux. A traditional explanation for this type of biphasic behavior is the interaction with more than one class of binding sites on the RyR. At low micromolar concentration of $\mathrm{Pg}$, binding to high affinity at binding sites results in channel activation, while at higher concentrations, binding to a lower affinity site results in inhibition of the channel. This may be the case here but $\mathrm{Pg}$ also can show prooxidant behavior at low concentrations and antioxidant behavior at higher concentrations (see chapter 1 and 3 ) and this characteristic may also contribute to the biphasic character shown here. The data in this section doesn't support the decreased $\left[\mathrm{Ca}^{2+}\right]_{\max }$ at higher Pg concentrations (Figure 5.1). The reason for this inconsistency is not known and warrants replicate trials to confirm results. The complex effect that Pg has on the RyR coupled with the lack of more detailed concentration dependence data would render further quantitative analysis as questionable and thus kinetic analysis will not be presented. 


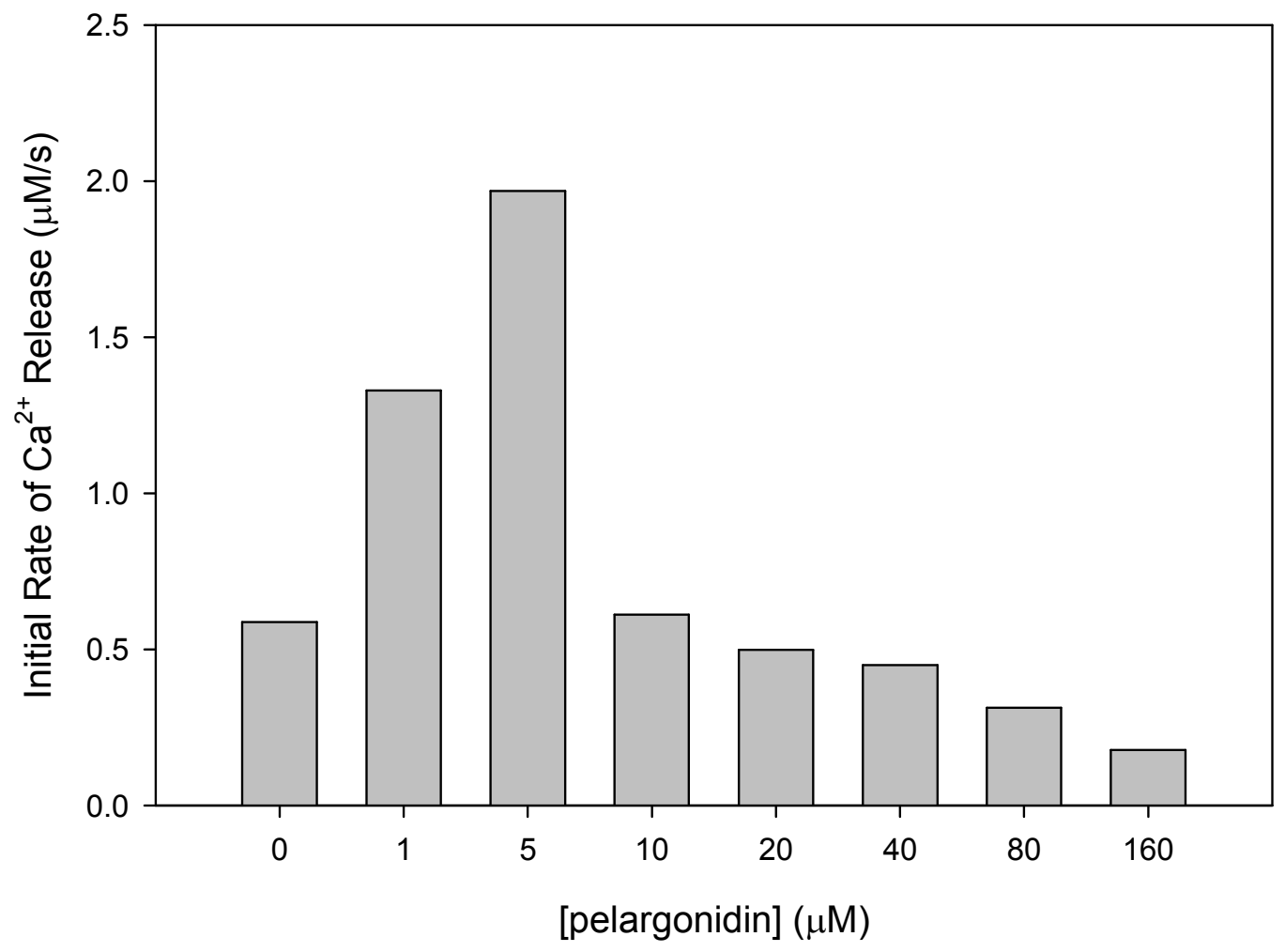

Figure 5.3 $\mathrm{Pg}$ modulates the initial rate of $\mathrm{Ca}^{2+}$ efflux from skeletal $\mathrm{SR}$ in a biphasic manner.

Initial rate of $\mathrm{Ca}^{2+}$ release is stimulated by $1 \mu \mathrm{M}$ and $5 \mu \mathrm{M} \mathrm{Pg}$ and inhibited by $\mathrm{Pg}$ concentrations greater than $10 \mu \mathrm{M}$ with respect to the control $(0.5 \% \mathrm{EtOH})$. Experiments performed in $200 \mu \mathrm{M}$ APIII, $100 \mathrm{mM} \mathrm{KCI}, 20 \mathrm{mM}$ HEPES, $\mathrm{pH} \mathrm{7.4}$. $\mathrm{Ca}^{2+}$ release is stimulated by dilution of SR into APIII buffer ( 40:1). Stock SR vesicles $(\sim 20 \mathrm{mg} / \mathrm{ml}$ protein) incubated with $1 \mathrm{mM} \mathrm{CaCl}{ }_{2}$ overnight ( 12-16 hours) on ice. Pg was added to APIII buffer immediately prior to addition of SR. Final protein concentration $=0.3-0.5 \mathrm{mg} / \mathrm{ml}$. Results shown are for one trial. 


\subsubsection{Delphinidin stimulates $\mathrm{Ca}^{2+}$ release from the RyR of the $\mathrm{SR}$}

Delphinidin stimulates the initial rate of $\mathrm{Ca}^{2+}$ efflux from the RyR for all concentrations tested (Figure 5.3). $\mathrm{EC}_{50}=9.3 \mu \mathrm{M}+/-1.3 \mu \mathrm{M}$ (initial rate data (Table 5.4) fit to a four parameter logistic function (Figure 5.5)). The data is the result of only one trial at each concentration and therefore should be repeated to obtain statistical confidence. The data value at $80 \mu \mathrm{M}$ is approximately $30 \%$ less, and not in agreement with, the surrounding data point at $40 \mu \mathrm{M}$ and $160 \mu \mathrm{M}$. The reason for this is unknown but I suspect that this is an artifact of an experimental error and warrants additional experimental confirmation. 


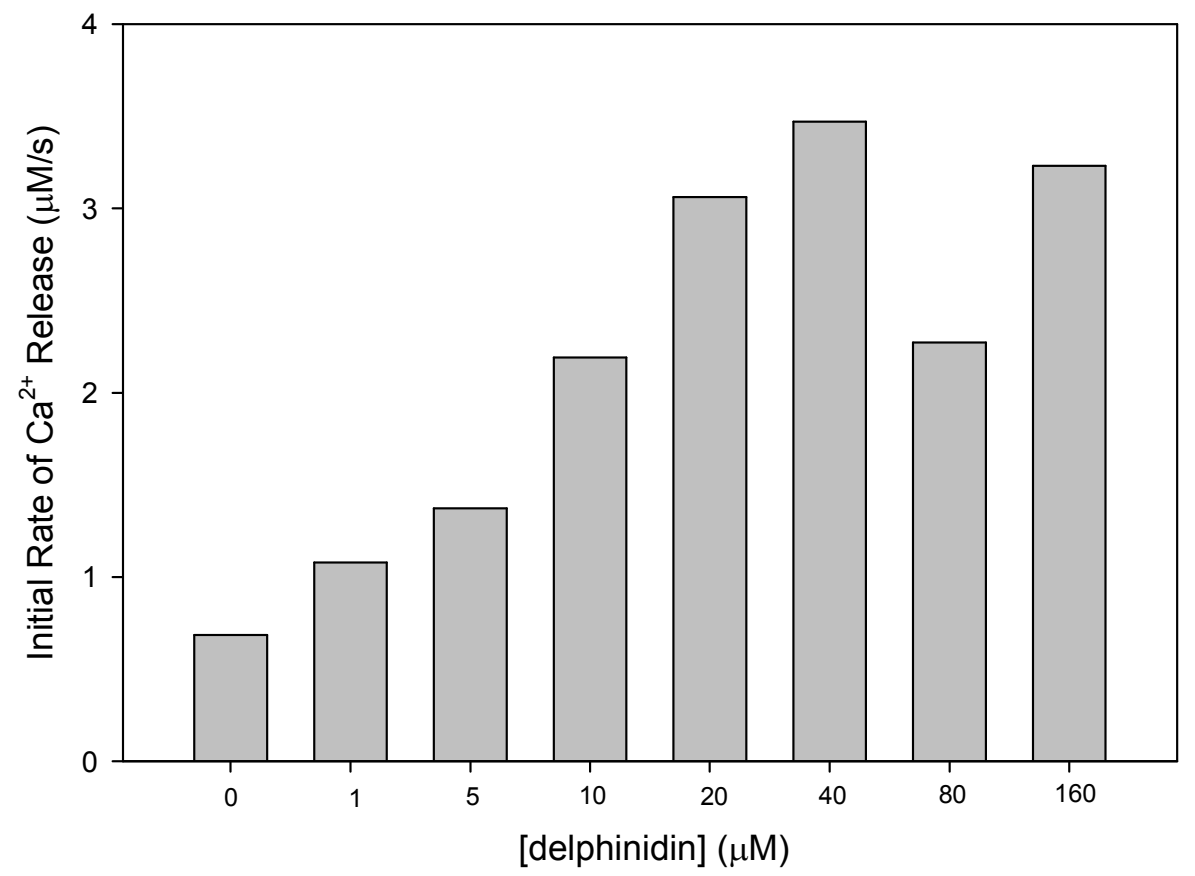

Figure 5.4 Dp stimulates initial rate of $\mathrm{Ca}^{2+}$ release from skeletal SR.

Initial rate of $\mathrm{Ca}^{2+}$ release is stimulated by $\mathrm{Dp}$ in a concentration dependent manner with respect to the control $(\sim 0.5 \% \mathrm{EtOH})$. Experiments performed in $200 \mu \mathrm{M} \mathrm{APIII,} 100 \mathrm{mM} \mathrm{KCl}$, $20 \mathrm{mM}$ HEPES, pH 7.4. $\mathrm{Ca}^{2+}$ release is stimulated by dilution of SR into APIII buffer $(\sim 40: 1)$. Stock SR vesicles $\left(\sim 20 \mathrm{mg} / \mathrm{ml}\right.$ protein) incubated with $1 \mathrm{mM} \mathrm{CaCl}{ }_{2}$ overnight $(\sim 12-16$ hours) on ice. Dp was added to APIII buffer immediately prior to addition of SR. Final protein concentration $=0.3-0.5 \mathrm{mg} / \mathrm{ml}$. Results shown are for one trial. 


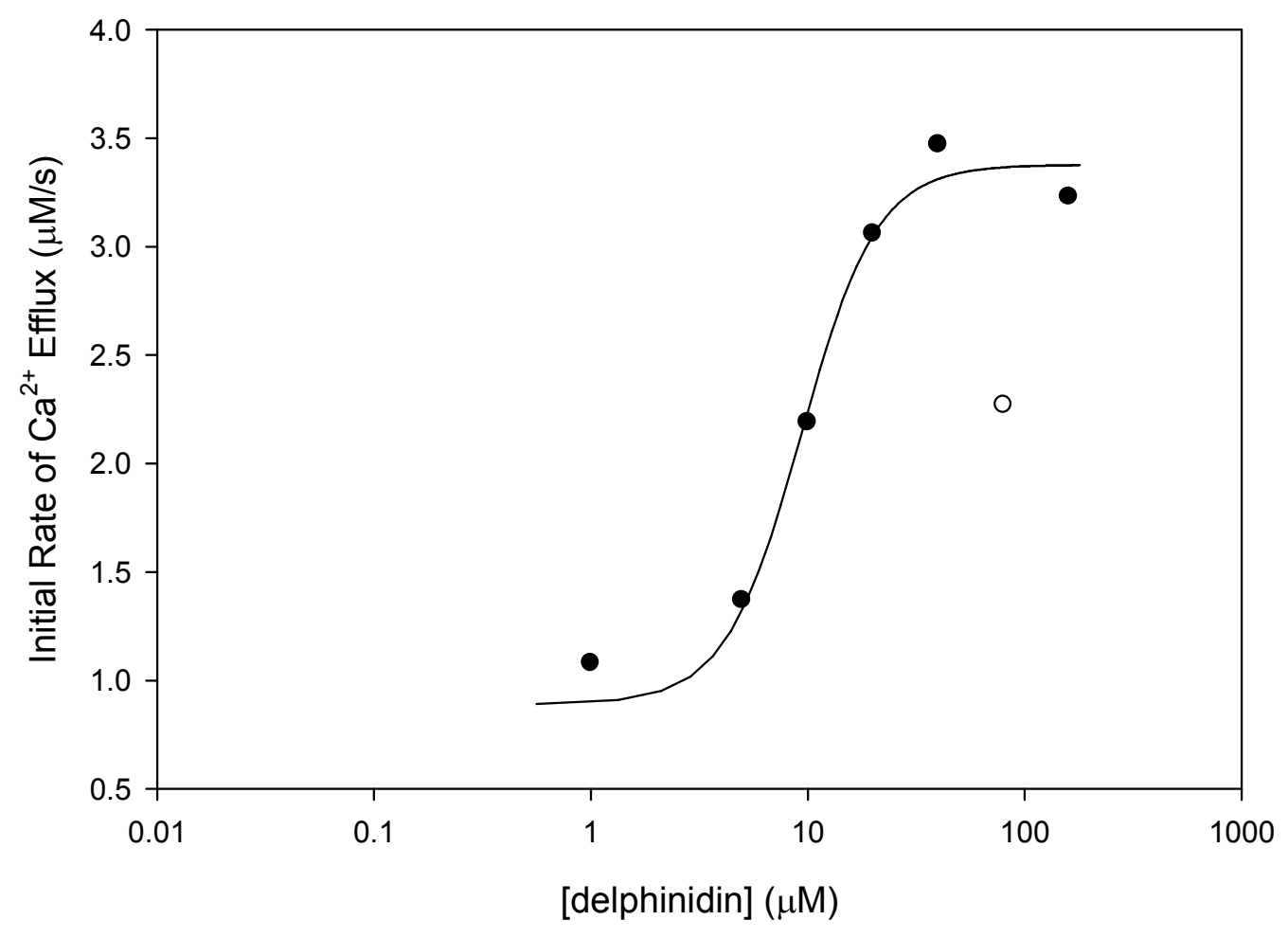

Figure 5.5 Dp - Dose Response Curve.

Dose-response data from figure 5.4 fit to a four parameter log function and the half maximal effective concentration $\left(E_{50}\right)$ was obtained (Sigma Plot). $E C_{50}=9.3 \mu \mathrm{M}+/-1.3 \mu \mathrm{M}$. Data point at $80 \mu \mathrm{M}$ (open circle) omitted from curve fit. Experiments performed in $200 \mu \mathrm{M}$ APIII, $100 \mathrm{mM} \mathrm{KCl}, 20 \mathrm{mM}$ HEPES, $\mathrm{pH} 7.4 . \mathrm{Ca}^{2+}$ release is stimulated by dilution of SR into APIII buffer ( 40:1). Stock SR vesicles $(\sim 20 \mathrm{mg} / \mathrm{ml}$ protein) incubated with $1 \mathrm{mM} \mathrm{CaCl}$ overnight ( 12-16 hours) on ice. Dp was added to APIII buffer immediately prior to addition of SR. Final protein concentration $=\mathbf{0} .3-0.5 \mathrm{mg} / \mathrm{ml}$. Results shown are for one trial. 


\subsubsection{Pelargonidin and Delphinidin; Different Forms, Different Effects}

Both pelargonidin and delphinidin undergo structural changes when exposed to

weakly acidic to alkaline solutions (see chapters 1 and 3 ). The $\mathrm{Ca}^{2+}$ efflux assay has the benefit of being able to more tightly control the time in which $\mathrm{Pg}$ and $\mathrm{Dp}$ are exposed to the environmental conditions of the assay. In this experiment, stock $\mathrm{Pg}$ and $\mathrm{Dp}$ were diluted 1:1 in 20mM HEPES at pH7.4 and allowed to set for times periods of $1 \mathrm{hr}, 2 \mathrm{hrs}$, and $4 \mathrm{hrs}$ (all $+/-15$ minutes). The samples were then used to determine their effect on $\mathrm{Ca}^{2+}$ efflux. Significant structural changes in $\mathrm{Pg}$ and $\mathrm{Dp}$ take place in this time period at $\mathrm{pH} 7.4$. Results show (Figure 5.6) that Dp loses its ability to stimulate the RyR by a factor of almost 2 after a $1 \mathrm{hr}$ exposure to $\mathrm{pH7.4}$. An additional decrease in effectiveness is also seen after $2 \mathrm{hrs}$ and $4 \mathrm{hrs}$ of dilution time with the final effect being only a slight stimulation of channel activity as compared to the control. Pg loses its inhibitory effect completely after 1 hour of exposure to $\mathrm{pH} 7.4$ and its effects on the RyR seem to change from inhibitory effect to a slight stimulating effect after $1 \mathrm{hr}$ of dilution.. 


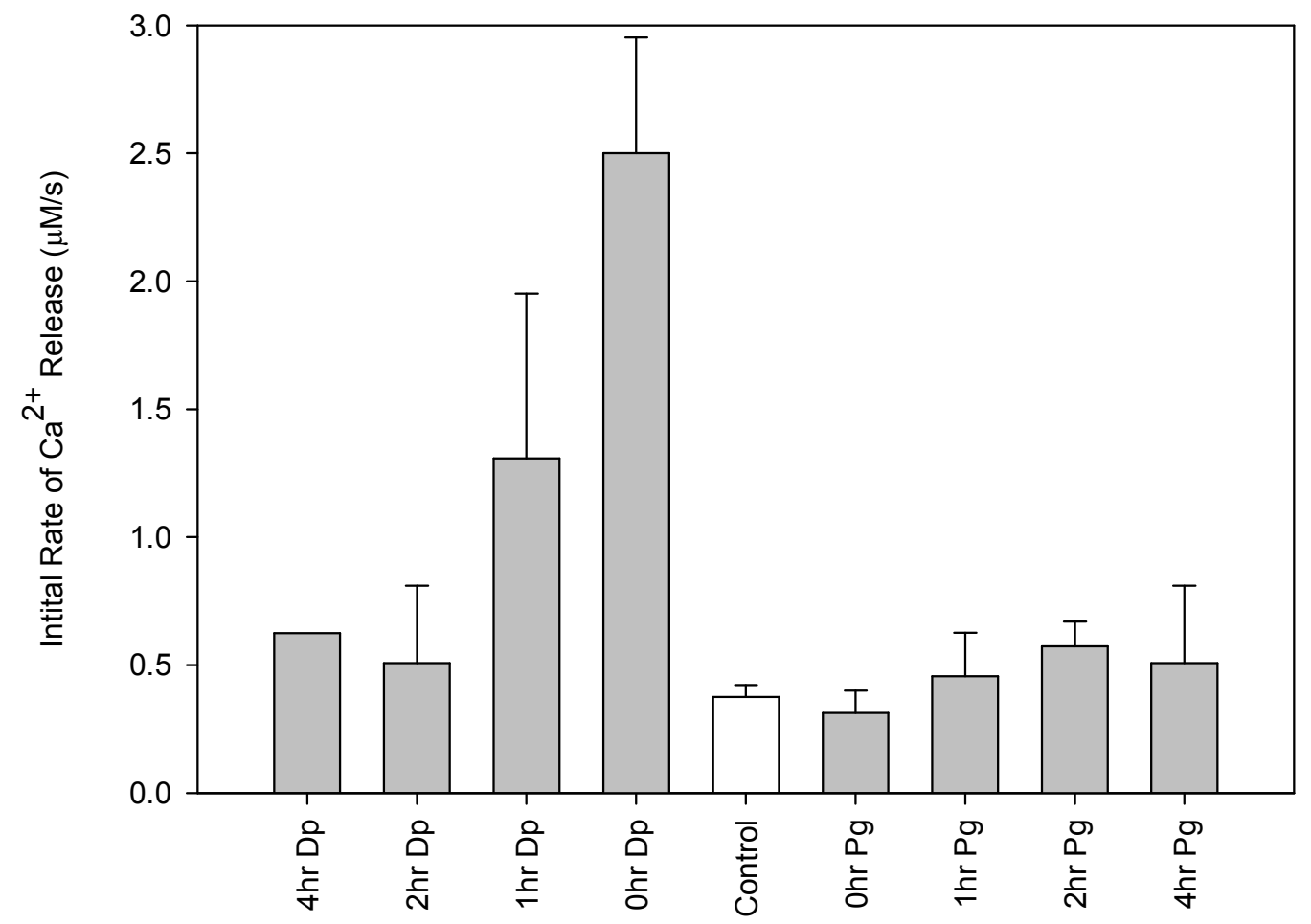

Figure 5.6 Time of exposure to $\mathrm{pH} 7.4$ alters the modulation effects that $\mathrm{Dp}$ and $\mathrm{Pg}$ have on the initial rate of $\mathrm{Ca}^{2+}$ release on skeletal SR.

The inhibition effects of $\mathrm{Pg}(25 \mu \mathrm{M})$ are lost after it is exposed to $\mathrm{pH} 7.4$ for 1 hour and slight stimulatory effects are exhibited at longer exposures (2 and 4 hours). Dp $(25 \mu \mathrm{M})$ loses approximately half of its stimulatory effect after 1 hour and continues to lose its stimulatory action at longer exposures (2 and $4 \mathrm{hrs}$ ). Experiments performed in $200 \mu \mathrm{M}$ APIII, $100 \mathrm{mM} \mathrm{KCI}, 20 \mathrm{mM}$ HEPES, $\mathrm{pH} 7.4$. $\mathrm{Ca}^{2+}$ release is stimulated by dilution of SR into APIII buffer ( $\sim 40: 1)$. Stock SR vesicles $(\sim 20 \mathrm{mg} / \mathrm{ml}$ protein) incubated with $1 \mathrm{mM} \mathrm{CaCl} 2$ overnight ( 12-16 hours) on ice. Dp was added to APIII buffer immediately prior to addition

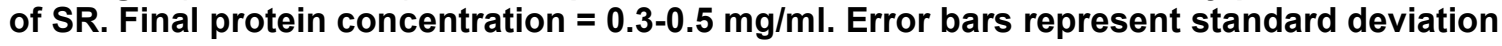
for $n=3$ trial for the control, $n=1$ for $4 \mathrm{hr}$ Dp trial, and $n=2$ for all other trials. 


\subsection{Ryanodine Equilibrium Binding}

\subsubsection{Pelargonidin and Delphinidin Modulate $\left[{ }^{3} \mathrm{H}\right]-$ Ryanodine Binding}

The equilibrium binding assay is carried out over for 3 hours to ensure chemical equilibrium of the binding of ryanodine to the RyR. Qualitatively, Figure 5.9 shows that both $\mathrm{Dp}$ and $\mathrm{Pg}$ stimulate equilibrium binding with respect to the control but with Dp stimulating the channel more effectively than Pg. Quantitative analysis and determination of the $\mathrm{EC}_{50}$ would require an assay that includes a broader range of concentrations (greater than $25 \mu \mathrm{M}$ ) and thus was not performed. Interestingly, in this assay, $\mathrm{Pg}$ exhibits a stimulatory effect. The reason for this is unknown but it can be hypothesized that the change is related to the structural and function changes that $\mathrm{Pg}$ undergoes during the 3 hour incubation at neutral $\mathrm{pH}$ conditions required for this assay. This stimulatory effect by $\mathrm{Dp}$ is consistent with the stimulatory effect seen in the $\mathrm{Ca}^{2+}$ efflux studies. 


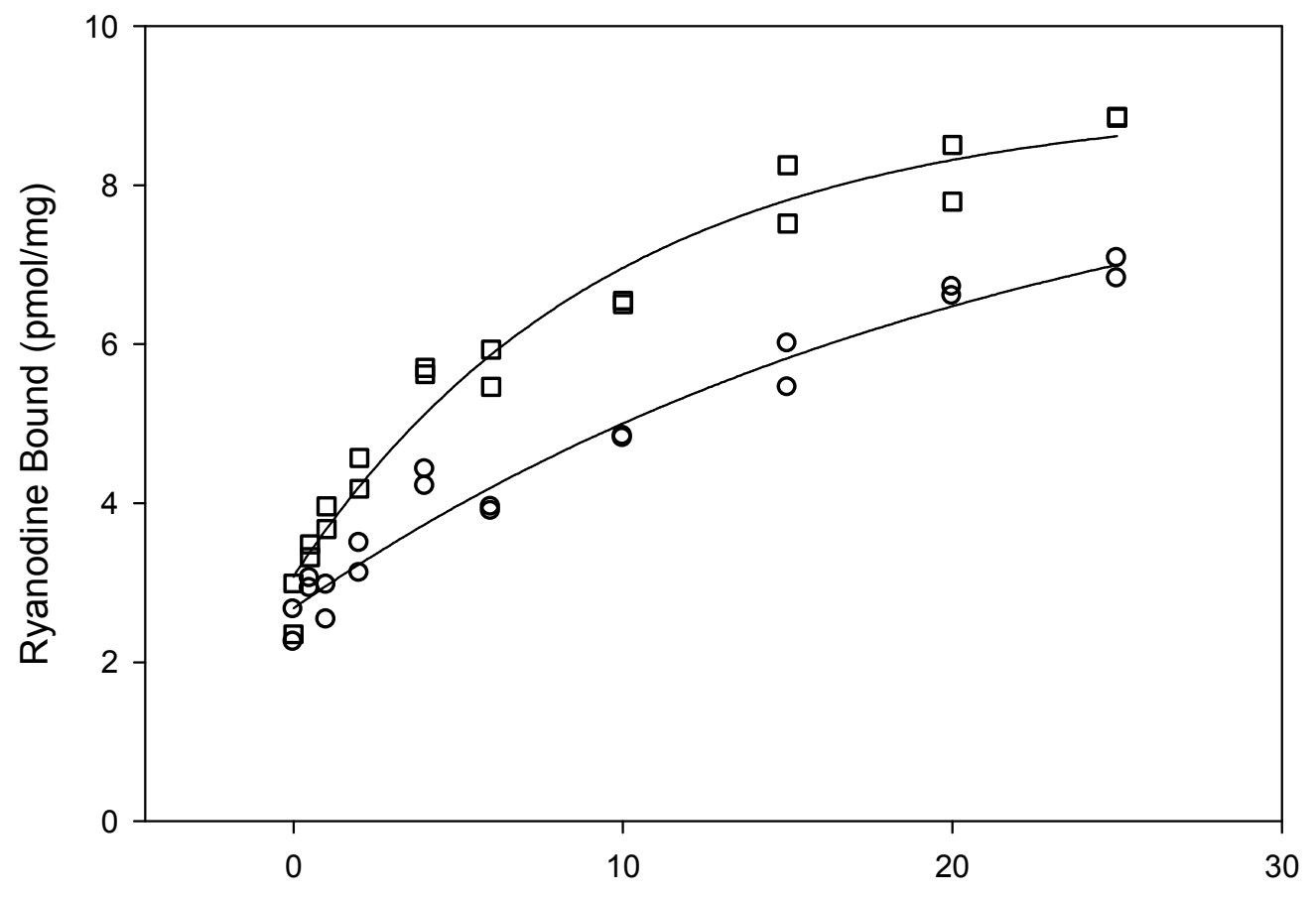

[Dp and $\mathrm{Pg}](\mu \mathrm{M})$

Figure 5.7 Pg and $\mathrm{Dp}$ stimulate ryanodine equilibrium binding.

Both $\mathrm{Dp}(\square)$ and $\mathrm{Pg}(\mathrm{O})$ stimulate ryanodine equilibrium binding in a concentration

dependent manner with respect to the control. Samples contain $4 \mathrm{nM}$ Ryanodine, $0.5 \mathrm{mg} / \mathrm{ml}$ SR vesicles, $50 \mu \mathrm{M} \mathrm{Ca}^{2+}$ in $\mathrm{pH} 7.1$ binding buffer. SR vesicles and ryanodine solutions kept on ice prior to dispensing into incubation tubes. Addition sequence: $S R(1 \mathrm{mg} / \mathrm{ml})$ in Ry buffer, ${ }^{3}[\mathrm{H}] \mathrm{Ry}$ in Ry buffer, and $\mathrm{Pg}$ or $\mathrm{Dp}$. After addition of $\mathrm{Pg} / \mathrm{Dp}$ samples are put in $37^{\circ} \mathrm{C}$ bath, removed after $3 \mathrm{hrs}$, and the reaction is quenched by rapid filtration. 


\subsection{Short Duration Ryanodine Binding}

Short duration Ry binding measures Ry binding over a time period of generally less than 20 minutes but other time periods can also be used. Figure 5.8 shows the results of this assay. Delphinidin clearly causes an increase in the initial rate of ryanodine binding with increasing concentration. Attempts made to fit the data to dose response curves did not converge. The lack of strong inhibition in this experiment by Pg can be partially attributed to the low level of binding by the control. In addition, changes in Pg's structure and the resulting change in its effect on the RyR may also be of importance. In an attempt to enhance the background level of binding and better reveal the effects of Pg on ryanodine binding during initial exposure to $\mathrm{pH} 7.1$ buffers, assays were conducted with both $5 \mathrm{mM}$ and $10 \mathrm{mM}$ caffeine, a known RyR stimulator, added to the experiment. Figure 5.9 shows that caffeine stimulated binding is strongly inhibited by Pg. 


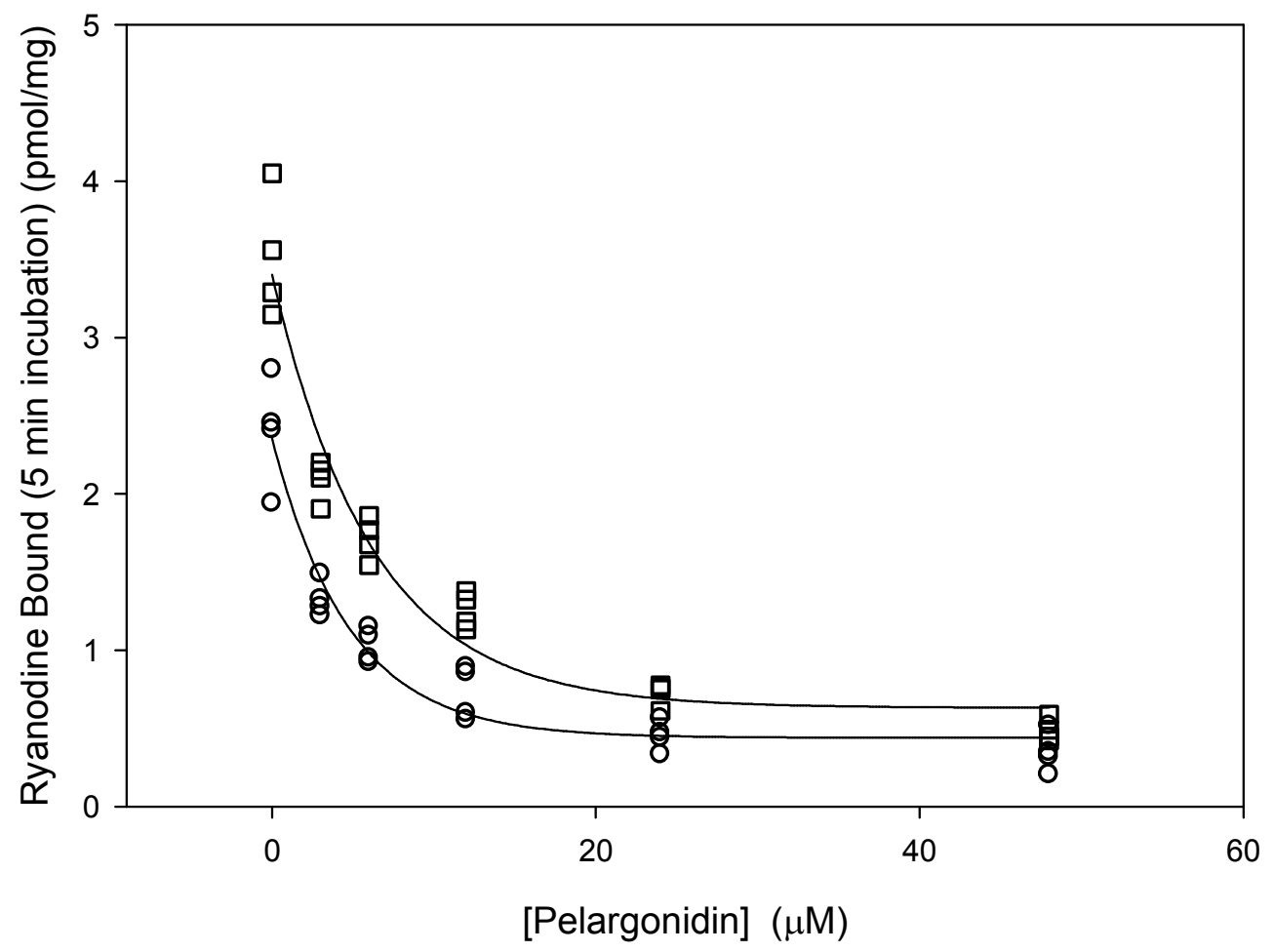

Figure 5.8 Pelargonidin inhibits caffeine stimulated ryanodine binding

Pelargonidin inhibits $5 \mathrm{mM}(O)$ and $10 \mathrm{mM}(\square)$ caffeine stimulated ryanodine binding in a concentration dependent manner with respect to the control. Samples contain $4 \mathrm{nM}{ }^{3}[\mathrm{H}]-$ Ryanodine, $0.5 \mathrm{mg} / \mathrm{ml} \mathrm{SR}$ vesicles, $50 \mu \mathrm{M} \mathrm{Ca}^{2+}$ in $\mathrm{pH} 7.1$ binding buffer. SR vesicles and ryanodine solutions kept on ice prior to dispensing into incubation tubes. Addition sequence: SR (1 mg/ml) in Ry buffer, ${ }^{3}[\mathrm{H}]-R y$ in Ry buffer, and Pg. After addition of Pg, samples are put in $37^{\circ} \mathrm{C}$ bath for $5 \mathrm{~min}$ and then removed and the reaction quenched by rapid filtration. 


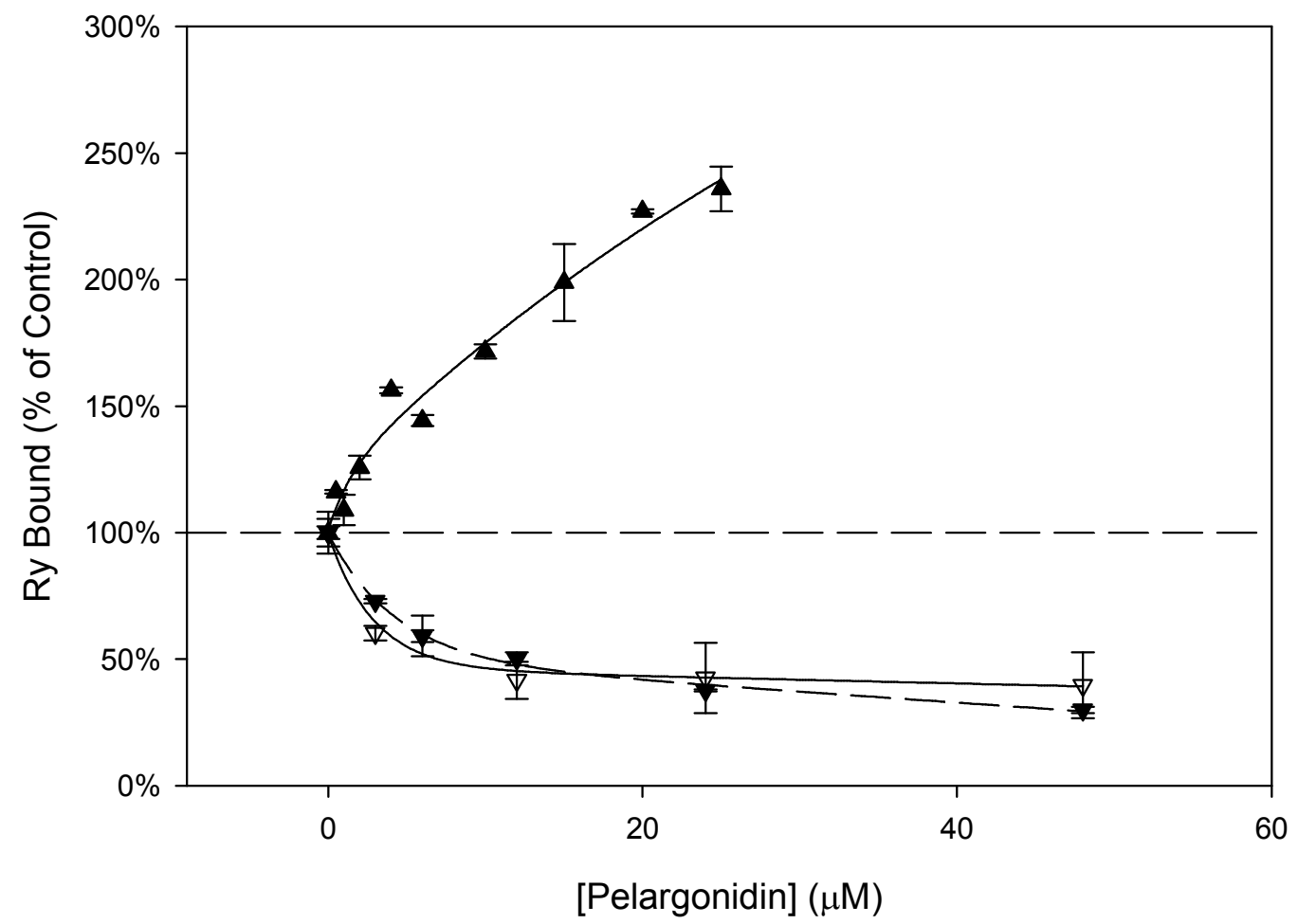

Figure 5.9 Comparison of ${ }^{3}[\mathrm{H}]$-ryanodine binding effects of $\mathrm{Pg}$ at short and long exposures to a $\mathrm{pH} 7.1$ aqueous buffer.

When Pg's exposure to a pH 7.1 buffer is limited to $5(\nabla)$ or $6(\nabla)$ minutes, $\mathrm{Pg}$ inhibits ${ }^{3}[\mathrm{H}]-$ Ryanodine binding to the skeletal RyR. When the structural changes are allowed to proceed for 3 hours $(\Delta)$, Pg stimulates ${ }^{3}[\mathrm{H}]$-ryanodine binding to the skeletal RyR. Samples contain $4 \mathrm{nM}^{3}[\mathrm{H}]$-ryanodine, $0.5 \mathrm{mg} / \mathrm{ml} \mathrm{SR}$ vesicles, $50 \mu \mathrm{M} \mathrm{Ca}{ }^{2+}$ in $\mathrm{pH} 7.1$ binding buffer. SR vesicles and ryanodine solutions kept on ice prior to dispensing into incubation tubes. Addition sequence: SR $(1 \mathrm{mg} / \mathrm{ml})$ in Ry buffer, ${ }^{3}[\mathrm{H}]-\mathrm{Ry}$ in Ry buffer, and Pg. After addition of $\mathrm{Pg}$, samples are put in $37^{\circ} \mathrm{C}$ bath for $5 \mathrm{~min}$ and then removed and the reaction quenched by rapid filtration. 


\subsection{Spectrophotometric Characteristics of Pelargonidin and Delphinidin}

\subsubsection{Absorbance Spectrum of $\mathrm{Pg}$ and $\mathrm{Dp}$}

The absorbance spectrum exhibited by $\mathrm{Pg}$ and $\mathrm{Dp}$ is very dependent upon the $\mathrm{pH}$ of the solution as well as the time that $\mathrm{Pg}$ and $\mathrm{Dp}$ have been exposed to that $\mathrm{pH}$. Figures 5.11 and 5.12 show the spectrums of $\mathrm{Pg}$ and $\mathrm{Dp}$ respectively at various pH's. The spectrum was taken as quickly as possible $(\sim 3 \mathrm{sec})$ after the dilution of $40 \mu \mathrm{M}$ (final concentration) $\mathrm{Pg}$ or $\mathrm{Dp}$ from its $\mathrm{EtOH}$ stock solution into $1 \mathrm{mM}$ Tris buffer at various $\mathrm{pH}$ 's. Results show the characteristic bathochromatic shifts of their spectrums that are expected at increasing pH (Cabrita, Fossen, and Øyvind M. Andersen 2000). 


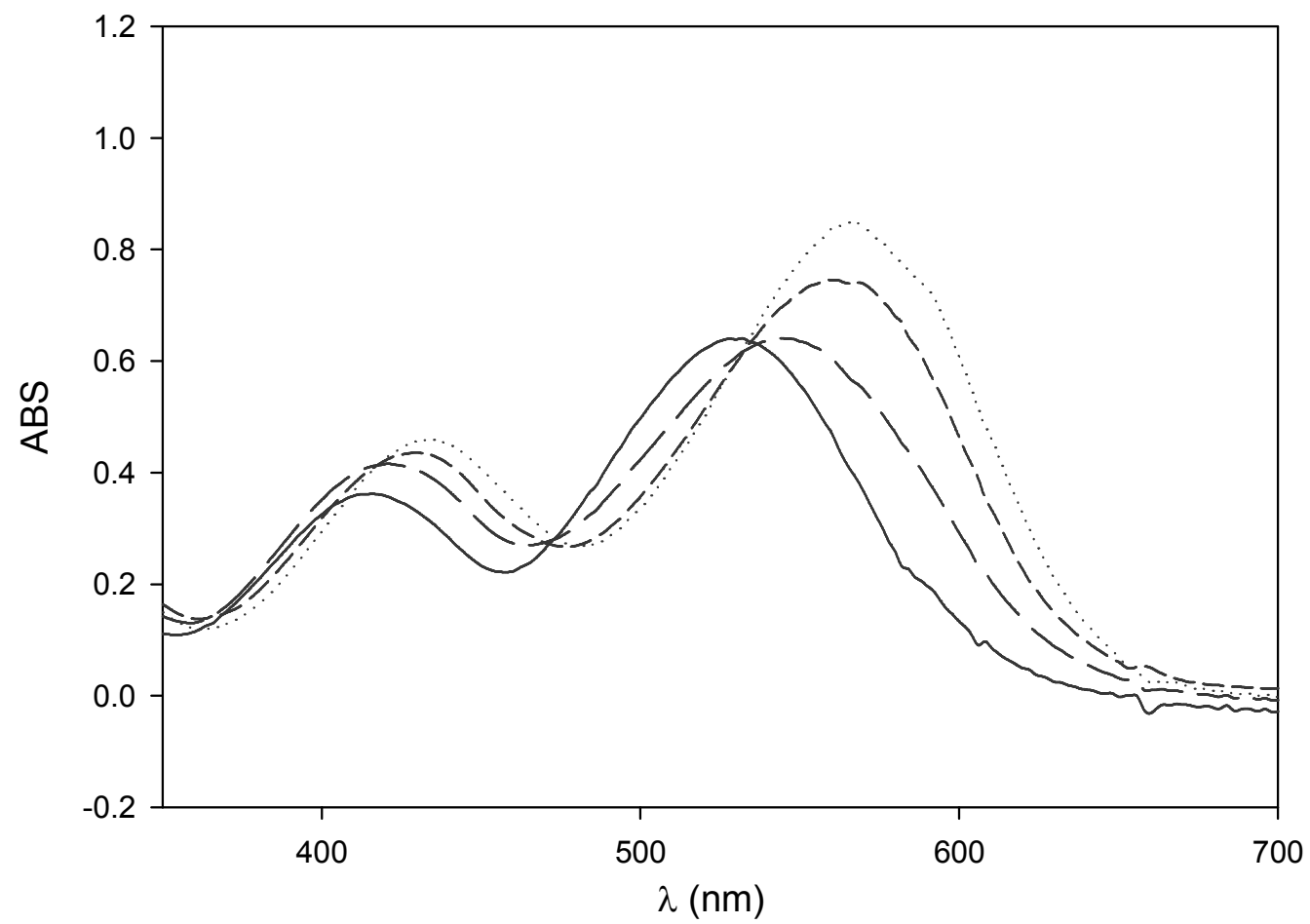

Figure $5.10 \mathrm{pH}$ dependent absorbance spectrum of pelargonidin

40uM Pg pipetted from $10 \mathrm{mM}$ stock in EtOH to $1 \mathrm{mM}$ TRIS (pH'd with $\mathrm{HCl}$ and/or $\mathrm{KOH}$ ) and spectrum collected within 5 seconds. Solid line: $\mathrm{pH}=6.5$, long dashes: $\mathrm{pH}=7.0$, short dashes: $\mathrm{pH}=7.5$, dotted trace: $\mathrm{pH}=8.0$ 


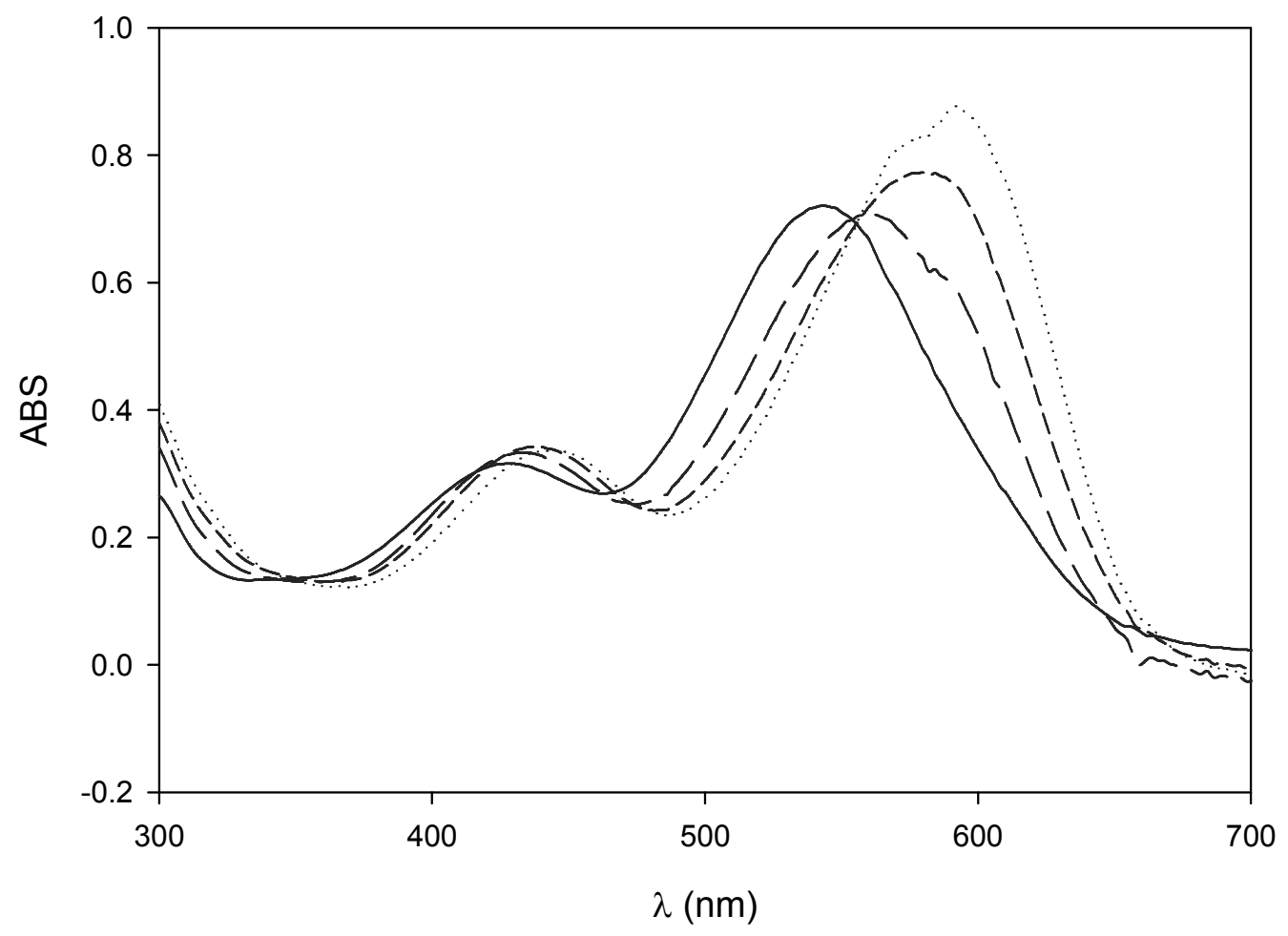

Figure $5.11 \mathrm{pH}$ dependent absorbance spectrum of delphinidin

40uM Dp pipetted from $10 \mathrm{mM}$ stock in EtOH to $1 \mathrm{mM}$ TRIS (pH'd with $\mathrm{HCl}$ and/or $\mathrm{KOH}$ ) and spectrum collected within 5 seconds. Solid line: $\mathrm{pH}=6.5$, long dashes: $\mathrm{pH}=7.0$, short dashes: $\mathrm{pH}=7.5$, dotted trace: $\mathrm{pH}=8.0$ 


\subsection{2 pH Dependent Transformation Kinetics of $\mathrm{Pg}$ and $\mathrm{Dp}$}

Upon dilution into a neutral $\mathrm{pH}$ solution, $\mathrm{Pg}$ and $\mathrm{Dp}$ rapidly deprotonate into their respective quinoidal base forms. This transformation occurs in a time frame faster than that required to add, mix, and collect the initial spectrum and thus cannot be followed using the technique described here. The subsequent slower transformation from the quinoidal base form to the carbinol pseudobase form is shown in Figure 5.13. The time required to add, mix, and collect the initial spectrum is on the order of a few seconds and therefore this measurement will only provide an estimate of the actual kinetics. However, this data is in agreement with the literature in that the transformation kinetics of these compounds increase with increasing acidity. In addition, the relative concentration of the quinoidal form with respect to the (colorless) carbinol form is dependent on $\mathrm{pH}$. Unfortunately, the equilibrium constants for these compounds are not known and concentrations of the different forms cannot be determined. The kinetics of $\mathrm{Pg}$ and $\mathrm{Dp}$ are similar and when fitted to a first order decay equation, the $t_{1 / 2}$ is on the order of 100 seconds at $\mathrm{pH} 7.0$. The kinetics significantly slow down at $\mathrm{pH} 7.5$ and it is therefore not possible to estimate the $\mathrm{t}_{1 / 2}$ at this $\mathrm{pH}$. 


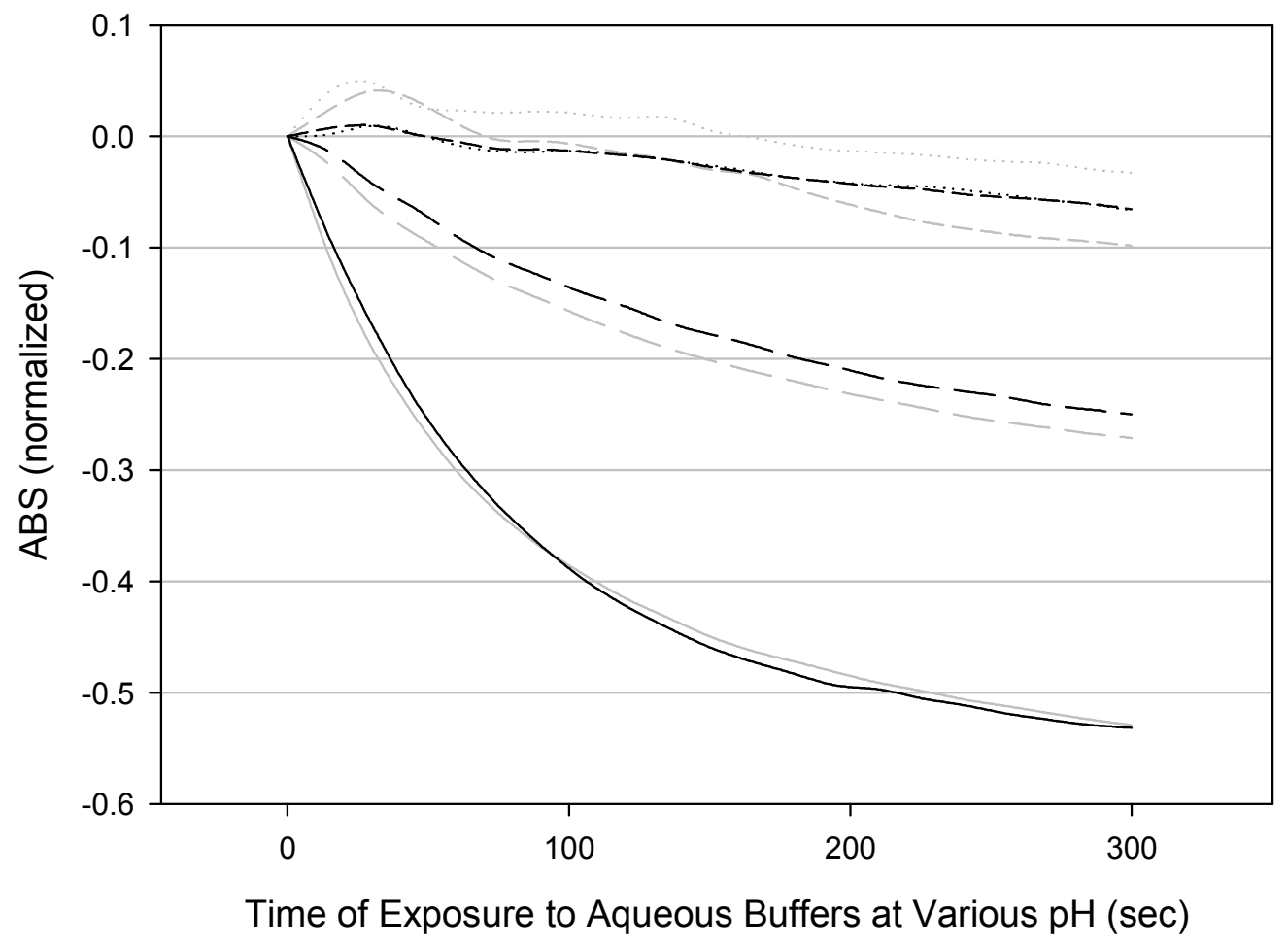

Figure $5.12 \mathrm{pH}$ dependent transformation kinetics of $\mathrm{Pg}$ and $\mathrm{Dp}$

Kinetics of the decrease in absorbance of the quinoidal form of $\mathrm{Pg}$ and $\mathrm{Dp}$ over $\mathbf{3 0 0}$ seconds. Traces for $\mathrm{pH} 6.5\left(\mathrm{t}_{1 / 2} \sim 50 \mathrm{sec}\right), 7.0\left(\mathrm{t}_{1 / 2} \sim 50 \mathrm{sec}\right), 7.5\left(\mathrm{t}_{1 / 2} \sim\right.$ not enough data) and 8.0 $\left(t_{1 / 2} \sim\right.$ not enough data) are shown. Black traces are $\mathrm{Dp}$ and Lt.Grey traces are Pg. Solid line: $\mathrm{pH}=6.5$, long dashes: $\mathrm{pH}=7.0$, short dashes: $\mathrm{pH}=7.5$, dotted trace: $\mathrm{pH}=8.0$. 


\section{Discussion}

The complex nature of pelargonidin and delphinidin with respect to their $\mathrm{pH}$ dependent molecular structures and properties makes it difficult to quantitatively assess the two compounds with regards to RyR modulation. However, calcium efflux experiments do allow for assessment of the effects of pelargonidin and delphinidin within seconds of exposure when concentrations of specific forms are known to dominate. Upon exposure to physiological pH solutions, pelargonidin and delphinidin rapidly ( $\sim 1$ second) deprotonate to their corresponding quinoidal base and quinoidal base anion forms whereas the subsequent transformation to the carbinol pseudobase is on the order of minutes at $\mathrm{pH} 7$ and significantly longer in more alkaline solutions. The $\mathrm{Ca}^{2+}$ efflux assays utilized in this thesis can probe the modulatory effect that a compound has on the channel in time periods as short as several seconds and therefore can effectively assay pelargonidin and delphinidin in their quinoidal forms. Additionally, the transformation of pelargonidin and delphinidin to the chalcone form is likely on the order of twelve to twenty four hours (based on similar compounds found in literature) and therefore there is a time period after the transformation into the carbinol pseudobase that the $\mathrm{Ca}^{2+}$ efflux assay can probe the effects of that form as well.

Delphinidin is predicted to be in a quinoidal base anion form almost immediately after exposure to a pH 7.4 solution. Hydroxyl groups at positions 4' and 5 are the predicted deprotonation sites. Calcium efflux results show that delphinidin is a 
good RyR1 stimulator with an $\mathrm{EC}_{50}$ of $9.3 \mu \mathrm{M}$. However this result is obtained within the first fraction of a minute after $\mathrm{Dp}$ is exposed to the $\mathrm{pH} 7.4$ of the $\mathrm{Ca}^{2+}$ efflux buffer. When Dp is allowed to transform into the carbinol pseudobase form, a majority of its stimulatory effects are essentially lost. This implies that the quinoidal base form is primarily responsible for Dp's stimulatory effects on the RyR. This also implies that the carbinol pseudobase form doesn't have a strong modulatory effect. Although there is still a small stimulatory effect seen even after the carbinol is formed, this may be due to the fact that there is still an equilibrium concentration (not known) of quinoidal base in solution or that stimulatory autoxidation products of $\mathrm{Dp}$ are present in the solution (both superoxide and hydrogen peroxide have been shown to stimulate the RyR1 (T. G Favero, A. C Zable, and J. J Abramson 1995; Kawakami and Okabe 1998)). [ $\left.{ }^{3} \mathrm{H}\right]$-ryanodine binding experiments at both short $\left[{ }^{3} \mathrm{H}\right]$-ryanodine incubation times $(\sim 6$ minutes (data not shown)) and long incubation times ( 3 hours) also show stimulatory effects. Again, the stimulatory effects for longer time periods are suspect in part due to the autoxidation capabilities of $\mathrm{Dp}$.

With pelargonidin, the modulating mechanism is more complex. Pelargonidin is also predicted to be in a quinoidal base anion form immediately after exposure to a pH 7.4 solution. Hydroxyl groups at positions 5 and 4' are the predicted deprotonation sites but the 5 and 3 are close in energy and probably co-exists in significant concentrations. Calcium efflux results imply that the quinoidal form of pelargonidin is a RyR1 inhibitor. In contrast, the carbinol pseudobase does not 
seem to be effective at inhibiting the RyR. There is even a slight hint of some channel stimulatory effects. $\left[{ }^{3} \mathrm{H}\right]$-ryanodine binding experiments performed with short $\left[{ }^{3} \mathrm{H}\right]$-ryanodine incubation times ( 5 minutes) also show activation of receptor binding. As is the case with delphinidin, the structural form 3 hours after exposure to neutral $\mathrm{pH}$ conditions is also the carbinol pseudobase although, for pelargonidin, the predicted (lowest) $\mathrm{pK}_{\mathrm{a}}$ of that form is $8.32(3-\mathrm{OH})$ and therefore it probably exists with a neutral charge. Longer $\left[{ }^{3} \mathrm{H}\right]$-ryanodine incubation times ( $~ 3$ hours) exhibited significant channel stimulatory effects on the RyR. Unlike $\mathrm{Dp}, \mathrm{Pg}$ is not known to autoxidize and therefore the generation of oxidation products doesn't seem to be a probable explanation for the stimulatory action.

For the quinoidal base forms, both compounds are predicted to be planar and both compounds are charged with the deprotonation sites on the 5 and 4' oxygens. However, the relative order of the acidities of the hydrogens of those groups are reversed. Dp loses its first hydrogen at O4' (experimental $\mathrm{pK}_{\mathrm{a} 1} \sim 5.30$ ) and its second hydrogen at $\mathrm{O} 5$ (predicted $\mathrm{pK}_{\mathrm{a} 2} \sim 6.30$ ) whereas pelargonidin loses its first hydrogen at $\mathrm{O} 5$ (experimental $\mathrm{pK}_{\mathrm{a} 1} \sim 5.79$ ) and its second hydrogen at $\mathrm{O} 4$ ' (predicted $\mathrm{pK}_{\mathrm{a} 2} \sim 7.05$ ). The second predicted deprotonation of pelargonidin is also close to the $\mathrm{pH}$ of the assays performed in this thesis $(\mathrm{pH} 7.1$ for ryanodine binding and $\mathrm{pH} 7.4$ for $\mathrm{Ca}^{2+}$ efflux) which means that pelargonidin will exist as more of a mixture of both the neutral quinoidal base and the anionic quinoidal base forms. This may impart more of a hydrogen donor characteristic to 
pelargonidin relative to delphinidin. The relative order of the deprotonation sites may also impart differing molecular polarization characteristics to Pg. How this may affect the RyR is unknown due to the lack of knowledge regarding the $\mathrm{Pg}$ (and Dp) binding site(s). Structural information regarding the carbinol pseudobase forms of these compounds was not found in literature however the predicted $\mathrm{pK}_{\mathrm{a} 2}$ of the carbinol pseudobase forms of pelargonidin and delphinidin are 8.35 (at the $3-\mathrm{OH}$ ) and 7.25 (at the $4{ }^{\prime} \mathrm{OH}$ ) respectively. Thus, when the carbinol pseudobase structures are formed (in neutral pH conditions), pelargonidin carries mostly a neutral charge whereas $D p$ is in a mixture of neutral and anionic forms (Borkowski et al. 2005).

In conclusion, the distinct and powerful effects that the anthocyanidin compounds studied in this thesis potentially have on skeletal ryanodine receptor mediated $\mathrm{Ca}^{2+}$ homeostasis is further proof of the necessity to fully understand the complete effects of nutraceuticals before dietary intake recommendations can be made. 


\section{References}

Abramson, J. J, J. R Cronin, and G. Salama. 1988. Oxidation induced by phthalocyanine dyes causes rapid calcium release from sarcoplasmic reticulum vesicles* ${ }^{1}$. Archives of biochemistry and biophysics 263 , no. 2 : 245-255.

Abramson, J. J., E. Buck, G. Salama, J. E. Casida, and I. N. Pessah. 1988. Mechanism of anthraquinone-induced calcium release from skeletal muscle sarcoplasmic reticulum. Journal of Biological Chemistry 263, no. 35: 18750.

Abramson, J.J., and G. Salama. 1988. Sulfhydryl oxidation and Ca2+ release from sarcoplasmic reticulum. Mol.Cell Biochem. 82, no. 1 (July): 81-84.

Abramson, J.J., J.L. Trimm, L. Weden, and G. Salama. 1983. Heavy metals induce rapid calcium release from sarcoplasmic reticulum vesicles isolated from skeletal muscle. Proc.Natl.Acad.Sci.U.S.A 80, no. 6 (March): 15261530.

Abramson, Jonathan J. et al. 1989. Critical sulfhydryls regulate calcium release from sarcoplasmic reticulum. Journal of Bioenergetics and Biomembranes 21, no. 2 (April 1): 283-294. doi:10.1007/BF00812073.

Andersen, Øyvind M., and Kenneth R. Markham. 2006. Flavonoids: chemistry, biochemistry, and applications. CRC Press. 
Beard, N. A, M. M Sakowska, A. F Dulhunty, and D. R Laver. 2002.

Calsequestrin is an inhibitor of skeletal muscle ryanodine receptor calcium release channels. Biophysical journal 82, no. 1: 310-320.

Belevych, A., Z. Kubalova, D. Terentyev, R. L Hamlin, C. A Carnes, and S. Gylörke. 2007. Enhanced ryanodine receptor-mediated calcium leak determines reduced sarcoplasmic reticulum calcium content in chronic canine heart failure. Biophysical journal 93, no. 11: 4083-4092.

Belevych, A., and D. Terentyev. 2010. Redox Modification of Ryanodine Receptors in Cardiac Arrhythmia And Failure: A Potential Therapeutic Target.

Belevych, A. E, D. Terentyev, S. Viatchenko-Karpinski, R. Terentyeva, A. Sridhar, Y. Nishijima, L. D Wilson, et al. 2009. Redox modification of ryanodine receptors underlies calcium alternans in a canine model of sudden cardiac death. Cardiovascular research.

Belevych, A. E, D. Terentyev, S. Viatchenko-Karpinski, R. Terentyeva, A. Sridhar, C. Rio, Y. Nishijima, C. Carnes, G. Billman, and S. Gyorke. 2008. Abstract 1539: Redox-Modification of Ryanodine Receptor Underlies Sarcoplasmic Reticulum Luminal Calcium-Dependent Cardiac Alternans in a Canine Model of Sudden Cardiac Death. Circulation 118, no. 18.

Boots, A. W, N. Kubben, G. R.M.M Haenen, and A. Bast. 2003. Oxidized 
quercetin reacts with thiols rather than with ascorbate: implication for quercetin supplementation. Biochemical and biophysical research communications 308 , no. 3: 560-565.

Borkowski, T., H. Szymusiak, A. Gliszczynska-Swiglo, I. M.C.M Rietjens, and B. Tyrakowska. 2005. Radical Scavenging Capacity of Wine Anthocyanins Is Strongly pH-Dependent. J. Agric. Food Chem. 53, no. 14: 5526-5534.

Brouillard, R., and B. Delaporte. 1977. Chemistry of anthocyanin pigments. 2. Kinetic and thermodynamic study of proton transfer, hydration, and tautomeric reactions of malvidin 3-glucoside. Journal of the American Chemical Society 99, no. 26: 8461-8468.

Brouillard, R., and J. E Dubois. 1977. Mechanism of the structural transformations of anthocyanins in acidic media. Journal of the American Chemical Society 99, no. 5: 1359-1364.

Brouillard, R., G. A. lacobucci, and J. G. Sweeny. 1982. Chemistry of anthocyanin pigments. 9. UV-visible spectrophotometric determination of the acidity constants of apigeninidin and three related 3-deoxyflavylium salts. Journal of the American Chemical Society 104, no. 26: 7585-7590.

Cabrita, Luis, Torgils Fossen, and Oyvind M Andersen. 2000. Colour and stability of the six common anthocyanidin 3-glucosides in aqueous solutions. Food Chemistry 68, no. 1 (January): 101-107. 
Cabrita, Luis, Torgils Fossen, and Øyvind M. Andersen. 2000. Colour and stability of the six common anthocyanidin 3-glucosides in aqueous solutions. Food Chemistry 68, no. 1 (January): 101-107. doi:10.1016/S0308-8146(99)00170-3.

Canada, A. T., E. Giannella, T. D. Nguyen, and R. P. Mason. 1990. The production of reactive oxygen species by dietary flavonols. Free Radical Biology \& Medicine 9, no. 5: 441-449.

Carnes, C. A, others, A. E Belevych, D. Terentyev, S. Viatchenko-Karpinski, R. Terentyeva, A. Sridhar, et al. 2009. Redox modification of ryanodine receptors underlies calcium alternans in a canine model of sudden cardiac death. Cardiovascular research.

Chance, B., V. Legallais, J. Sorge, and N. Graham. 1975. A versatile timesharing multichannel spectrophotometer, reflectometer, and fluorometer. Analytical Biochemistry 66, no. 2: 498-514.

Dangles, O., G. Fargeix, and C. Dufour. 2000. Antioxidant properties of anthocyanins and tannins: a mechanistic investigation with catechin and the 3', 4', 7-trihydroxyflavylium ion. Journal of the Chemical Society, Perkin Transactions 2 2000, no. 8: 1653-1663.

Davies, K.J., A.T. Quintanilha, G.A. Brooks, and L. Packer. 1982. Free radicals and tissue damage produced by exercise Three-dimensional visualization 
of FKBP12.6 binding to an open conformation of cardiac ryanodine receptor. Biochem.Biophys.Res.Commun. 107, no. 4: 1198-1205.

Davies, M. J., and R. T. Dean. 1997. Radical-mediated protein oxidation: from chemistry to medicine. Oxford University Press, August 1.

Dhalla, N S, L Golfman, S Takeda, N Takeda, and M Nagano. 1999. Evidence for the role of oxidative stress in acute ischemic heart disease: a brief review. The Canadian Journal of Cardiology 15, no. 5 (May): 587-593.

Dulhunty, Angela., Haarmann, C., Green, D., and Hart, J. 2000. How many cysteine residues regulate ryanodine receptor channel activity? Antioxid.Redox.Signal. 2, no. 1: 27-34.

Dulhunty, Angela, Lan Wei, and Nicole Beard. 2009. Junctin - the quiet achiever. The Journal of Physiology 587, no. 13: 3135-3137. doi:10.1113/jphysiol.2009.171959.

Estevez, L., and R. A. Mosquera. 2008. Molecular structure and antioxidant properties of delphinidin. The journal of physical chemistry. A 112, no. 42: 10614.

Fan, H., N. R Brandt, and A. H Caswell. 1995. Disulfide bonds, N-glycosylation and transmembrane topology of skeletal muscle triadin. Biochemistry 34 , no. 45: 14902-14908.

Favero, T G, A C Zable, and J J Abramson. 1995. Hydrogen peroxide stimulates 
the $\mathrm{Ca} 2+$ release channel from skeletal muscle sarcoplasmic reticulum. Journal Of Biological Chemistry 270, no. 43 (October 27): 25557-63.

Favero, T. G, A. C Zable, and J. J Abramson. 1995. Hydrogen peroxide stimulates the $\mathrm{Ca} 2+$ release channel from skeletal muscle sarcoplasmic reticulum. Journal of Biological Chemistry 270, no. 43: 25557.

Feng, W., G. Liu, R. Xia, J J Abramson, and I N Pessah. 1999. Site-selective modification of hyperreactive cysteines of ryanodine receptor complex by quinones. Molecular Pharmacology 55, no. 5 (May): 821-31.

Ferguson, D G, H W Schwartz, and C Franzini-Armstrong. 1984. Subunit structure of junctional feet in triads of skeletal muscle: a freeze-drying, rotary-shadowing study. The Journal of Cell Biology 99, no. 5 (November 1): 1735 -1742. doi:10.1083/jcb.99.5.1735.

Franzini-Armstrong, Clara, and John W. Kish. 1995. Alternate disposition of tetrads in peripheral couplings of skeletal muscle. Journal of Muscle Research and Cell Motility 16, no. 3 (6): 319-324. doi:10.1007/BF00121140.

Fridovich, Irwin. 1978. The Biology of Oxygen Radicals. Science 201, no. 4359. New Series (September 8): 875-880.

Galati, G., T. Chan, B. Wu, and P. J O'Brien. 1999. Glutathione-dependent generation of reactive oxygen species by the peroxidase-catalyzed redox 
cycling of flavonoids. Chem. Res. Toxicol 12, no. 6: 521-525.

Goonasekera, S. A, N. A Beard, L. Groom, T. Kimura, A. D Lyfenko, A.

Rosenfeld, I. Marty, A. F Dulhunty, and R. T Dirksen. 2007. Triadin binding to the C-Terminal luminal loop of the ryanodine receptor is important for skeletal muscle excitation-contraction coupling. The Journal of general physiology 130 , no. 4: 365 .

Graziani, Y., R. Chayoth, N. Karny, B. Feldman, and J. Levy. 1982. Regulation of protein kinases activity by quercetin in Ehrlich ascites tumor cells. Biochimica et Biophysica Acta (BBA)-General Subjects 714, no. 3: 415421.

Guerra, L., E. Cerbai, S. Gessi, P. A Borea, and A. Mugelli. 1996. The effect of oxygen free radicals on calcium current and dihydropyridine binding sites in guinea-pig ventricular myocytes. British journal of pharmacology 118 , no. 5: 1278.

Harborne, J. B., T. J. Mabry, and H. Mabry. 1975. The flavonoids. London.

Harborne, J.B. 1967. Comparative Biochemistry of the Flavonoids. Academic Press, London.

He, X., Y. Liu, V. Sharma, R. T Dirksen, R. Waugh, S. S Sheu, and W. Min. 2003. ASK1 associates with troponin T and induces troponin T phosphorylation and contractile dysfunction in cardiomyocytes. American Journal of 
Pathology 163, no. 1: 243.

Herrmann-Frank, A., M. Richter, S. Sarklözi, U. Mohr, and F. Lehmann-Horn. 1996. 4-Chloro-m-cresol, a potent and specific activator of the skeletal muscle ryanodine receptor. Biochimica et Biophysica Acta (BBA)-General Subjects 1289, no. 1: 31-40.

Hidalgo, C., and P. Donoso. 2008. Crosstalk between calcium and redox signaling: from molecular mechanisms to health implications. Antioxidants \& Redox Signaling 10, no. 7: 1275-1312.

Higuchi, Y., K. Otsu, K. Nishida, S. Hirotani, H. Nakayama, O. Yamaguchi, Y. Matsumura, H. Ueno, M. Tada, and M. Hori. 2002. Involvement of Reactive Oxygen Species-mediated NF-[kappa] B Activation in TNF[alpha]-induced Cardiomyocyte Hypertrophy. Journal of molecular and cellular cardiology 34, no. 2: 233-240.

Hodnick, W. F, F. S Kung, W. J Roettger, C. W Bohmont, and R. S Pardini. 1986. Inhibition of mitochondrial respiration and production of toxic oxygen radicals by flavonoids:: A structure-activity study. Biochemical pharmacology 35 , no. 14: 2345-2357.

Hodnick, W. F, E. B MllosavljeviC, J. H Nelson, and R. S Pardini. 1988. Electrochemistry of flavonoids:: Relationships between redox potentials, inhibition of mitochondrial respiration, and production of oxygen radicals 
by flavonoids. Biochemical pharmacology 37, no. 13: 2607-2611.

Huikuri, H. V, A. Castellanos, and R. J Myerburg. 2001. Sudden death due to cardiac arrhythmias. New England Journal of Medicine 345, no. 20: 1473.

lacobucci, G. A, and J. G Sweeny. 1983. The chemistry of anthocyanins, anthocyanidins and related flavylium salts. Tetrahedron 39, no. 19: 30053038.

Jiang, Y., A. Lee, J. Chen, V. Ruta, M. Cadene, B. T Chait, and R. MacKinnon. 2003. X-ray structure of a voltage-dependent K\&plus; channel. Nature 423, no. 6935 : 33-41.

Jiang, Y., V. Ruta, J. Chen, A. Lee, and R. MacKinnon. 2003. The principle of gating charge movement in a voltage-dependent $\mathrm{K}^{+}$; channel. Nature 423, no. 6935 : $42-48$.

Jones, L. R, L. Zhang, K. Sanborn, A. O Jorgensen, and J. Kelley. 1995. Purification, primary structure, and immunological characterization of the 26-kDa calsequestrin binding protein (junctin) from cardiac junctional sarcoplasmic reticulum. Journal of Biological Chemistry 270, no. 51: 30787.

Jurd, L. 1963. Anthocyanins and related compounds. I. Structural transformations of flavylium salts in acidic solutions. The Journal of Organic Chemistry 28, no. 4: 987-991. 
Jurd, L. 1964. Anthocyanins and related compounds. III. Oxidation of substituted flavylium salts to 2-phenylbenzofurans. The Journal of Organic Chemistry 29, no. 9: 2602-2605.

Jurd, L., and T. A. Geissman. 1963. Anthocyanins and related compounds. II. Structural transformations of some anhydro bases. The Journal of Organic Chemistry 28, no. 9: 2394-2397.

Jurd, L., and A. C. Waiss. 1965. Anthocyanins and related compounds-VI Flavylium salt—phloroglucinol condensation products. Tetrahedron 21, no. 6: 1471-1483.

Kahkonen, M. P, and M. Heinonen. 2003. Antioxidant Activity of Anthocyanins and Their Aglycons. J. Agric. Food Chem. 51, no. 3: 628-633.

Kaldas, M. I, U. K Walle, H. van der Woude, J. E.M McMillan, and T. Walle. 2005. Covalent binding of the flavonoid quercetin to human serum albumin. $J$. Agric. Food Chem 53, no. 10: 4194-4197.

Kaplan, P., E. Babusikova, J. Lehotsky, and D. Dobrota. 2003. Free radicalinduced protein modification and inhibition of $\mathrm{Ca} 2+-\mathrm{ATP}$ ase of cardiac sarcoplasmic reticulum. Molecular and cellular biochemistry 248, no. 1: $41-47$.

Kawakami, M., and E. Okabe. 1998. Superoxide anion radical-triggered Ca2+ release from cardiac sarcoplasmic reticulum through ryanodine receptor 
Ca2+ channel. Molecular pharmacology 53, no. 3: 497.

Khatri, J. J, C. Johnson, R. Magid, S. M Lessner, K. M Laude, S. I Dikalov, D. G Harrison, H. J Sung, Y. Rong, and Z. S Galis. 2004. Vascular oxidant stress enhances progression and angiogenesis of experimental atheroma. Circulation 109, no. 4: 520.

Kim, D. H., S. T. Ohnishi, and N. Ikemoto. 1983. Kinetic studies of calcium release from sarcoplasmic reticulum in vitro. Journal of Biological Chemistry 258, no. 16: 9662.

Kourie, J. I. 1998. Interaction of reactive oxygen species with ion transport mechanisms. American Journal of Physiology- Cell Physiology 275, no. 1: C1.

Lai, F.A., H.P. Erickson, E. Rousseau, Q.Y. Liu, and G. Meissner. 1988. Purification and reconstitution of the calcium release channel from skeletal muscle. Nature 331, no. 6154 (January 28): 315-319.

Lee, Eun Hui, Gerhard Meissner, and Do Han Kim. 2002. Effects of Quercetin on Single Ca2+ Release Channel Behavior of Skeletal Muscle. Biophysical Journal 82: 1266-1277.

Lee, J. M, S. H Rho, D. W Shin, C. Cho, W. J Park, S. H Eom, J. Ma, and D. H Kim. 2004. Negatively charged amino acids within the intraluminal loop of ryanodine receptor are involved in the interaction with triadin. Journal of 
Biological Chemistry 279, no. 8: 6994.

Lehnart, S. E, X. H.T Wehrens, P. J Laitinen, S. R Reiken, S. X Deng, Z. Cheng, D. W Landry, K. Kontula, H. Swan, and A. R Marks. 2004. Sudden death in familial polymorphic ventricular tachycardia associated with calcium release channel (ryanodine receptor) leak. Circulation 109, no. 25: 3208.

Liu, G., J.J. Abramson, A.C. Zable, and I.N. Pessah. 1994. Direct evidence for the existence and functional role of hyperreactive sulfhydryls on the ryanodine receptor-triadin complex selectively labeled by the coumarin maleimide 7-diethylamino-3-(4'-maleimidylphenyl)-4-methylcoumarin. Mol.Pharmacol. 45, no. 2 (February): 189-200.

Ludtke, S. J, I. I Serysheva, S. L Hamilton, and W. Chiu. 2005. The pore structure of the closed RyR1 channel. Structure 13, no. 8: 1203-1211.

Ma, J. 1993. Block by ruthenium red of the ryanodine-activated calcium release channel of skeletal muscle. The Journal of general physiology 102, no. 6 : 1031.

MacLennan, D. H, and P. T. S. Wong. 1971. Isolation of a calcium-sequestering protein from sarcoplasmic reticulum. Proceedings of the National Academy of Sciences of the United States of America 68, no. 6: 1231.

Benjamin S. Marinov, Rotimi O. Olojo, Ruohong Xia and Jonathan J. Abramson. Non-Thiol Reagents Regulate Ryanodine Receptor Function by Redox 
Interactions That Modify Reactive Thiols. Antioxidants \& Redox Signaling. March 2007, 9(5): 609-621.

Meissner, G., E. Darling, and J. Eveleth. 1986. Kinetics of rapid calcium release by sarcoplasmic reticulum. Effects of calcium, magnesium, and adenine nucleotides. Biochemistry 25, no. 1: 236-244.

Metodiewa, D., A. K Jaiswal, N. Cenas, E. Dickancaité, and J. Segura-Aguilar. 1999. Quercetin may act as a cytotoxic prooxidant after its metabolic activation to semiquinone and quinoidal product. Free radical biology and medicine 26, no. 1: 107-116.

Moopanar, Terence R, and David G Allen. 2005. Reactive oxygen species reduce myofibrillar $\mathrm{Ca} 2+$ sensitivity in fatiguing mouse skeletal muscle at $37^{\circ} \mathrm{C}$. The Journal of Physiology 564, no. 1 (April 1): 189-199. doi:10.1113/jphysiol.2005.083519.

Noda, Y., Kaneyuki, T. Mori, A., and Packer, L. 2002. Antioxidant activities of pomegranate fruit extract and its anthocyanidins: delphinidin, cyanidin, and pelargonidin. J. Agric. Food Chem 50, no. 1: 166-171.

Orlova, E. V, I. I Serysheva, M. van Heel, S. L Hamilton, and W. Chiu. 1996. Two structural configurations of the skeletal muscle calcium release channel. Nature Structural Biology 3, no. 6: 547-552.

Pessah, I. N., A. O. Francini, D. J. Scales, A. L. Waterhouse, and J. E. Casida. 
1986. Calcium-ryanodine receptor complex. Solubilization and partial characterization from skeletal muscle junctional sarcoplasmic reticulum vesicles. Journal of Biological Chemistry 261, no. 19: 8643.

Samsó, M., X. Shen, and P. D Allen. 2006. Structural characterization of the RyR1-FKBP12 interaction. Journal of molecular biology 356, no. 4: 917927.

Samsó, M., and T. Wagenknecht. 2002. Apocalmodulin and Ca2+-calmodulin bind to neighboring locations on the ryanodine receptor. Journal of Biological Chemistry 277, no. 2: 1349.

Satue-Gracia, M. T, M. Heinonen, and E. N Frankel. 1997. Anthocyanins as Antioxidants on Human Low-Density Lipoprotein and Lecithin- Liposome Systems. J. Agric. Food Chem 45, no. 9: 3362-3367.

Scarpa, A., F. J. Brinley Jr, and G. Dubyak. 1978. Antipyrylazo III, a" middle range" Ca2+ metallochromic indicator. Biochemistry 17, no. 8: 1378.

Schafer, F. Q, and G. R Buettner. 2001. Redox environment of the cell as viewed through the redox state of the glutathione disulfide/glutathione couple. Free Radical Biology and Medicine 30, no. 11: 1191-1212.

Sekher Pannala, A., T. S Chan, P. J O'Brien, and C. A Rice-Evans. 2001. Flavonoid B-ring chemistry and antioxidant activity: fast reaction kinetics. Biochemical and Biophysical Research Communications 282, no. 5: 
$1161-1168$.

Sekher Pannala, Ananth, Tom S Chan, Peter J O'Brien, and Catherine A RiceEvans. 2001. Flavonoid B-Ring Chemistry and Antioxidant Activity: Fast Reaction Kinetics. Biochemical and Biophysical Research Communications 282, no. 5 (April): 1161-1168.

Sen, C. K, and L. Packer. 2000. Thiol homeostasis and supplements in physical exercise. American Journal of Clinical Nutrition 72, no. 2: 653S.

Serysheva, I., W. Chiu, and S. Ludtke. 2007. Single-particle electron cryomicroscopy of the ion channels in the excitation-contraction coupling junction. Cellular electron microscopy: 407.

Serysheva, I., S. Ludtke, M. L. Baker, Y. Cong, M. Topf, A. Sali, S. Hamilton, and W. Chiu. 2007. Single Particle Cryo-EM of RyR1 Channel at Subnanometer Resolution. Microscopy and Microanalysis 13, no. 02: 408409.

Serysheva, I. I, S. J Ludtke, M. L Baker, Y. Cong, M. Topf, D. Eramian, A. Sali, S. L Hamilton, and W. Chiu. 2008. Subnanometer-resolution electron cryomicroscopy-based domain models for the cytoplasmic region of skeletal muscle RyR channel. Proceedings of the National Academy of Sciences 105, no. 28: 9610.

Serysheva, I. I., M. Schatz, M. Van Heel, W. Chiu, and S. L. Hamilton. 1999. 
Structure of the skeletal muscle calcium release channel activated with Ca2+ and AMP-PCP. Biophysical journal 77, no. 4: 1936-1944.

Sharma, S., J. V Adrogue, L. Golfman, I. Uray, J. Lemm, K. Youker, G. P Noon, O. H. Frazier, and H. Taegtmeyer. 2004. Intramyocardial lipid accumulation in the failing human heart resembles the lipotoxic rat heart. The FASEB Journal 18, no. 14: 1692.

Smith, J. S, E. Rousseau, and G. Meissner. 1989. Calmodulin modulation of single sarcoplasmic reticulum Ca2+-release channels from cardiac and skeletal muscle. Circulation research 64, no. 2: 352.

Smith, J.S., R. Coronado, and G. Meissner. 1986. Single channel measurements of the calcium release channel from skeletal muscle sarcoplasmic reticulum. Activation by $\mathrm{Ca} 2+$ and ATP and modulation by Mg2+ Threedimensional visualization of FKBP12.6 binding to an open conformation of cardiac ryanodine receptor. J.Gen.Physiol 88, no. 5 (November): 573-588.

Takeshima, H., S. Nishimura, T. Matsumoto, H. Ishida, K. Kangawa, N. Minamino, H. Matsuo, et al. 1989. Primary structure and expression from complementary DNA of skeletal muscle ryanodine receptor. Nature 339: $439-445$.

Trimm, J. L., G. Salama, and J. J. Abramson. 1986. Sulfhydryl oxidation induces rapid calcium release from sarcoplasmic reticulum vesicles. Journal of 
Biological Chemistry 261, no. 34: 16092.

Tripathy, A., L. Xu, G. Mann, and G. Meissner. 1995. Calmodulin activation and inhibition of skeletal muscle Ca2+ release channel (ryanodine receptor). Biophysical journal 69, no. 1: 106-119.

Van Acker, S. A., M. J. De Groot, D. J. Van den Berg, M. N. Tromp, K. G DonnéOp, W. J. Van der Vijgh, and A. Bast. 1996. A quantum chemical explanation of the antioxidant activity of flavonoids. Chemical research in toxicology 9, no. 8: 1305.

Van Acker, Saskia A. B. E, Dirk-jan Van Den Berg, MichEI N. J. L Tromp, Desiree H Griffioen, Wout P Van Bennekom, Wim J. F Van Der Vijgh, and Aalt Bast. 1996. Structural aspects of antioxidant activity of flavonoids. Free Radical Biology and Medicine 20, no. 3: 331-342.

Vanacker, S., M. Tromp, G. Haenen, W. J. F. Vandervijgh, and A. Bast. 1995. Flavonoids as scavengers of nitric oxide radical. Biochemical and biophysical research communications 214, no. 3: 755-759. 
Wada, M., H. Kido, K. Ohyama, T. Ichibangase, N. Kishikawa, Y. Ohba, M. N. Nakashima, N. Kuroda, and K. Nakashima. 2007. Chemiluminescent screening of quenching effects of natural colorants against reactive oxygen species: Evaluation of grape seed, monascus, gardenia and red radish extracts as multi-functional food additives. Food Chemistry 101, no. 3: 980-986.

Wei, L., E. M Gallant, A. F Dulhunty, and N. A Beard. 2009. Junctin and triadin each activate skeletal ryanodine receptors but junctin alone mediates functional interactions with calsequestrin. The International Journal of Biochemistry \& Cell Biology 41, no. 11: 2214-2224.

Wei, L., A. D Hanna, N. A Beard, and A. F Dulhunty. 2009. Unique isoformspecific properties of calsequestrin in the heart and skeletal muscle. Cell calcium 45, no. 5: 474-484.

Xia, R., T. Stangler, and J. J Abramson. 2000. Skeletal muscle ryanodine receptor is a redox sensor with a well defined redox potential that is sensitive to channel modulators. Journal of Biological Chemistry 275, no. 47: 36556 .

Xu, L., J. P Eu, G. Meissner, and J. S Stamler. 1998. Activation of the cardiac calcium release channel (ryanodine receptor) by poly-S-nitrosylation. Science 279, no. 5348: 234. 
Yeh, Y. H, R. Wakili, X. Y Qi, D. Chartier, P. Boknik, S. Kaab, U. Ravens, P. Coutu, D. Dobrev, and S. Nattel. 2008. Calcium-handling abnormalities underlying atrial arrhythmogenesis and contractile dysfunction in dogs with congestive heart failure. Circulation: Arrhythmia and Electrophysiology 1, no. 2: 93.

Zable, A C, T G Favero, and J J Abramson. 1997. Glutathione modulates ryanodine receptor from skeletal muscle sarcoplasmic reticulum. Evidence for redox regulation of the $\mathrm{Ca} 2+$ release mechanism. Journal Of Biological Chemistry 272, no. 11 (March 14): 7069-77.

Zima, A. V, and L. A Blatter. 2006. Redox regulation of cardiac calcium channels and transporters. Cardiovascular research 71, no. 2: 310. 